NBER WORKING PAPER SERIES

\title{
ECONOMIC GROWTH AND THE ENVIRONMENT: A REVIEW OF THEORY AND EMPIRICS
}

\author{
William A. Brock \\ M. Scott Taylor \\ Working Paper 10854 \\ http://www.nber.org/papers/w10854 \\ NATIONAL BUREAU OF ECONOMIC RESEARCH \\ 1050 Massachusetts Avenue \\ Cambridge, MA 02138 \\ October 2004
}

The views expressed herein are those of the author(s) and not necessarily those of the National Bureau of Economic Research.

(C2004 by William A. Brock and M. Scott Taylor. All rights reserved. Short sections of text, not to exceed two paragraphs, may be quoted without explicit permission provided that full credit, including (C) notice, is given to the source. 
Economic Growth and the Environment: A Review of Theory and Empirics

William A. Brock and M. Scott Taylor

NBER Working Paper No. 10854

October 2004

JEL No. F1, Q2

\begin{abstract}
$\underline{\text { ABSTRACT }}$
This paper reviews both theory and empirical work on economic growth and the environment. We develop four simple growth models to help us identify key features generating sustainable growth. We show how some combination of technological progress in abatement, intensified abatement, shifts in the composition of national output and induced innovation are necessary for sustainable growth, and then demonstrate how growth models employing any one of these mechanisms generate other potentially refutable predictions on abatement costs, pollution levels, or emission intensities.

William A. Brock

Department of Economics

University of Wisconsin

1180 Observatory Drive

Madison, WI 53705

wbrock@ssc.wisc.edu

M. Scott Taylor

Department of Economics

University of Calgary

2500 University Drive, NW

Calgary, Alberta, Canada T2N 1N4

and NBER

mstaylor@ucalgary.ca
\end{abstract}




\section{Introduction}

The relationship between economic growth and the environment is, and may always remain, controversial. Some see the emergence of new pollution problems, the lack of success in dealing with global warming and the still rising population in the Third World as proof positive that humans are a short-sighted and rapacious species. Others however see the glass as half full. They note the tremendous progress made in providing urban sanitation, improvements in air quality in major cities and marvel at the continuing improvements in the human condition made possible by technological advance. The first group focuses on the remaining and often serious environmental problems of the day; the second on the long, but sometimes erratic, history of improvement in living standards.

These views are not necessarily inconsistent and growth theory offers us the tools needed to explore the link between environmental problems of today and the likelihood of their improvement tomorrow. It allows us to clarify these conflicting views by use of theory, and when differences still remain, to create useful empirical tests that quantify relative magnitudes.

For many years, the limited natural resource base of the planet was viewed as the source of limits to growth. This was, for example the focus of the original and subsequent "Limits to Growth" monograph and the efforts by economists refuting its conclusions. ${ }^{1}$ Recently however it has become clear that limits to growth may not only arise from nature's finite source of raw materials, but instead from nature's limited ability to act as a sink for human wastes. It is perhaps natural to think first of the environment as a source of raw materials, oil and valuable minerals. This interpretation of nature's service to mankind led to a large and still growing theoretical literature on the limits to growth created by natural resource scarcity. Empirically it led to studies of the drag limited natural resources may have on growth, and a related examination of long run trends in resource prices. ${ }^{2}$

Nature's other role - its role as a sink for unwanted by-products of economic activity - has typically been given less attention. As a sink, nature dissipates harmful air, water and solid pollutants, is the final resting place for millions of tons of garbage, and is the unfortunate repository for many toxic chemicals. When the environment's ability to dissipate or absorb wastes is exceeded, environmental quality falls and the policy response to this reduction in quality may in turn limit growth. Growth may be limited because reductions in environmental quality call forth more intensive clean up or abatement efforts that lower the return to investment, or more apocalyptically, growth may be limited when humans do such damage to the ecosystem that it deteriorates beyond repair and settles on a new lower, less productive steady state. ${ }^{3}$

\footnotetext{
${ }^{1}$ See Nordhaus (1992) for the latest refutation.

${ }^{2}$ For work on resource price trends see most importantly Barnett and Morse (1963) and Slade (1982).

${ }^{3}$ This branch of the literature relies on case study evidence of irreversible damage created in the past and argues that our now greater technological capabilities may portend even worse outcomes in the future. For a primarily theoretical discussion of irreversibilities and hysteresis caused by nonlinearities see the symposium edited by Dasgupta and Maler (2003). For related nonlinear theory see Dechert (2001). For case study
} 
This link between growth and the environment has of course received much more attention recently because of the rapidly expanding empirical literature on the relationship between per capita income and pollution. This literature, known as the Environmental Kuznets Curve (EKC) literature, has been enormously influential. So to a certain extent, the tables have now turned: there is far less concern over the ultimate exhaustion of oil or magnesium, and far more concern over air quality, global warming, and the emissions of industrial production.

The economics literature examining the link between growth and the environment is huge; it covers, in principle, much of the theory of natural resource extraction, a significant body of theory in the 1960s and 1970s on resource depletion and growth; a large literature in the 1990s investigating the implications of endogenous growth theories; and a new and still growing literature created in the last decade examining the relationship between pollution and national income levels. Every review has to make difficult choices about exclusion and we make ours on the basis of novelty. There are excellent book length treatments on the depletion of renewable and non-renewable resources, and several reviews of endogenous growth theory's contributions already exist. ${ }^{4}$ This leaves us to focus on the relatively new theoretical literature linking environmental quality to income levels. For the most part, we discuss the link between industrial pollution and growth, but also show how this most recent work is related to earlier contributions on exhaustible resources and growth.

While no review can settle the perennial debate over the limits to growth, this review hopes to play a positive role in moving the literature forward by identifying important unresolved theoretical questions, reporting on the results of recent empirical work, and providing an integrative assessment of where we stand today. ${ }^{5}$ To do so, we focus on three questions. These are: (1) what is the relationship between economic growth and the environment?; (2) how can we escape the limits to growth imposed by environmental constraints?; and (3), where should future research focus its efforts?

To answer these questions we start by introducing definitions and providing a preliminary result linking the environment and growth. We define the scale, composition and technique effects of growth on the environment, and then use these definitions to prove a useful but negative result on the limits to growth. We show that changes in the composition of national output - as occur when the economy specializes in relatively less pollution intensive services or relatively less natural intensive industries- can at best delay the impact of binding environmental constraints. In the long run, emission intensities must fall towards zero if growth is to be sustainable.

In many models this constraint is met through the substitution of clean inputs for dirty ones, in others via increased abatement, and in still others through some combination of technological progress and the other channels. This result is helpful to us because it allows

evidence from prehistory see Brander et al. (1998).

${ }^{4}$ See the classic book length treatments of renewable and nonrenewable resources by Clark (1990), and Dasgupta and Heal (1979). A good introduction to the relationship between endogenous growth theory and the environment is contained in the review by Smulders (1999).

${ }^{5}$ Whether there are serious limits to growth is an unending controversy that reached its peak with the publication of the Limits to Growth by Meadows et al. in 1972. See the subsequent contributions by Solow (1973) followed by Meadows et al. (1991) and then Nordhaus (1992). 
us to distinguish between empirical regularities that are consistent with a short run growth and environment relationship (along a transition path) from those consistent with the long run relationship (along a balanced growth path). It also helps us sort through the literature by focusing on how a given model can generate what we take as our definition of sustainable growth: a balanced growth path with increasing environmental quality and ongoing growth in income per capita. ${ }^{6}$

With our definitions and result in hand we then turn to present some stylized facts on the environment and growth. These facts concern the trend and level of various pollutants, and measures of the cost of pollution control. In many cases, the data underlying the construction of these facts is of limited quality; the time periods are sometimes insufficiently long to draw strong conclusions and the relevant magnitudes imprecise relative to their constructs in theory. Nonetheless, they are the best data we have.

Overall these data tell three stories. The first is that by many measures the environment is improving at least in developed countries. The level of emissions for regulated pollutants is falling, and the quality of air in cities is rising. The U.S. and other advanced industrial countries have seen secular improvements in the quality of their environments over the last 30 years. To a large extent cities are cleaner than in the past, emissions of health-threatening toxics are reduced, and in some cases the changes in environmental quality are quite dramatic.

The second feature of the data is that pollution control measures have been both relatively successful and relatively cheap. While there are severe difficulties in measuring the full cost of environmental compliance most methods find costs of at most 1-2\% of GDP for the U.S. Comparable figures from OECD countries support this finding. ${ }^{7}$

The last feature of the data is that there is a tendency for the environment to at first worsen at low levels of income but then improve at higher incomes. This is the so-called Environmental Kuznets Curve. We first present raw emission data drawn from the U.S. and then briefly review the empirical literature on the Environmental Kuznets's Curve that relies on cross-country comparisons. The raw data from the US are unequivocal, while the cross-country empirical results are far less clear but generally supportive of the finding.

Having reviewed the relevant data and set out definitions we turn to a review of the theory. To do so, we develop a series of 4 simple growth and environment models. The models serve as a vehicle to introduce related theoretical work. For the most part we focus on balanced growth path predictions and eschew formal optimization taking as exogenous savings or depletion rates and sometimes investments in abatement. We do so because in

\footnotetext{
${ }^{6}$ This is different from other definitions. We wanted to avoid stagnation as a sustainable growth path and hence require positive growth; but with positive income growth giving more marketable goods along the balanced growth path it seems only appropriate to require an improving environment as well since this gives us more non market goods.

${ }^{7}$ Aggregate compliance costs were reported in a 1990 EPA study that has apparently never been updated. (See EPA (1990) Environmental Investments: The cost of a clean environment) The earlier study predicted year 2000 compliance costs of approximately 200 billion dollars (1990 dollars), but recent EPA publications (EPA's 2004 Strategic Plan) distances themselves from this estimate and reiterates just how difficult it is to estimate compliance costs. OECD evidence can be found in the publication Pollution Abatement \& Control Expenditures in OECD countries, Paris: OECD Secretariat.
} 
many cases, these rates must be constant along any balanced growth path and hence we identify a set of feasible conditions for sustainable growth. Moreover the resulting simplicity of the models allows us to identify key features of fully developed research contributions already present in the literature. In some cases, the choice of abatement or savings matters critically to the point we are making and hence in those cases we provide optimal rules.

The 4 models were developed to highlight the different ways we can meet environmental constraints in the face of ongoing growth in per capita incomes. In the first, which we dub the Green Solow Model, emission reductions arise from exogenous technological progress in the abatement process. Although this model is very simple it provides three useful results. First, we show that even with the economy's abatement intensity fixed, the dynamics of the Solow model together with those of a standard regeneration function are sufficient to produce the Environmental Kuznet's Curve. The transition towards any sustainable growth path has environmental quality at first worsening with economic growth and then improving as we approach the balanced growth path. This is a surprising result. While numerous explanations for the EKC relationship have been put forward, this explanation is simple, novel, and quite general as it relies only on basic properties of growth functions.

Second, the Green Solow model provides a useful benchmark since this model predicts that a more strict pollution policy has no long run effect on growth. In true Solow tradition, different abatement intensities create level differences in income but have no effect on the economy's growth rate along the balanced growth path. This result provides partial justification for the current practice of measuring the costs of pollution control as the sum of current private and public expenditures with no correction for the reduction in growth created. It also points out the stringent conditions needed for a stricter policy policy to cause no drag whatsoever on economic growth.

Third, the model clearly shows how technological progress in goods production has a very different environmental impact than does technological progress in abatement. Technological progress in goods production creates a scale effect that raises emissions, technological progress in abatement creates a pure technique effect driving emissions downwards. In the Green Solow model both rates are exogenous, and as such they provide especially clean examples of scale and technique effects for us to refer to later. And as we show throughout the review, the presence or absence of technological progress in abatement is key to whether we can lower emissions, support ongoing growth, and provide reasonable predictions for the costs of pollution control.

The second model, which we dub the Stokey Alternative, was inspired by Nancy Stokey's (1998) influential paper on the limits to growth. Here we present a simplified version to highlight the role abatement can play in improving the environment over time. The model we present focuses on balanced growth paths and not the transition paths as emphasized by Stokey, but nevertheless it contains two results worthy of note. The first is simply the observation that once we model abatement as an economic activity that uses scarce resources, increases in the intensity of abatement that are needed to keep pollution in check will have a drag on economic growth. Rising abatement creates a technique effect by lowering emissions per unit output, but also lowers pollution by lowering the growth rate of output. 
By rewriting the model along the lines of Copeland and Taylor (1994) so that pollution emissions appear as if they are a factor of production, it is now relatively simple to conduct growth drag exercises for the cost of pollution control in much the same way that others have examined the growth drag of natural resource depletion. ${ }^{8}$ By doing so, the model makes clear the limits to growth brought about by environmental policy.

The second feature we focus on is the model's prediction concerning the intensity of abatement. In models with falling pollution levels, neoclassical assumptions on abatement, and no abatement specific technological progress, the intensity of abatement must rise continuously through time. For example, in Stokey's analysis the share of "potential output" allocated to abatement approaches one in the limit. Since this share represents pollution abatement costs relative to the value of aggregate economic activity, models that rely on abatement alone tend to generate counterfactual predictions for abatement costs. This is true even though ongoing economic growth is fueled by technological progress, and hence this result reinforces our earlier remarks about the importance of technological progress in abatement.

Our third model links the source and sink roles of nature by assuming energy use both draws down exhaustible resource stocks and creates pollution emissions that lower environmental quality. This "source and sink" formulation allows us to examine how changes in the energy intensity of production help meet environmental constraints. In this model, the intensity of abatement is taken as constant and there is no technological progress in abatement. Instead the economy lowers its emissions to output ratio over time by adopting an ever cleaner mix of production methods. As such the model focuses on the role of composition effects in meeting environmental constraints. We show that the economy is able to grow while reducing pollution because of continuous changes in the composition of its inputs, but this form of "abatement" has costs. Growth is slowed as less and less of the natural resource can be used in production.

This "source and sink" formulation is important in linking the earlier 1970s and 1980s literature focusing on growth and resource exhaustion with the newer 1990s literature focusing on the link between economic growth and environmental quality. We show that the finiteness of natural resources implies a constraint on per capita income growth that is worsened with higher population growth rates. This constraint is relaxed if the rate of natural resource use is slower as this implies reproducible factors have less of a burden in keeping growth positive. But sustainability also requires falling emissions, and this constraint is most easily met if the economy makes a rapid transition away from natural resource inputs as this reduces the energy and pollution intensity of output.

Putting the constraints from the source and sink side together, we show there exist parameter values for which the twin goals of positive ongoing growth and falling emission levels are no longer compatible. This is not a doomsday prediction. Together with our previous analysis it suggests that abatement or composition shifts alone are unlikely to be responsible for the stylized facts. Technological progress directly targeted to lowering abatement costs (i.e. induced innovation) must be playing a key role in determining growth

\footnotetext{
${ }^{8}$ See for example Nordhaus (1992).
} 
and environment outcomes. Therefore, in the remainder of the paper we turn to a model where technological progress in abatement is set in motion by the onset of active regulation and works to generate sustainable growth paths.

To highlight the importance of technological progress in abatement our final model draws on the analysis of Brock and Taylor (2003) by adopting their Kindergarten Rule model. While the previous models were useful vehicles to discuss the literature and describe possibilities, they were necessarily incomplete because they eschew formal optimization. Optimizing behavior is however important in discussions of the magnitude of drag created by pollution policy, and also important in discussions concerning the timing or onset of active regulation. The Kindergarten model provides two contributions to our discussion.

First, it shows how technological progress in abatement can hold compliance costs down in the face of ongoing growth. In contrast to the Green Solow model, there are ongoing growth drag costs from regulation, but as long as abatement is productive it is possible to generate sustainable growth without skyrocketing compliance costs. By highlighting the important role for progress in abatement, the model points out the need to make endogenous the direction of technological progress as well as its rate.

Second, the model generates a first worsening and then improving environment much like that in Stokey (1998). In contrast however to the methods employed in the empirical EKC literature, we show that the path for income and pollution will differ systematically across countries. This systematic difference leads to the model's Environmental Catch-up Hypothesis relating income and pollution paths to countries initial income levels. Poor countries experience the greatest environmental degradation at their peak, but once regulation begins environmental quality across both Rich and Poor converges. Despite this, at any given income level an initially Poor country has worse environmental quality than an initially Rich country. Moreover, since both Rich and Poor economies start with pristine environments, the qualities of their environments at first diverge and then converge over time. In addition to this cross-country prediction, the model also links specific features of the income and pollution profile to characteristics of individual pollutants such as their permanence in the environment, their toxicity, and their instantaneous disutility. Together these predictions suggest a different empirical methodology than that currently employed, and expand the scope for empirical work in this area considerably.

The final section of our review is a summary of the main lessons we have drawn from the literature, offers suggestions for future research and briefly discusses some of the most important topics that we did not discuss elsewhere in the review.

\section{Preliminaries}

\subsection{Scale, Composition and Technique}

We start with some algebra linking emissions of a given pollutant to a measure of economic activity, its composition and the cleanliness of production techniques. By doing so we illustrate that any growth model that predicts both rising incomes and falling pollution levels has 
to work on lowering pollution emissions via one of three channels. Consider a given pollutant and let $E$ denote the sum total of this pollutant's emissions arising from production across the economy's $n$ industries. ${ }^{9}$ Let $a_{i}$ denote the pounds of emissions per dollar of output produced in industry $i, s_{i}$ denote the value share of industry $i$ in national output, and $Y$ national output. Then by definition total emissions $E$ are given by:

$$
E=\sum_{i=1}^{n} a_{i} s_{i} Y \text { where } \sum_{i=1}^{n} s_{i}=1
$$

Since this is a definition we can differentiate both sides with respect to time to find:

$$
\hat{E}=\sum_{i=1}^{n} \pi_{i}\left[\hat{a}_{i}+\hat{s}_{i}\right]+\hat{Y} \text { where } \pi_{i}=\frac{E_{i}}{E}
$$

where a ${ }^{\wedge}$ over $x$ indicates $[d x / d t] / x$. Changes in aggregate emissions can arise from three sources that we define to be the Scale, Composition and Technique effects. ${ }^{10}$

To start, note that holding constant the cleanliness of production techniques and the composition of final output (i.e. holding both $\hat{a}_{i}=0$ and $\hat{s}_{i}=0$ for all $i$ ) emissions rise or fall in proportion to the scale of economic activity as measured by real GDP or $Y$. This is the scale effect of growth and unless it is offset by other changes, emissions rise lock step with increases in real output.

Alternatively, we can hold both the scale of real output and the techniques of production constant to examine the impact of changes in the composition of output. To do so, in (2) we set $\hat{Y}=0$ and $\hat{a}_{i}=0$ for all $i$ as this isolates the pure composition effect on pollution emissions.

$$
\hat{E}=\sum_{i=1}^{n} \pi_{i} \hat{s}_{i}
$$

Emissions fall via the pure composition effect if an economy moves towards producing a set of goods that are cleaner on average than the set they produced before. To see why this is true, note that the change in value shares across all $\mathrm{n}$ industries must sum to zero; i.e. $\sum_{i=1}^{n} d s_{i}=0$. Now using this result in (3) we obtain the change in emissions arising from a pure composition effect as:

$$
\hat{E}=\sum_{i=1}^{n} \hat{s}_{i}\left[\pi_{i}-s_{i}\right]
$$

Given our definitions $\pi_{i}-s_{i}>0$ if and only if $E_{i} / p_{i} y_{i}>E / Y$. In words, the element $\pi_{i}-s_{i}$ is positive if and only if industry $i$ 's emissions per dollar of output is greater than the national average. Define a dirty industry as one whose emissions per dollar of output

\footnotetext{
${ }^{9}$ The pollutant could instead be produced via consumption. In that case we adopt weights reflecting industry $i$ 's share in final demand. This has little impact on our results here, but would have some relevance in an open economy setting.

${ }^{10}$ See Copeland and Taylor (1994) for model based definitions of these effects in a static setting. This terminology was popularized by Grossman and Krueger's (1993) NAFTA study.
} 
exceed the economy wide average $E / Y$; define a clean industry as one where emissions per dollar of output are less than the economy average. Then equation (4) holds that aggregate emissions fall from the pure composition effect whenever the composition of output changes toward a more heavy reliance on clean industries and rises otherwise.

Finally, emissions can fall when the techniques of production become cleaner even though output and its composition remain constant. To isolate this technique effect, we set $\hat{Y}=0$ and $\hat{s}_{i}=0$ for all $i$ to find that emissions fall if emissions per unit output fall for all activities. In this case we find:

$$
\hat{E}=\sum_{i=1}^{n} \pi_{i} \hat{a}_{i}
$$

and hence if techniques are getting cleaner, emissions per unit of output fall, and overall emissions fall from this pure technique effect.

When the environment is modeled as a sink for human wastes it is often assumed that emissions together with natural regeneration determine environmental quality. When the environment adjusts relatively slowly to changes in the pollution level, natural regeneration can play an important role in determining environmental quality. A typical and very useful specification assumes the environment dissipates pollutants at an exponential rate. Let $X$ denote the pollution stock (an inverse measure of environmental quality) and let the pristine level be given by $X=0$. Then since the flow of emissions per unit time is $E$, the evolution of the pollution stock is given by:

$$
\dot{X}=E-\eta X \text { where } \eta>0
$$

This formulation is convenient because it is generally assumed that $X$ must be bounded for human life to exist and hence (6) yields a simple negative linear relationship between the steady state flow of pollution $E$, and the pollution stock $X$. A bound on $X$ then implies a similar bound on steady state emissions, $E .{ }^{11}$ Moreover, given the linear relationship any scale, composition or technique effect on emissions is translated directly into impacts on $X$.

One cost of (6) is that the percentage rate of natural regeneration is independent of the state of the environment. A common modification is to assume the rate of natural regeneration rises as $X$ gets further and further from its pristine level. Letting $\eta=\eta(X)$, we can introduce this possibility by writing the evolution of $X$ as:

$$
\dot{X}=E-\eta(X) X \text { where } \eta^{\prime}(x)>0
$$

$\eta(X)$ is often assumed to be linear.

An alternative and equally valid interpretation of (2) is that $E$ is the instantaneous flow of natural resources used in production. Under this interpretation, equation (1) gives us an economy wide factor demand for this natural resource evaluated at the equilibrium level of use given by $E$. For example, the demand for oil equals the sum of demand arising from all

\footnotetext{
${ }^{11}$ Along a balanced growth path the time rate of change of $X$ must equal that of $E$. To see this divide both sides of (6) by $X$ and note that a constant rate of change in $X$ requires the ratio $E / X$ to be constant.
} 
sectors of the economy. In this interpretation $a_{i}$ are barrels of oil used per unit of output in industry $i, s_{i}$ is the value share of industry $i$ in national output, and $Y$ is again national output.

For example, if the flow of resources extracted is falling at some constant rate over time while real output is rising, then we know that some combination of changes in energy efficiency per unit of output (a technique effect) and changes in the output mix to less energy intensive goods (a composition effect) must be carrying the burden of adjustment. Changes in resource use over time can then be linked to the relative strength of scale, composition and technique effects. To complete the translation let the current stock of natural resources $S$ be given by our initial endowment $K$ less the sum over time of extraction by humans, $E$. If this resource has a zero regeneration rate we obtain the standard equation governing stock depletion in exhaustible resources:

$$
\dot{S}=-E
$$

Alternatively, we can leave open the possibility of regeneration. Making the needed changes to (8) gives us the standard accumulation equation for a renewable resource such as a forest or fishery when growth is stock dependent.

$$
\dot{S}=\eta(S) S-E
$$

And again if $\eta(S)$ is linear we obtain the familiar logistic growth for a naturally regenerating resource. $^{12}$

Although (1) is a definition it implicitly contains an assumption on how economic growth and the environment interact. Note that the value shares sum to 1 and $a_{i}(t) \geq 0$ for all $i$ and $t$. Assume that $a_{i}(t)>0$ for all $i$ and $t$. This assumption turns out to be an important, because if some activities are perfectly clean, or approach perfectly clean activities in the limit, then it is possible for composition effects alone to hold pollution in check despite ongoing growth. Conversely, if all economic activities must pollute even a small amount, then environmental quality can only rise in the long run via continuous changes in the techniques of production and these may run into diminishing returns.

It is not helpful here to enter into philosophical discussions over the definition of pollution or the likelihood of today's unwanted outputs becoming tomorrow's valuable inputs. Instead we just note that all production involves the transformation of one set of materials into another and that this transformation requires work. All work requires energy and energy is always wasted in work effort. Therefore some unintentional by products of production

\footnotetext{
${ }^{12}$ It should be noted however that different assumptions on $\eta(S)$ can lead to drastically different conclusions when they lead to growth functions with what biologists call critical depensation [See Clark (1990) for a formal definition and discussion]. Critical depensation refers to a property of the natural growth function such that at some minimum $S$, natural growth becomes negative. Natural growth can turn negative because of predator prey interactions across species, or because the species has a minimum viable population. Introducing thresholds and critical depensation into either (9) or (7) can alter results considerably. Unfortunately little is known about the extent of non-convexities of this type empirically. For theoretical work examining their impact see the symposium edited by Dasgupta and Maler (2003). Scheffer and Carpenter (2003) document some examples of catastrophic regime shifts in ecosystems.
} 
are always produced and we most often call these by products pollution. Since this is a statement of belief and not a rigorous proof, we note this as an assumption.

Assumption 1. Pollution is a by-product of all production:

$$
\text { for all } i, t \geq 0, \text { lim inf }\left\{a_{i}(t)\right\}>0
$$

this implies that there exists for each $i$, a strictly positive $\varepsilon>0$ such that $a_{i}(t)>\varepsilon$. With Assumption 1 in hand, it is now possible to show that composition effects are at best a transitory method to lower pollution emissions. Let us explain in detail why this conclusion holds. Suppose there is a bound, $B>0$ such that if $E(t)$ exceeds $B$, human life cannot exist. Then if $Y(t)$ goes to infinity as $t$ goes to infinity, (10) implies:

$$
E(t) \leq B \Rightarrow \sum_{i=1}^{n} a_{i}(t) s_{i}(t) \leq \frac{B}{Y(t)} \text { for all } t \geq 0
$$

Thus we must have

$$
\stackrel{*}{a}_{i}(t):=\min \left\{a_{i}(t)\right\} \leq \frac{B}{Y(t)} \rightarrow 0 \text { as } t \rightarrow \infty
$$

But (12) contradicts Assumption 1. Hence if we are to have bounded emissions with growing $Y(t)$, we must have the cleanest industry emission rate $\stackrel{*}{a}_{i}(t)$ going to zero. Therefore, falling pollution levels and rising incomes are only possible if there are continual reductions in emissions per unit output and zero emission technologies are possible, at least in the limit.

\section{$3 \quad$ Stylized Facts on Sources and Sinks}

We present three stylized facts drawn from post WW II historical record. We present data on pollution emissions and environmental control costs and leave the discussion of energy prices to later sections. Since data is typically only available for pollutants that are presently under active regulation we discuss the US record with regard to its six so-called criteria air pollutants, but amend these with international sources where possible. These are: sulfur dioxide, nitrogen oxides, carbon monoxide, lead, large particulates and volatile organic compounds. ${ }^{13}$ With the exception of lead, these air pollutants all typically classified as irritants and so we also briefly discuss the US history of regulation of long-lived and potentially harmful chemical products. For the most part we present data on emissions rather than concentrations because data on emissions covers a much longer time period and is unaffected by industry location and zoning regulation. On the other hand, the longest time spans of data (from 1940 onwards) reflect some changes in collection and estimation methods. ${ }^{14}$ Nevertheless,

\footnotetext{
${ }^{13}$ The long series of historical data presented in the figures is taken from the EPA's 1998 report National Pollution Emission Trends, available at http://www.epa.gov/ttn/chief/trends/trends98.

${ }^{14}$ As methods of estimation improve new categories of emissions are included and some revision occurs as well. For example, prior to 1985 the PM10 data excluded fugitive dust sources and other miscellaneous
} 
this data is the best we have available and where possible we direct the reader to concentration data and related empirical work. In addition we present data on industry pollution abatement costs from Vogan (1996), although these are only available for the 1972-1994 period.

We start by presenting in Figure 1 emissions per dollar of GDP for all pollutants except lead. Lead is excluded since data is only available over a much shorter period. As shown, emissions per unit of output for sulfur, nitrogen oxides, particulates, volatile organic compounds, and carbon monoxide all fall over the 1940-1998 period. For ease of comparison emission intensities were normalized to 100 in 1940 and the figure adopts a log scale. PM10 fell by approximately 98\%, sulfur, volatile organic compounds and carbon monoxide fell by perhaps $88 \%$, and nitrogen oxides fell by perhaps $60 \%$. Somewhat surprisingly, it is also apparent that if we exclude the years of WWII at the start of the data, the rate of reduction for each pollutant appears to be roughly constant over time.

Although there is a tendency to see good news in falling emission intensities, there are good reasons for not doing so. One reason is simply that real economic activity increased by a factor of 8.6 over this period and this masks the fact that emissions of many of these pollutants rose during this period. The second is that this measure - like that for aggregate emissions - has very little if any welfare significance. Since our measure is physical tons of emissions added up over all sources, it necessarily ignores the fact that some tons of emissions create greater marginal damage than others. ${ }^{15}$

Our second stylized fact is presented in Figure 2. In it we plot business expenditures on pollution abatement costs per dollar of GDP over the period 1972-1994. These twentytwo years are the only significant time period where data is available. ${ }^{16}$ As shown, pollution abatement costs as a fraction of GDP rise quite rapidly until 1980 and then remain relatively constant. As a fraction of overall output, these costs are relatively small. Alternatively, if we consider pollution abatement costs specifically directed to the six criteria air pollutants and scale this by real US output, the ratio is then incredibly small - approximately one half of one percent of GDP - and has remained so for over twenty years (See Vogan (1996)). ${ }^{17}$

Data from other countries supports the general conclusion that pollution abatement costs

emissions, so these are eliminated from the time series graphed in Figure 7. As well revision occurs. A close look at the 2001 Trends report shows that emissions reported for our pollutants during the 1970s and 1980s does not exactly match the figures given in the 1998 report. We use the 1998 figures rather than those from 2001 since the 2001 report only contains estimates to 1970, and we import the EPA's graphics directly into our figures because we cannot match them precisely from the raw data.

${ }^{15}$ In contrast, a quality-adjusted measure of emissions would add up the various components weighing them by their marginal damage; or a quality-adjusted measure of aggregate concentrations in a metropolitan area would weigh concentrations in each location by the marginal damage of concentrations at point (urban, industrial, suburban, etc.).

${ }^{16}$ In 1999 the PACE survey was run again this time as a pilot project. Using the 1999 survey we find the ratio of PACE to GDP of approximately $1.9 \%$ which is very much in line with Figure 2. This 1999 survey is different in some respects from earlier ones. For details see the Survey of Pollution Abatement Costs and Expenditures, U.S. Census Bureau 1999 available at www.census.gov/econ/overview/mu1100.html

${ }^{17}$ These figures are also similar to those presented in the review of pollution abatement costs in Jaffe et al. (1995). 
are a small fraction of GDP and show perhaps a slight upward trend. For example, total expenditures by both government and business in France rose from 1.2\% of GDP in 1990 to $1.6 \%$ in 2000. Over the 1991-1999 period, these same expenditures in Germany rose from $1.4 \%$ of GDP to $1.6 \%$. Austria and the Netherlands show somewhat higher expenditures on the order of $2.1 \%$ and $1.6 \%$ in 1990 rising to $2.6 \%$ and $2.0 \%$ in 1998 . While this data is clearly fragmentary, expenditures in the order of $1-2 \%$ of GDP seem to be the norm in OECD countries, with perhaps half of this being spent by private establishments and the remainder by governments. ${ }^{18}$

These figures however reflect to a certain degree the changing composition of output over time and therefore understate the impact higher pollution abatement costs have had on some industries. Levinson and Taylor (2003) for example argue that since the composition of U.S. manufacturing has been shifting towards less pollution intensive industries, aggregate measures understate the true costs of pollution regulations. They construct estimates of pollution abatement costs holding the composition of industry output fixed at the 2 and 3 digit industry levels and then compare these estimates with estimates allowing the composition of output to change. In all cases, holding the composition of US output fixed in earlier periods leads to a higher estimate of industry wide abatement cost increases. As a result, the small increases in pollution abatement costs shown in the aggregate data are at least partially due to the U.S. shedding some of its dirtiest industries over time.

Our third and final fact is presented in Figures 3 to 8. These figures show a general tendency for emissions to at first rise and then fall over time. Note that the falling emissions/intensities reported in Figure 1 are necessary but not sufficient for this result. This pattern in the data is visible for all pollutants except nitrogen oxides that may at present be approaching a peak in emissions. Conversely, particulate pollution peaked much earlier than the other pollutants, while lead has a dramatic drop in the mid-1970s. These raw U.S. data support the contention that environmental quality at first deteriorates and then improves with increases in income per capita.

Another interesting aspect of these figures is the breakdown of emissions by end-use category. Apart from some exceptions arising from the miscellaneous category the withinpollutant source of the emissions remains roughly constant in many of the figures. For example, consider SO2. Aggregate emissions follow an EKC pattern, but the components of fuel combustion and industrial processes do as well. A similar pattern is found in volatile organic compounds, but less so in the case of carbon monoxide which presumably is due to the change in automobile use over the period. In total the rough constancy in the withinpollutant sources of emissions suggests that the overall EKC pattern is not driven by strong compositional shifts.

Our finding of an EKC in the raw emission data is consistent with the recent flurry of formal empirical work linking per capita income and pollution levels. This empirical literature was fueled primarily by the work of Grossman and Krueger (1993, 1995) who found that, after controlling for other non-economic determinants of pollution, measures of

\footnotetext{
${ }^{18}$ These data are drawn from the Organization for Economic Cooperation and Development 2003, "Pollution Abatement and Control Expenditures in OECD Countries", Paris: OECD Secretariat.
} 
some (but not all) pollution concentrations at first rose and then fell with increases in per capita income. ${ }^{19}$ Their work is important in several respects: it brought the empirical study of aggregate pollution levels into the realm of economic analysis; it debunked the commonly held view that environmental quality must necessarily decrease with economic growth; and it provided highly suggestive evidence of a strong policy response to pollution at higher income levels.

Unfortunately, empirical research has progressed very little from this promising start. Subsequent empirical research has focused on either confirming or denying existence of similar relationships across different pollutants. ${ }^{20}$ Subsequent research has shown that the inverse-U relationship does not hold for all pollution, and there are indications the relation may not be stable for any one type of pollution. ${ }^{21}$ Since the empirical work on the EKC typically employs cross-country variation in income and pollution to identify parameters, it is perhaps not surprising that there are signs of parameter instability. This instability could arise from country specific differences in the mechanism driving the two processes, but very little, if any, work has gone into evaluating the various hypotheses offered for the EKC. This interpretation of the econometric problems is of course consistent with our finding that the raw US data offers a dramatic confirmation of Grossman and Krueger's cross-country results. Crosscountry differences leading to parameter instability are of course irrelevant in a one-country context.

In its original application, the EKC was interpreted as reflecting the relative strength of scale versus technique effects. However, it is difficult to support this interpretation. To isolate either the scale or technique effect we need to hold constant the composition of output, but this is not typically done in this literature. Therefore, the shape of the EKC may reflect some mixture of scale, composition and technique effects.

Despite these criticisms, the major and lasting contribution of this literature is to suggest a strong environmental policy response to income growth. The EKC studies are generally supportive of the hypothesis that income gains created by ongoing growth lead to policy changes that in turn drive pollution downwards. However, as our discussion in later sections will show, an EKC is compatible with many different underlying mechanisms and is entirely compatible with pollution policy remaining unchanged in the face of ongoing growth.

While most studies do not present evidence that allows us to distinguish between the underlying mechanisms responsible for the EKC, two recent studies offer additional insights. Hilton and Levinson (1998) examine the link between lead emissions and income per capita using a panel of 48 countries over the twenty-year period 1972-1992. This study is important because it finds strong evidence of an inverted U-shaped relationship between lead emissions and per capita income, and then factors the changes in pollution into two different compo-

\footnotetext{
${ }^{19}$ In addition to Grossman and Krueger $(1993,1995)$, other early contributions are Shafik and Bandyopadhyay (1994), Selden and Song (1994), Hilton and Levinson (1998), Gale and Mendez (1996).

${ }^{20}$ See, for example, Selden and Song (1994), El-Ashry (1993), Harbaugh et al (forthcoming), Stern and Common (2001) and the surveys mentioned previously.

${ }^{21}$ Hilton and Levinson (1998) contains some of the most convincing evidence of an EKC. Harbaugh, et al. (forthcoming) examines the sensitivity of the original Grossman and Krueger finding to new data and alternative functional forms.
} 
nents. The first is a technique effect that produces an almost monotonic relationship between lead content per gallon of gasoline and income per capita. The second is a scale effect linking greater gasoline use to greater income. ${ }^{22}$ This study is the first to provide direct evidence on two distinct processes (scale and technique effects) that together result in an EKC.

To interpret the empirical evidence as reflecting scale and technique effects one needs to rule out other possibilities. Although the authors do not couch their analysis in this context, their analysis implicitly presents the necessary evidence. First, they document a significant negative relationship between the lead content of gasoline and income per capita (post 1983). This relationship shows up quite strongly in just a simple cross-country scatter plot of lead content against income per capita. Since lead content is arguably pollution per unit output, it is difficult to attribute the negative relationship to much other than income driven policy differences. ${ }^{23}$

Second, the authors find a hump-shaped EKC using data from the post-1983 period, but in earlier periods they find a monotonically rising relationship between lead emissions and income. The declining portion of the EKC only appears in the data once the negative health effects of lead had become well known. The emergence of the declining portion in the income pollution relationship is very suggestive of a strong policy response to the new information about lead. The fact this only appears late in the sample makes it difficult to attribute the decline in lead to other factors that could be shifting the demand for pollution. For example if the declining portion of the EKC was due to increasing returns to scale in abatement, then it should appear in both the pre and post-1983 data and vary across countries being correlated with an appropriate measure of economic scale. If it was due to shifts in the composition of output arising naturally along the development path, why would it only appear in the post-1983 data? While it is possible to think of examples where these other factors are at play, the scope for mistaking a strong policy response for something else is drastically reduced in this study. The natural inference to draw is that the decline only occurs late in the sample because with greater information about lead's health effects, policy tightened and emissions fell.

A second important study is Gale and Mendez (1998). They re-examine one year of sulfur dioxide data drawn from Grossman and Krueger's (1993) study. The study does not offer a theory of pollution determination, but is original in investigating the role factor endowments may play in predicting cross-country differences in pollution levels. They regress pollution concentrations on factor endowment data from a cross-section of countries together with income-based measures designed to capture scale and technique effects. Their results suggest a strong link between capital abundance and pollution concentrations even after controlling for incomes per capita. Their purely cross-sectional analysis cannot, however,

\footnotetext{
${ }^{22}$ Lurking in the background of this study is a composition effect operating through changes in the fleet of cars. This composition effect is not investigated in the paper, although it may be responsible for the jump in lead per gallon of gasoline use at low income levels shown in Figure 4 of the paper.

${ }^{23}$ To be precise we should note that since lead content per gallon is an average, and cars differ in their use of leaded versus unleaded gas, the composition of the car fleet is likely to be changing as well. Therefore, the fall in average lead content may reflect an income-induced change in the average age of the fleet (which would lower average lead content) plus a pure technique effect.
} 
differentiate between location-specific attributes and scale effects. Nevertheless, their work is important because the strong link they find between factor endowments and pollution suggests a role for factor composition in determining pollution levels. That is, even after accounting for cross-country differences in income per capita, other national characteristics matter to pollution outcomes.

Combining our three stylized facts on pollution emissions presents us with an important question. How did aggregate emissions and emissions per unit output fall so dramatically in the U.S. without raising pollution abatement costs precipitously?

There are several possible explanations. One possibility is that ongoing changes in the composition of US output have led to a cleaner mix of production that has lowered both aggregate measures of costs and emissions. The downward trend in emissions per unit output shown in Figure 1 prior to the advent of the Clean Air Act suggests some role for composition effects. While changes in the composition of US output are surely part of the story, there are reasons to believe that they cannot be the most important part. Over the 1971-2001 period of active regulation by the EPA, total emissions of the 6 criteria air pollutants (Nitrogen Dioxide, Ozone, Sulfur Dioxide, Particulate matter, Carbon Monoxide, and Lead) decreased on average by $25 \%$. Over this same period, gross domestic product rose $161 \%$ and pollution abatement costs have risen only slightly. ${ }^{24}$ The magnitude of these emission reductions is too large for it to reflect composition changes alone.

To get a feel for the magnitudes involved note that if changes in the composition of output over the 1971-2001 period are to carry all the burden of adjustment, then we would set the changes in $a_{i}$ to zero in (2). Then using the EPA's estimate of an average $25 \%$ reduction for $E$ and the $161 \%$ increase for $Y$, we find that the weighted average of industry level changes must add up to - $186 \%$ change. This is just too large a realignment in the composition of industry to be credible.

It is also apparent from the figures that emissions for most pollutants have been falling since the early 1970s and as we saw earlier there are limits to how far aggregate emissions can fall via composition effects. Our earlier discussion of the static nature of the within-pollutant sources of emissions also argues against strong composition effects. Finally, there is little evidence that international trade is playing a major role in shifting dirty goods industries to other countries but stronger composition effects after the advent of federal policy in early 1970s would be necessary to explain the fall in emissions seen in the figures. ${ }^{25}$ For this set of reasons it seems clear that composition effects alone cannot be responsible for the result.

Another possible explanation is that ongoing growth in incomes has generated a strong demand for environmental improvement. In this account, income gains over the post WWII period produce a change in policy in the early 1970s and usher in the EPA and the start of emission reductions. While this explanation fits with the decline in emission to output ratios and the lowered emissions since the early 1970s, it too cannot be the entire story. As we discuss in Section 4, if rising incomes are to be wholly responsible for the change in pollution

\footnotetext{
${ }^{24}$ These figures are from the EPA's Latest Findings on National Air Quality, 2001 Status and Trends, available at http://www.epa.gov/air/aqtrnd01/ published September 2002.

${ }^{25}$ See for example Antweiler et al. (2001) and Grossman and Krueger (1993).
} 
policy, agents must being willing to make larger and larger sacrifices in consumption for improving environmental quality. For example, the theory models of Stokey (1998), Aghion and Howitt (1998), Smulders (2001), Lopez (1994), etc. all require a rapidly declining marginal utility of consumption to generate rising environmental quality and ongoing growth. But as Aghion and Howitt note:

"Thus it appears that unlimited growth can indeed be sustained, but it is not guaranteed by the usual sorts of assumptions that are made in endogenous growth theory. The assumption that the elasticity of marginal utility of consumption be greater than unity seems particularly strong, in as much as it is known to imply odd behavior in the context of various macroeconomics models..." (p. 162.)

A rapidly declining marginal utility of consumption is required in earlier work because increasingly large investments in abatement are required to hold pollution in check. ${ }^{26}$ This implies the share of pollution abatement costs in the value of output approaches one in the limit, which is inconsistent with available evidence. ${ }^{27}$

A final possibility is technological advance. Ongoing technological progress in production and abatement could simultaneous drive long run growth and hold pollution abatement costs in check. Technological progress in goods production could be the driving force for growth in final output, while technological progress in abatement allows emissions per unit of output to fall precipitously without raising environmental control costs skyward. In this explanation, income gains from ongoing growth are responsible for the onset of serious regulation in the 1970s, but the advent of regulation then brought forth improvements in abatement methods. As a consequence agents have not been required to make increasingly large sacrifices in consumption for improving environmental quality. As we show in section 4, this explanation is consistent with the predictions of both our Green Solow and Kindergarten models.

Before we proceed we should note that the stylized facts given thus far exclude a discussion of many other pollutants. By selecting only pollutants for which data is available we may have erred on the side of optimism since the measurement of pollutants is often a precursor to their active regulation. One important omission from the above is any discussion of air toxics such as benzene (in gasoline), perchloroethylene (used by dry cleaners), and methyl chloride (a common solvent). These are chemicals are believed to cause severe health effects such as cancer, damage to the immune system, etc. At present the EPA does not maintain an extensive national monitoring system for air toxics, and only limited information is available. ${ }^{28}$

Another omission is any discussion of the set of long-lived chemicals and chemical byproducts that have found their way into waterways, soils and the air. These products have

\footnotetext{
${ }^{26}$ This restriction also implies a large income elasticity of marginal damage and many question whether the demand for a clean environment can be so income elastic. For example, McConnell (1997) argues that current empirical estimates from contingent valuation and hedonic studies do not support the very strong income effects needed.

${ }^{27}$ See the discussion in Aghion and Howitt (1998, page 160-161) and our discussion of abatement in Section 5 of Brock and Taylor (2003).

${ }^{28}$ See U.S. EPA, Toxic Air Pollutants, at www.epa.gov/airtrends/toxic.html.
} 
very long half-lives and produce serious health and environmental effects. Prominent among these in US history are DDT, PCBs, Lead, and most recently CFCs. Official estimates on emissions of these pollutants is difficult to find, but historical accounts and partial data indicate their emissions follow a pattern roughly similar to that of lead shown in Figure 8. As shown by the figure the history of lead is one of strong initial growth in emissions, followed by a rapid phase-out and virtual elimination. In fact, lead continues to be emitted in small amounts, whereas PCB emissions rose from very low production levels in the 1930s to millions of pounds per year of production in the 1970s, to end with a complete ban in 1979. Similarly, DDT was used extensively after WWII but banned in 1972. CFC production in the US rose quickly with the advent of refrigeration and air conditioning, but this set of chemicals now faces a detailed phase-out with CFC-11 and CFC-12 already facing a complete production ban. The salient feature of these accounts is strong early growth followed by quite rapid elimination.

A final failing of these data is that they are on emissions and not concentrations. ${ }^{29}$ Concentration data is available for most of these data at least over the last 20 to 30 years, but the data is well known to be noisy and suffers from other problems related to comparability over time. Nevertheless most aggregate measures of air quality in cities have been improving over time. For example, data on the number of US residents living in counties that were designated non-attainment because of their failure to achieve federal air quality standards shows that over the 1986 to 1998 period these numbers have been falling quite dramatically for sulfur dioxide, nitrogen oxide, carbon monoxide, lead and PM10. The number of people living in counties who failed the federally mandated ozone air quality has however risen from 75 million in 1986 to 131 million in $1998 .^{30}$

\section{Some Illustrative Theory}

\subsection{The Green Solow Benchmark ${ }^{31}$}

Every model relating economic growth to emissions or environmental quality has by construction made implicit assumptions regarding the strength of scale, composition and technique effects. These assumptions are often hidden in choices made over functional form, over the number of goods, the inclusion of finite resources, or in assumptions concerning abatement. Since we have data on the composition of output, its scale, and emissions per unit of output, it is often useful to divide models into categories according to their reliance on scale, technique and composition effects rather than model specifics like the number of goods, types of factors or assumptions over abatement. By dividing up the literature along these lines,

\footnotetext{
${ }^{29}$ Note however that much of the empirical EKC work employs pollution concentration data as does Antweiler et al. (2001).

${ }^{30}$ For these data see U.S. Environmental Protection Agency, Office of Air Quality Planning and Standards, National Air Quality and Emissions Trend Report, 1998 (EPA, Research Triangle Park, NC 2000) and earlier trend reports.

${ }^{31}$ For a detailed exposition see Brock and Taylor (2004).
} 
we can weigh the relative merits of model's that rely exclusively on composition effects by looking at their strength in the data rather than by asking ourselves far less obvious questions such as are capital and resources good or poor substitutes or does abatement exhibit increasing returns.

The literature linking growth and pollution levels is immense starting with very early work in the 1970s by Forster (1973), Solow (1973), Stiglitz (1974), Brock (1977) and others, and culminating in the more recent work investigating the Environmental Kuznet's curve such as Stokey (1998), Aghion and Howitt (1998), or Jones and Manuelli (2001). Although the earlier and late literatures differ greatly in their assumptions regarding the driving force behind growth, all models of economic growth must produce changes in scale, composition, or techniques that satisfy (1). Models that produce similar aggregate relationships between income and pollution often rely on different mechanisms to drive pollution downward. Because of these differences, they have other observable implications that we can use for evaluation.

To start our enquiry into the various mechanisms authors have employed to generate sustainable growth or an EKC prediction, we develop an augmented Solow model where exogenous technological progress in both goods production and abatement leads to continual growth with rising environmental quality. This is the simplest model to explore the importance of technological progress in driving down emissions per unit of output. ${ }^{32}$

Consider the standard one sector Solow model with a fixed savings rate $s$. Output is produced via a CRS and strictly concave production function taking effective labor and capital to produce output, $Y$. Capital accumulates via savings and depreciates at rate $\delta$. We assume the rate of labor augmenting technological progress is given by $g$. All this implies:

$$
\begin{aligned}
Y & =F(K, B L) \\
\dot{K} & =s Y-\delta K \\
\dot{L} & =n L \\
\dot{B} & =g B
\end{aligned}
$$

To model the impact of pollution we follow Copeland and Taylor (1994) by assuming every unit of economic activity, $F$, generates $\Omega$ units of pollution as a joint product of output. The amount of pollution released into the atmosphere may differ from the amount produced if there is abatement. We assume abatement is a CRS activity and write the amount of pollution abated as an increasing function of the total scale of economic activity, $F$, and the economy's efforts at abatement, $F^{A}$. If abatement at level $A$, removes the $\Omega A$

\footnotetext{
${ }^{32} \mathrm{~A}$ full description of the model together with supporting empirical work can be found in Brock and Taylor (2004), NBER working paper No. 10557.
} 
units of pollution from the total created, we have:

$$
\begin{aligned}
E & =\text { pollution created }- \text { pollution abated } \\
& =\Omega F-\Omega A\left(F, F^{A}\right) \\
& =\Omega F\left[1-A\left(1, \frac{F^{A}}{F}\right)\right] \\
& =F e(\theta) \text { where } e(\theta) \equiv \Omega[1-A(1, \theta)] \text { and } \theta \equiv \frac{F^{A}}{F}
\end{aligned}
$$

where the third line follows from the linear homogeneity of $A$, and the fourth by the definition of $\theta$ as the fraction of economic activity dedicated to abatement.

The relationship in (14) requires several comments. The first is simply that (14) is a single output analog of (1) showing that emissions are determined by the scale of economic activity $F$, and the techniques of production as captured by $e(\theta)$. The second is that the production of output per se and not input use is the determinant of pollution. Since there is only one output, this means the composition effect must be zero. In a subsequent section we alter our formulation to consider pollution created by input use, but note in passing here that making pollution proportional to the employment of capital has no effect on our results. Finally, since $F^{A}$ is included in $F$, even the activity of abatement pollutes.

To combine the assumptions on pollution in (14) with our Solow model, it is useful to assume the economy employs a fixed fraction of its inputs - both capital and effective labor - in abatement. This means the fraction of total output allocated to abatement $\theta$ is a fixed much like the familiar fixed saving rate assumption. ${ }^{33}$ As a result, output available for consumption or investment $Y$, becomes $[1-\theta] F$. In addition we must adopt some assumption concerning natural regeneration. To do so we assume the quality of the environment evolves over time according to (6). Therefore, the evolution of the pollution stock is given by:

$$
\dot{X}=F e(\theta)-\eta X
$$

Finally, since the Solow model assumes exogenous technological progress, we assume emissions per unit of output fall at the exogenous rate $g^{A}$. Putting these assumptions together and transforming our measures of output and capital into intensive units, our Green Solow model becomes:

$$
\begin{aligned}
y & =f(k)[1-\theta], \\
\dot{k} & =s f(k)[1-\theta]-[\delta+n+g] k \\
E & =B L f(k) e(\theta), \\
\dot{X} & =E-\eta X, \\
\dot{\Omega} & =-g^{A} \Omega
\end{aligned}
$$

\footnotetext{
${ }^{33}$ We treat $\theta$ as endogenous when examining transition paths in section 5 . It is possible that no abatement is optimal in some limited circumstances, but in models generating balanced growth this would imply every increasing pollution levels. In models without growth, such as Keeler et al. (1972), a Murky Age or Polluted Age equilibrium result is possible with $\theta$ set to zero.
} 
where $k$ is $K / B L$ and $y$ is $Y / B L$; i.e. capital and output measured in intensive units. The top line of (16) repeats the basic Solow model where net output is a fraction of total output. Taking $\theta$ as given, and assuming the Inada conditions, there is a $k^{*}$ such that output, capital, and consumption per person all grow at rate $g$.

Using standard notation, direct calculation reveals that along the balanced growth path we must have $g_{y}=g_{k}=g_{c}=g>0$. A potentially worsening environment however threatens this happy existence. From (16) it is easy to see that constant growth in environmental quality requires $g_{x}=g_{E}$. Since $k^{*}$ is constant along the balanced growth path, the growth rate of emissions is simply:

$$
g_{E}=g+n-g^{A}
$$

which may be positive, negative, or zero. The first two terms in (17) represent the scale effect on pollution since output grows at rate $g+n$. The second term is a technique effect created not by greater abatement efforts, but because emissions per unit output fall via exogenous technological progress at rate $g^{A}$.

Therefore our requirements for sustainable growth are very simple in this model.

$$
\begin{aligned}
g & >0 \\
g^{A} & >g+n
\end{aligned}
$$

Technological progress in abatement must exceed that in goods production because of population growth; and some technological progress in goods production is necessary to generate per capita income growth.

The Green Solow model, although very simple, demonstrates several important points. The first is that investments to improve the environment may cause only level and not growth effects. This is obviously true here since the growth rate of per capita magnitudes is explicitly linked to the rate of technological progress, but not to $\theta$. By setting the time derivative of capital per effective worker to zero in (16) it is straightforward to show that a tighter environmental policy (higher $\theta$ ) lowers output, capital and consumption per worker, but has no effect on their long run growth rates.

The implied income and consumption loss from a tighter policy is however quite small. Adopting a Cobb-Douglas formulation for final output with the share of capital equal to $\alpha$ shows that the ratio of consumption per person along the balanced growth paths of the economy adopting weak versus strong abatement is just:

$$
\frac{c_{w}}{c_{s}}=\left[\frac{1-\theta_{W}}{1-\theta_{s}}\right]^{\frac{1}{1-\alpha}}
$$

since both economies grow at rate $g+n$. If weak abatement means adopting a share of pollution abatement costs in national output of .5\%, and strong abatement means $10 \%$, then consumption per person will differ by $16 \%$ along the balanced growth path (assuming capital's share in output is 0.35). Therefore, a twenty-fold difference in the intensity of abatement creates only a $16 \%$ difference in consumption per person! 
The calculation however seems to imply that environmental policy cannot be much of a limit on economic growth. Recall though that for any given choice of abatement intensity, if we are to have ongoing growth, an improving environment, and a constant (relative) cost of environmental policy, then technological progress in abatement must be sufficiently strong. If technological progress is slower than that given in (18) then one of two things must happen. Either additional investments in abatement must be undertaken to maintain environmental quality, or environmental quality must decline. At this point however we should note that the strict concavity of $A$ implies there are diminishing returns to greater and greater abatement efforts. From (14) we find that $e^{\prime}(\theta)=-A_{2}<0$, but $e^{\prime \prime}(\theta)=-A_{22}>0$. Therefore, in the absence of strong technological progress in abatement, growth in income per capita is only consistent with lower pollution levels if abatement grows over time. ${ }^{34}$

One final observation concerns the transition path of the model. Despite the fact that the intensity of abatement is fixed and there are no composition effects in our one good framework, simulations of the Green Solow model produce a path for income and environmental quality tracing out an Environmental Kuznets Curve. This surprising result is shown graphically in Figure 9 below. In Figure 9 we present the trajectories for two economies that are identical in all respects except for their abatement intensity. Each starts from an initially pristine environment and a small initial capital level. Strong abatement refers to a $10 \%$ share of output spent on abatement; weak abatement to a $0.5 \%$ share. The other parameters were chosen for the purposes of illustration. Per capita income grows at $1 \%$ along the balanced growth path, the population grows at $2 \%$ and the abatement technology improves at $5 \%$. Note that these parameters ensure that growth is sustainable according to (18). Capital's share is set at 0.35 , the savings rate is $10 \%$ and depreciation is $2 \%$. Regeneration is set with $\eta=0.1$ implying a $10 \%$ rate for any $X>0$.

As shown, the environment at first worsens and then improves as the economy converges on its balanced growth path. Note that along the balanced growth path emissions fall and the environment improves at $2 \%$ per unit time, which is close to what the simulation delivers in its last periods.

This result follows for three reasons. First, the convergence properties of the Solow model imply that output growth is at first rapid but then slows as $k$ approaches $k^{*}$. With a fixed intensity of abatement, pollution emissions grow quickly at first but slower later. Therefore, part of the dynamics is governed by the convergence properties of the neoclassical model.

Second, when we start at a pristine environment the effective rate of natural regeneration is zero. This is true because "nature" is at a biological equilibrium with $X=0$. When production begins the environment deteriorates. At $X=0$, the introduction of any emissions overwhelms the rate of regeneration and lowers environmental quality. As $X$ rises, natural regeneration rises. This must be a feature of the regeneration function in order for $X=0$ to be a stable biological equilibrium.

Third, we have assumed emissions fall along the balanced growth path.

Together the first two facts imply that at the outset of economic growth the rapid pace

${ }^{34} \mathrm{~A}$ rising intensity of abatement will lower growth rates introducing other problems in meeting the sustainability criteria. We leave this issue for the next section. 
of growth swamps nature's slow or zero regeneration; but the economic growth rate slows and regeneration rebounds. As we approach the balanced growth path natural regeneration must overwhelm the now less rapid inflows of pollution. The environment improves.

It is important to recognize that this result is more general than our Cobb-Douglas technology and instead relies on quite general properties of production and growth functions. To verify write the dynamic system governing $k$ and $X$ as:

$$
\begin{aligned}
\dot{k} & =s f(k)[1-\theta]-[\delta+n+g] k \\
\dot{X} & =c_{o} \exp \left[-c_{1} t\right] f(k)-\eta X
\end{aligned}
$$

where $c_{0}>0$ and $c_{1}=g^{A}-(g+n)>0$ are positive constants. To show the environment must at first worsen evaluate the accumulation equation for $X$ at $t=0$. Since the environment is initially pristine, $X(0)=0$, and the initial capital stock cannot be zero so $k(0)>0$. Substituting these values into (20) and evaluating shows the environment must at first worsen. $X$ has to be growing at least initially. To examine the rest of the transition path recall that $k(t)$ is increasing in time until it reaches $k^{*}$ because this is, after all, a Solow model. Using this fact, we can bound the path for $X$ by noting:

$$
\dot{X}=c_{o} \exp \left[-c_{1} t\right] f(k)-\eta X<c_{o} \exp \left[-c_{1} t\right] f\left(k^{*}\right)-\eta X
$$

Therefore for any $t>0, X(t)$ must be below the solution to the ordinary differential equation: $\dot{X}=c_{o} \exp \left[c_{1} t\right] f\left(k^{*}\right)-\eta X, X(0)=0$. This ordinary differential equation has a closed form solution showing $X(t)$ tends to zero as $t$ goes to infinity. Using the inequality in (21) we can conclude that pollution must fall along its trajectory. ${ }^{35}$

This explanation for the EKC is entirely distinct from those offered in the literature. There are no composition effects, no increasing intensity of pollution abatement, no increasing returns to abatement, no evolution of the political process, and no international trade. The result follows primarily from the mechanics of convergence coupled with the dynamics predicted by a standard natural regeneration function. Moreover from (14) it is easy to see that emissions per unit of GDP falls both during the transition and along the balanced growth path at the constant rate $g_{A}$ (recall Figure 1 at this point). This is quite surprising because both output and emissions growth varies over time, with the level of emissions tracing out an EKC. Since $\theta$ is fixed throughout, the share of pollution abatement costs in value-added is constant. Therefore, although very simple, the Green Solow model matches three important features of the data: declining emissions to GDP ratios, the EKC, and pollution abatement costs that are roughly constant over time.

The Green Solow Model bears a family resemblance to several papers examining the growth and pollution link within a neoclassical framework. Forster (1973) examines a neoclassical model with zero population growth and no technological progress in either abatement or production. His main result is that steady state consumption per person and capital

\footnotetext{
${ }^{35}$ With a further assumption on technology we can ensure the EKC must be single humped. Our CobbDouglas formulation adopted in the figure is covered by our assumption.
} 
per person are lower when society invests in pollution control since these controls lower the net return to capital.

Although Forster's assumptions on abatement and pollution creation are different from ours, we can reproduce his main results in our fixed savings rate setting by adopting his assumptions of $g_{A}=g=n=0$. When we do so we find steady state capital per person and consumption per person both fall with increases in $\theta$ while pollution is lowered. Forster's work is important because it was perhaps the first examination of optimal pollution control in a neoclassical setting.

The Green Solow model is also similar to the neoclassical model adopted in Stokey (1998), but differs in that Stokey gives no role to technological progress in abatement. As a result increasing abatement intensity must carry the day in reducing pollution. Stokey also generates the EKC prediction but her result follows from a change in pollution policy along the transition path. Her simulations of the model must however to some extent reflect the same dynamic forces we have identified since the model is neoclassical and the evolution equation for the environment is identical.

More closely related work is Bovenberg and Smulders (1995). In their endogenous growth formulation "pollution augmenting technological progress" holds pollution in check and drives long run growth. In their two-sector model, ongoing investments in the knowledge sector raise the productivity of pollution leading to a balanced growth path with a constant level of environmental quality. Again our Green Solow model reproduces the flavor of their results. Setting $n=0$ to mimic their zero population growth assumption, and assuming $g=g_{A}$ to mimic the identical rates of technological progress found in both sectors, we find from (22) that emissions are constant along the balanced growth path and output per person grows at rate g.

This similarity should not be all that surprising because Bovenberg and Smulders' "pollution augmenting technological progress" is very similar to our technological progress in abatement. To see why divide both sides of our emissions function in (14) by $\Omega$, and then employ the monotonicity of $A$ in $\theta$ to invert the intensive abatement function and solve for $[1-\theta]$. Use this to write net output $Y=F[1-\theta]$ available for consumption or investment as:

$$
Y=G(F(K, B L), A E)
$$

where $A=1 / \Omega$, and $G$ is both CRS and concave. Hence "pollution augmenting technological progress" is equivalent to our technological progress in abatement.

\subsection{Intensifying Abatement: The Stokey Alternative}

We now amend our Green Solow model to incorporate a role for intensified abatement to lower pollution levels. In the model above reductions in pollution came about solely because of changes in the emission technology and not because society allocated a greater share of its resources to pollution prevention. In an important paper Nancy Stokey [Stokey (1998)] presented a series of simple growth and pollution models to investigate the links between the 
limits to growth and industrial pollution. She examined the ability of these models to reproduce the results of empirical work finding an Environmental Kuznets Curve and investigated how an active environmental policy may place limits on growth. An important feature of Stokey's analysis was its dependence on increased abatement and tightening regulations to drive pollution downward.

Her analysis contains two contributions. The first is a simple explanation for the empirical finding of an Environmental Kuznets curve. Like Lopez (1994) before her, and Copeland and Taylor (2003) after, Stokey shows how an income elastic demand for environmental protection can usher in tighter regulations and eventually falling pollution levels. This assumption on tastes, together with certain assumptions on abatement, succeeds in generating a first worsening and then improving environment as growth proceeds.

Stokey's second contribution was to investigate whether there are limits to growth imposed by regulating industrial pollution. In section 5 we discuss her analysis within an $A K$ framework; here we focus on her work within the neoclassical model that formed the bulk of her paper. To do so we make the smallest departures possible from the Green Solow model. We again take the savings rate as fixed, but allow the intensity of abatement to vary over time. Since we are primarily interested in feasibility rather than optimality, our fixed savings rate assumption will simplify the analysis at little or no cost. Stokey assumed zero population growth, exogenous technological progress in goods production, a Cobb-Douglas aggregator over capital and labor in final goods production, and adopted an abatement function drawn from Copeland and Taylor (1994). In Stokey's analysis an optimizing representative agent determine savings and abatement decisions.

Although it is not obvious from Stokey (1998), a process of pollution abatement is implicit in her analysis. In Stokey's formulation the planner chooses a consumption path and the techniques of production as indexed by " $z$ ". The choice of techniques determines the link between potential output, $F$, and final output $Y$ available for consumption or investment. The two are related by $Y=F z$; while aggregate emissions are given by $E=F z^{\beta}$ for some $\beta>1$. To see how this choice of "techniques" is really one over abatement intensity make the change of variables $(1-\theta)=z$, and then let $\mathrm{e}(\theta)=(1-\theta)^{\beta}$ for $\beta>1$. It is now easy to see that the "techniques" chosen by the planner correspond to choices over the abatement intensity $\theta$. The resulting $e(\theta)$ is just a specific form of an emissions function coming from the assumptions of constant returns to abatement and pollution being a joint product of output. Since $\theta$ is in principle observable, we conduct our analysis in this unit.

Our amended model assumes zero technological progress in abatement, and to follow Stokey adopts the specific emissions function given above and a Cobb-Douglas aggregator 
over factors. The model is described by:

$$
\begin{aligned}
Y & =F[1-\theta] \\
F & \equiv K^{\alpha}(B L)^{1-\alpha} \\
\dot{K} & =s Y-\delta K \\
\dot{L} & =n L \\
\dot{B} & =g B \\
E & =F e(\theta) \equiv F[1-\theta]^{\beta}
\end{aligned}
$$

To examine the feasibility of balanced growth with a non-deteriorating environment we start with the last equation in (23) giving emissions and log differentiate to find:

$$
G_{E}=\alpha G_{k}+(1-\alpha)(g+n)+G_{e(\theta)}
$$

recall $G_{E}$ must be zero or negative or else the environment deteriorates. In the absence of technological progress in the emissions function, this implies the growth rate of emissions per unit of output $G_{e(\theta)}$ must be negative. To identify what this may imply for growth, we eliminate $G_{K}$. To do so, note balanced growth requires $Y / K$ constant. Divide both sides of the final goods production function by $Y^{\alpha}$. Rearrange and $\log$ differentiate with respect to time to find:

$$
G_{Y}=G_{K}=g+n+\frac{G_{e(\theta)}}{(1-\alpha) \beta}
$$

where $G_{Y}$ is the growth rate of final output. At this point it is worthwhile to note that final output growth is reduced by active abatement since $G_{e(\theta)}$ must be negative.

To determine the evolution of emissions along the balanced growth path substitute (25) into (24) and rearrange slightly to obtain:

$$
G_{E}=g+n+\frac{G_{e(\theta)}}{(1-\alpha) \beta}+\frac{(\beta-1) G_{e(\theta)}}{\beta}
$$

The first two terms of this expression, $(n+g)$, represent the scale effect of growth. They represent the growth rate of emissions that would arise along the balanced growth path if $\theta$ was held constant. This is clear from (23) since if $\theta$ is constant $G_{e(\theta)}=0$.

The final two terms in (26) represent the technique effect created by lowering emissions per unit output along the balanced growth path. This technique effect is itself composed of two parts. The first component is the reduction in the growth rate of final output caused by the diversion of resources to abatement. Since $\theta$ is increasing along the balanced growth path, the growth rate of $F$ exceeds that of final output by this amount. ${ }^{36}$ Therefore, this component of the technique effect lowers pollution by slowing down the growth rate of final output (recall (25)).

The second component of the technique effect is the reduction in emissions per unit of final output created by abating more intensively. This is the standard component identified

\footnotetext{
${ }^{36}$ The growth rate of $\theta$ and $e(\theta)$ are related by $G_{e(\theta)}=-\beta[\theta /(1-\theta)] G_{\theta}$.
} 
in static models. This component of the technique effect need not be as large as previously to lower pollution. To see this solve (26) for the rate at which emissions per unit of output must fall to drive emissions downward. Algebra yields:

$$
-G_{e(\theta)}>\left[\frac{g+n}{1+[\alpha /[(1-\alpha) \beta]]}\right]
$$

which is smaller than the minimum rate of $(g+n)$ needed in (17). Not surprisingly because abatement has a negative effect on growth rates, it has less of a role to play in lowering emissions per unit of output. Therefore in set-ups where abatement is responsible for pollution reduction, the burden is shared across two margins: abatement lowers growth rates and abatement also lowers emissions per unit output.

These two roles for abatement now introduce the possibility that a sustainable growth path may not exist. To see why, note that the reduction in growth created by an ever tightening environmental policy is very similar to the growth drag found in models with either fixed land or exhaustible natural resources. ${ }^{37}$ In the case with fixed or declining resources the ratio of resource use to effective labor falls along the balanced growth path and this lowers growth rates. The same is true here once we make the right translations. To see this parallel, use the final goods production function and the emissions function to write net output as if pollution were an input into production. Doing so we find:

$$
Y=F^{1-\frac{1}{\beta}} E^{\frac{1}{\beta}}
$$

Along the balanced growth path $E$ must fall while $F$ grows; therefore the reduction in $E$ works very much like the exhaustion of a resource that lowers growth. It is now apparent that while (27) tells us that the decline in emission intensity must be sufficiently fast to lower emissions; equation (25) tells us this same magnitude cannot be too large if we are to have positive growth in income per capita. Solving (25) for the implied restriction and combining with (27) yields, after some manipulation:

$$
g>-G_{e(\theta)}>\frac{g+n}{\alpha+(1-\alpha) \beta}
$$

The range given by this inequality defines the set of emission intensity reductions that are consistent with declining emissions and positive per capita output growth: i.e. sustainable growth. If we recall that $\beta>1$, then it is straightforward to see that the feasible region is not empty when there is zero population growth. When $n>0$ the region may not exist. By equating the two sides of (29) we can solve for the relationship between population growth and parameters that must be true for a sustainable growth path to exist. Algebra gives us:

$$
g[(1-\alpha)(1-1 / \beta)]>n\left[\frac{1}{\beta}\right]
$$

\footnotetext{
${ }^{37}$ An excellent review of growth drag is contained in Jones (2002; chapter 9).
} 
The left hand side of (30) is exactly labor's share in final goods production (use (28)and the definition of $F$ ) times the rate of labor augmenting technological progress, $g$. The right hand side is exactly emissions share in final output, $1 / \beta$, times the rate of population growth, $n$. The intuition for this condition is straightforward, and is identical to that we give later in a model where exhaustible energy resources create drag.

The left hand side of the expression represents the Solow forces of technological progress raising growth to the extent determined by labor's share and the rate of progress. The right hand side could be called the Malthusian forces since they capture the impact of diminishing returns caused by a falling ratio of emissions to effective labor along the balanced growth path. These forces are stronger the more important are emissions in the production of final output, and stronger the faster is population growth.

If the inequality in (30) goes the other way then we have two choices. Either per capita income growth is negative, or per capita income growth is positive but emissions rise. In either case we do not have sustainable growth according to our definition.

This observation of course suggests we follow the path of earlier authors and calculate the growth drag due to pollution policy. For example, Nordhaus (1992) adopts a model similar to (28) with emissions $E$ replaced by either land or an exhaustible natural resource and then generates estimates for the drag caused by finite land and natural resources. But without a formal framework in which to estimate the long run growth impact of tighter environmental policy, Nordhaus resorts to estimates of contemporaneous expenditures on abatement to calculate future costs of pollution control.

We can go further here, although our methods are far from ideal. To generate an estimate for the growth drag caused by environmental policy we need estimates of $\beta, \alpha$ and $G_{e(\theta)}$. We note using (23) that $G_{e(\theta)}=G_{E / Y} \beta /[\beta-1]$ where $G_{E / Y}$ is the observable growth rate of emissions per unit of final output. For various measures of $E$ it is shown in Figure 1. We take capital's share of production, $\alpha$ to be 0.35 . To eliminate the parameter $\beta$ write emissions per unit of output, using (23) as $E / Y=(1-\theta)^{\beta-1}$. Since we have data on emissions, final output and pollution abatement costs we could in theory estimate $\beta$. Using this estimate we could then calculate the growth drag due to pollution policy. Since our purpose is not to provide definitive answers but rather suggest a methodology, take the $\log$ of $E / Y$ and differentiate with respect to time to find:

$$
\beta=1-\frac{G_{E / Y}}{G_{\theta}}\left[\frac{1-\theta}{\theta}\right]
$$

where $G_{\theta}$ is the growth rate of the pollution abatement cost share, and $\theta$ the average pollution abatement cost share over the period in consideration. Now use (31) to eliminate $\beta$ and rewrite (25) as:

$$
G_{Y}=g+n-\frac{G_{\theta}}{(1-\alpha)} \frac{\theta}{(1-\theta)}
$$

The drag due to environmental policy is now directly linked to observable measures: the share of pollution abatement costs in the value of overall economic activity, and the percentage growth rate of this measure. To investigate what a reasonable magnitude of 


\begin{tabular}{|llll|}
\hline PAC share percentage increase per year & 2.5 & 5.0 & 7.5 \\
Pollution abatement costs share 1970 & 1.0 & 1.0 & 1.0 \\
Pollution abatement cost share 2000 & 2.1 & 4.3 & 8.8 \\
Average $\theta /[1-\theta]$ across period & 1.57 & 2.72 & 5.15 \\
Growth drag percentage & 0.06 & 0.2 & 0.5 \\
\hline
\end{tabular}

Table 1: The drag pollution policy on growth (percentages)

growth drag maybe, we report in the table below a series of illustrative calculations. Recall that the share of pollution abatement costs in either manufacturing value-added or GDP is small - on the order of 1 or $2 \%$. In certain industries it can of course be much higher. Take 1970 as the base year and set the pollution abatement costs share in that year at $1 \%$. Then applying growth rates of 2.5 to $7.5 \%$ per year in this cost share, we obtain with the help of (32), the following results.

The first column assumes the share of pollution abatement costs in the value of output rises from $1 \%$ to a little over $2 \%$ in thirty years. The other columns report larger increases for illustrative purposes, although they are far in excess of the historic increases as shown by our data in Figure 2. A striking feature of the table is that the drag due to environmental policy is very small except in extreme cases. When pollution abatement costs rise from $1 \%$ to a little over $2 \%$ in 30 years, the drag on growth is only 6 hundredths of $1 \%$ point. When pollution abatement costs grow by $5 \%$ per year, the policy reduces growth by $0.2 \%$. If costs grow by the extremely large $7.5 \%$ per year, drag is now $\frac{1}{2}$ of $1 \%$ point which is significant. Note that growth in per capita income, $G_{Y}-n$, over the last 50 years is approximately $2 \%$ per year; therefore the last column would predict an ever strengthening environmental policy that raises the share of pollution abatement costs in value-added by $7.5 \%$ year would reduce per capita income growth by $25 \%$.

To a certain extent the relatively small effects in Table 1 are not that surprising. If pollution abatement costs as a fraction of value-added are in the order of $1 \%$, it is difficult to see how even relatively large percentage increases in their level would lower growth tremendously. To go slightly further, note from (31) that if $G_{E / Y}$ and $G_{\theta}$ are of the same magnitude, then it is easy to see that $\beta$ is approximately $1 / \theta .^{38}$ This implies the share of emissions in final production in (28), $1 / \beta$ is on the order of 0.01 or 0.02 . And if pollution emissions are such an unimportant input into the production of final output, then drag from any reduction in emissions over time must also be small.

Despite the optimistic results in Table 1 concerning growth rates, models that rely on active abatement often contain the prediction that abatement becomes a larger and larger component of economic activity. This is a direct consequence of two facts. The first is that for emissions to fall, emissions per unit of output must shrink continuously with ongoing growth. The second is that with constant returns to abatement, lowering emissions per unit

\footnotetext{
${ }^{38}$ This may not be such a bad assumption. In Figure 1 it appears that the growth rate of emissions per unit output for each pollutant may be roughly constant over the last 50 years. The important point is that the two growth rates are of a similar magnitude and not necessarily equal.
} 
output comes at increasing cost. As a consequence, an implication of an exclusive reliance on abatement is that abatement costs rise along the growth path to eventually take up most of national product. To verify this, return to our simple example and note $G_{e(\theta)}$ is constant along the balanced growth path. Using our specific emission function in (23), we know:

$$
G_{e(\theta)}=-\beta\left[\frac{\dot{\theta}}{1-\theta}\right]
$$

Solving this differential equation for $\theta$ yields:

$$
\theta(t)=1-(1-(1-\theta(0))) e^{\left(G_{e(\theta)} / \beta\right) t}
$$

starting from some $\theta(0)$ near the balanced growth path we see that as time goes to infinity $\theta$ goes to one because $G_{e(\theta)}<0$. Abatement must take up a larger and larger share of national product as time progresses. This is an uncomfortable conclusion in light of the data we have already presented showing a relatively weak increase in abatement over time. In addition the reader may wonder why it is that agents would willingly make such sacrifices in final consumption necessary for such a large abatement program.

At this point it is useful to refer to Stokey (1998) explicitly for an answer since Stokey's analysis shows that consumer's are indeed willing to make the sacrifice needed in net output to lower pollution albeit under certain conditions. Specifically, by adopting a CRRA utility function Stokey shows emissions fall along the balanced growth path if and only if the elasticity of marginal utility with respect to consumption exceeds one. Only if consumers valuation of consumption falls quickly are they willing to take a smaller and smaller slice of (an ever expanding) national income as growth proceeds.

Stokey's analysis also allows for a more theoretically based growth drag calculation. By adopting specific functional forms, Stokey solves for the growth rate of final output and emissions in terms of primitives. By rearranging slightly and recasting these results in terms of our notation we find the growth rate of output per person and overall emissions are just:

$$
\begin{aligned}
G_{y} & =g-g\left[\frac{\sigma+\gamma-1}{\sigma+\gamma-1+(1-\alpha)(\beta-1) \gamma}\right] \\
G_{E} & =\frac{1-\sigma}{\gamma} G_{y}
\end{aligned}
$$

where $\sigma$ is the elasticity of marginal utility in the CRRA utility function, $\gamma \geq 1$ is a measure of the convexity of damages from pollution, $\alpha$ is capital's share, $g$ is the exogenous rate of labor augmenting technological progress. There is zero population growth so $n=0 .{ }^{39}$

In comparison to our simple example the drag of environmental policy is now directly linked to the primitives of tastes and technology although it reflects similar forces at work.

\footnotetext{
${ }^{39}$ This is found by rearranging (3) page 14 of Stokey (1998). To rewrite the equation in our set up we need to note the rate of labor augmenting technological progress would be $g /(1-\alpha)$ which we write as $g$ in the above.
} 
For example, by rearranging we can isolate the percentage reduction in growth caused by active pollution policy:

$$
G_{y}=g\left[1-\frac{1-G_{E / Y}}{1-G_{E / Y}+(1-\alpha)(\beta-1)}\right]
$$

the greater is the rate of reduction in emissions per unit output, $G E / Y$, and the larger is emissions share in final output $1 / \beta$, the greater will be the drag. This is the same set of forces we found using our simpler framework.

We can of course estimate growth drag in this optimizing framework as well. In order to replicate the Environmental Kuznet's curve Stokey adopts a set of parameters for all the primitives we need. In doing so, the model predicts the EKC found in empirical work, but using these same values for capital's share, the abatement technology, etc. we find that growth drag is an unbelievable $60 \%$ of potential growth. Using the parameter specification chosen to mimic the EKC, growth in income per capita in the absence of pollution policy is $4 \%$ per year. ${ }^{40}$ But using (35) growth is actually approximately $1.6 \%$ per year with active pollution policy; therefore, growth in income per person is slowed by $60 \%$ from what it would be in the absence of environmental concerns. This is clearly far too high.

If we lower the elasticity of marginal utility to approach the lowest limit consistent with falling pollution ( $\sigma$ approaching 1 ), and set $\gamma=1$, then drag hits its minimum. But even in this case, drag is almost $55 \%$ of potential growth. The problem with these calculations is our assumption of $\beta=3$, which implies a share of pollution emissions in final output of $1 / 3$ which is clearly far too high. Altering $\beta$ to values similar to those used in our growth drag calculations suggests a much smaller drag.

For example, from Figure 1 it is apparent that 3 of the US criteria pollutants had an emissions per unit of output in 1998 that were just 1/10 of their value in 1940. This implies a growth rate of approximately $-4 \%$ per year from these pollutants. Assuming the share of emissions in final output is $0.02, \beta$ is 50 , and with a capital share of 0.35 we find the percentage reduction predicted by (36) to be just 0.03 . Therefore a $2 \%$ growth rate would be reduced to just $1.94 \%$ because of the drag of environmental policy. ${ }^{41}$

We would hasten to add however that these calculations are purely for illustration. They demonstrate how the growth drag due to environmental policy may be calculated from primitives on technologies, abatement costs, knowledge of historic growth, and emission levels. We leave it to future research to develop and refine these methods to generate estimates of the growth drag due to environmental policy. ${ }^{42}$

\footnotetext{
${ }^{40}$ This is just the effective rate of labor augmenting technical change which is $g /(1-\alpha)=0.024 / 0.6$ in Stokey's notation.

${ }^{41}$ The problem with this set of parameters is that the output elasticity of emissions in production is far too high at $1 / 3$. If the regulator used pollution taxes to implement the social optimum, this implies that at all periods of time the share of pollution taxes in value-added would be $1 / 3$. Setting $\beta$ much higher generates numbers closer to those we reported in Table 1.

${ }^{42}$ Other methods used to estimate the impact of tighter pollution policy on growth include the use of quite detailed computable general equilibrium models of the U.S. economy, econometric studies, and more
} 
Many other papers rely on an active role for abatement in lowering pollution levels, and therefore must contain predictions for both the drag of environmental policy and the evolution of pollution abatement costs over time. In some work, abatement is specified differently so that it escapes diminishing returns by assumption. For example, early work by Keeler et al. (1972) examines no growth steady states and assumes foregone output is the only input into abatement. As a result of this assumption, marginal abatement costs are constant in their formulation. Even with constant marginal abatement costs they find that when abatement is not very productive a "Murky Age" equilibrium arises: abatement is not undertaken and emissions are high in the steady state. Alternatively, when abatement is very productive in reducing emissions, the steady state is given by a Golden Age equilibrium with active abatement and lower emissions.

Other related work appears in Lopez (1994) and Copeland and Taylor (2003). In these contributions an optimizing social planner chooses the optimal level of abatement but factor supplies and technology are taken as parametric in their exclusively static analyses. Both adopt formulations where abatement is a constant returns activity using conventional inputs and examine how once for all growth in either technology or factor endowments affect pollution levels. ${ }^{43}$ When growth is fueled by neutral technological progress, Copeland and Taylor show that emissions fall with this source of growth if the elasticity of marginal damage from pollution exceeds one. In a CRRA framework this corresponds to the condition Stokey derived of $\sigma>1$.

In contrast when growth occurs by primary factor accumulation alone, then Lopez (1994) shows that whether pollution rises or falls now depends on both the elasticity of substitution between factor inputs and the income elasticity of marginal damage. If the elasticity of substitution between primary factors and emissions is large, then emissions fall quite easily. When production is Cobb-Douglas, Lopez's condition is identical to that of Stokey and $\sigma>1$ generates the result that emissions fall with growth.

Together these contributions demonstrate that an improving environment and rising incomes are surely feasible in a standard neoclassical model where abatement is a constant returns activity. This path is also optimal under certain conditions. But by relying exclusively on changes in the intensity of abatement to lower pollution levels consumers must be willing to make rather large sacrifices for a cleaner environment over time. It is in fact this rather large willingness to sacrifice for a cleaner environment that leads to regulation in the first place.

In Stokey (1998), regulation is at first not present as the shadow value of capital is too high and the shadow value of pollution too low when growth begins for the planner to allocate any output to abatement. An important input into this decision is that the

aggregative data exercises like the one we just conducted. The results from these studies are quite different. For example, Jorgenson and Wilcoxen (1990) build a 35 industry model of the U.S. economy to estimate the impact of pollution abatement costs and motor vehicle emission standards on overall output and growth. They find that output growth in the U.S. was reduced by almost $0.2 \%$ over the $1973-1985$ period by these environmental policies, and in level terms U.S. real GDP is lower by a quite significant $2.6 \%$.

${ }^{43}$ Lopez (1994) does not present an abatement function per se but it is implicit in his use of the revenue function listing primary factors and emissions as productive factors. 
marginal product of the first unit of abatement is bounded above even at zero abatement. ${ }^{44}$ As a result, no abatement is undertaken $\theta=0$ and pollution rises lock-step with output. Once the environment has deteriorated sufficiently and the now larger capital stock has depressed its shadow value, active abatement begins. There is then a transition period and the economy approaches the balanced growth path described previously.

This explanation for the EKC is quite persuasive. It links rising income levels with a lower shadow cost of abatement and a higher opportunity cost of doing nothing. It captures the idea that policy responds positively to real income growth and generates an $\mathrm{EKC}$ is a straightforward way. We have already seen however that a further implication of the model is an ever-rising pollution abatement cost share that may be inconsistent with the data. In addition we should note that this explanation predicts a constant emissions to output ratio prior to the regulation phase when emissions are rising. After regulation begins, the emissions to output ratio falls and does so at a constant rate along the balanced growth path (see (35)). Figure 1 however shows the emission to output ratio was falling long before emissions peaked in Figures 3 through 8. Therefore, using this data as our guide the model misses the long reduction in emissions per unit output that occurred in the US prior to peak pollution levels being achieved.

These observations suggest, at the very least, that other forces are simultaneously at work and partially responsible for the falling emissions to output ratio and roughly constant control costs in the U.S. historical record. One natural candidate is of course changes in the composition of output towards less energy intensive, and hence less pollution intensive, goods. Much has been made recently about the dematerialization of production and its environmental consequences, and hence we now turn to examine a model relying on just these effects.

\subsection{Composition shifts: The Source and Sink Model}

There are several ways to escape a worsening environment as economic growth proceeds. One possibility is for technological progress in abatement to lower pollution levels as shown in the Green Solow model; another is intensified abatement as shown by the Stokey Alternative. A third method is to alter the composition of output or inputs towards less pollution intensive activities. In this section we investigate the implication of changing energy use in production. Much of current concern over pollution arises from energy use and hence if the economy as a whole could conserve on energy this would have important implications for environmental quality. But raising energy efficiency per unit of output comes at some cost because energy is a valuable input and constraining its use will lower overall productivity. These losses must be compensated for by increases in capital, effective labor or new technology if growth is not to be slowed. Therefore, solving our pollution problems by altering an economy's input mix may introduce significant drag. These growth concerns are of course one of the major reasons why many countries have delayed ratification of the Kyoto protocol; and why many developing countries refuse to sign the agreement.

\footnotetext{
${ }^{44}$ We will show this in section 5 .
} 
While many models investigating the growth and pollution relationship rely on compositional changes to lower pollution levels, few make the role of energy explicit in their analyses. For example, Copeland and Taylor (2003) present a "Sources of Growth" explanation for the Environmental Kuznets curve arguing that if the development process relies heavily on capital accumulation in the earliest stages and human capital formation in later stages, these changes will alter the pollution intensity of production so that the environment should at first worsen and then improve over time. Related empirical work in Antweiler et al. (2001) finds growth fueled by capital accumulation is necessarily pollution increasing, while growth fueled by neutral technological progress lowers pollution levels. Behind these results is presumably a link between the different types of growth, energy use, and emissions.

Similarly, in Aghion and Howitt (1998)'s analysis of long run growth and environmental outcomes, their clean capital - knowledge - takes on a larger and larger role in growth in the long run and this too creates an eventually improving economy. But since they adopt the same assumptions on abatement as Stokey (1998), even with a changing composition of output large increases in abatement must made to hold pollution down to acceptable levels.

In most of these formulations the link to energy use is at best implicit with the reader having to interpret capital or other productive factors in a broad way to include energy or other natural resources. One of the major accomplishments of the early resource literature was to identify how and when finite resources impinge on the growth process. By ignoring the role of exhaustible resources in generating pollution, we run the risk of making pollution reductions look relatively painless because these analyses will miss the induced drag on economic growth created by lower energy use. In this section we make the connection between energy use, growth and environmental outcomes precise by combining earlier models of growth and exhaustible resources with newer models examining the pollution and growth link. By doing so we demonstrate how some of the results of the earlier 1960s and 1970s literature on natural resources and growth have relevance today.

One of the major research questions of the earlier "limits to growth" literature was the extent to which exhaustible natural resources impinged on growth. Seminal contributions by Solow (1974) and Stiglitz (1974) showed that growth with exhaustible resources was indeed possible, although it required a joint restriction on the rate of population growth, technological progress and the share of natural resources in output. There are two wellknown results from this literature.

The first, due to Solow (1974), is that a program of constant consumption is feasible even with limited exhaustible resources and a constant population if the share of capital in output exceeds the share of resources in final output. This observation led to a consideration of the optimal rate of savings to maximize the constant consumption profile. The answer was provided by John Hartwick (1977) and embodied in the now-famous Hartwick's rule: invest all the rents from the exhaustible resource in capital and future generations will be as well off as the currently living despite the asymptotic elimination of natural resources. ${ }^{45}$

The second result, due to Stiglitz (1974), is that growth in per capita consumption is

\footnotetext{
${ }^{45}$ Adopting Hartwick's rule in our source-and-sink model leads to increasing utility over time as the environment improves with resource exhaustion. Proof available upon request.
} 
possible with positive population growth if the rate of resource augmenting technological progress exceeds the population growth rate. Our formulation will also yield a similar restriction on technological progress to generate positive per capita output growth, but in addition we add the further restriction that environmental quality improves. Therefore, even when growth with exhaustible resources is feasible in terms of generating positive output growth (as required by Stiglitz (1974)), it may be unsustainable because this same plan implies rising pollution levels.

We remain as close as possible to our earlier formulation while introducing a role for natural resources. We make two important changes. First, we introduce energy as an intermediate good. The intermediate good "energy" is produced from an exhaustible natural resource, $R$, capital, and labor via a CRS and strictly concave production technology. Final output (used for investment or consumption) is then produced via capital, labor and the energy intermediate. To keep things simple we assume both production functions are CobbDouglas, and to remain consistent with our earlier formulations we assume technological progress is labor augmenting. ${ }^{46}$

Our second change is to assume pollution is produced via energy use, and not the overall scale of final goods production. In doing we sever the strong link we had thus far between pollution and final output by making pollution the product of input use. We retain our earlier assumption that pollution can be abated, but take the fraction of resources devoted to abatement as constant. We have already shown in the Stokey Alternative that increasing abatement creates drag on economic growth; here we show that even with the abatement intensity fixed, a move towards less energy intensive production lowers growth while it reduces the growth rate of emissions.

With these assumptions in hand, the production side of the economy becomes:

$$
\begin{aligned}
Y & =K_{y}^{b_{1}}\left(B L_{y}\right)^{n_{1}} I^{b_{2}} \\
I & =K_{I}^{b_{3}}\left(B L_{1}\right)^{n_{2}} R^{b_{4}}[1-\theta]
\end{aligned}
$$

where $I$ is the energy intermediate, $\theta$ is the fraction of the energy industry's activities devoted to abating pollution, $R$ denotes the flow of resources used per unit time, and subscripts denote quantities of capital and labor used in final good production, $Y$, and the intermediate good energy, $I$.

Capital and labor has to be allocated efficiently across the two activities - intermediate and final good production. It is straightforward to show that this implies a constant fraction of the capital stock is employed in intermediate good production and the remainder in final goods. The same is true for labor. This allows us to aggregate and rewrite the production function for final good output as follows:

$$
Y=K^{a_{1}}(L B)^{a_{2}} R^{a_{3}}[1-\theta]^{b_{2}}
$$

which is necessarily CRS with $a_{1}+a_{2}+a_{3}=1 .^{47}$

\footnotetext{
${ }^{46}$ This implicitly assumes that energy is not an essential input into production; i.e. energy per unit of output is not bounded below.

${ }^{47}$ Algebra shows $a_{1}=b_{1}+b_{2} b_{3}, a_{2}=n_{1}+b_{2} n_{2}$, and $a_{3}=b_{2} b_{4}$.
} 
To complete the model we add equations governing the labor force and technology growth, the relationship between extraction and the resource stock, S, plus our abatement assumptions linking emissions to energy use, I. These conditions are:

$$
\begin{aligned}
\dot{K} & =s Y-\delta K \\
\dot{L} & =n L \\
\dot{B} & =g B \\
E & =I \Omega e(\theta)=I \Omega[1-\theta]^{\beta} \\
\dot{S} & =-R
\end{aligned}
$$

where $e(\theta)$ measures the flow of emissions released per unit of energy used. It is instructive at this point to rewrite the emissions equation to focus on the role of a changing composition of inputs in determining pollution levels. To do so define the variable $\chi=I / Y$ which is the ratio of energy use to final good production, or what is commonly called the energy intensity of GDP. Then rewriting the emissions function we find:

$$
E=\chi Y \Omega e(\theta)
$$

A change in emissions can now come from any one of three sources: scale effects via changes in final good output $Y$; composition effects coming from changes in the energy intensity of final good production $\chi$; and technique effects that lower $\Omega e(\theta)$ directly.

We examine balanced growth paths and impose two requirements on the set of paths we investigate. First, as usual we require non-deteriorating environmental quality. Second, we require positive growth in per capita income. ${ }^{48}$

To solve for a balanced growth path note $Y / K$ must be constant along any such path. Using this requirement we can log differentiate (38) with respect to time, impose the requirement that $Y / K$ be constant, and find the growth rate of final output: ${ }^{49}$

$$
G_{Y}=(g+n)-\left[\frac{a_{3}}{1-a_{1}}\right]\left[(g+n)-g_{R}\right]
$$

The first term is the usual growth rate of output in the Solow model; the second is a negative element capturing the growth drag caused by natural resources. To see why this term appears suppose resources were in unlimited supply; then their services could grow over time at the same rate as effective labor and we would have $g_{R}=g+n$. In this case, capital, output,

\footnotetext{
${ }^{48}$ To this the reader may choose to add various efficiency conditions. For example, Stiglitz (1974) imposes the arbitrage condition requiring the return on capital equal that of the resource. This additional constraint is the well-known Hotelling (1931) result that the rate of capital gain on the resource in situ must equal the return on capital. This efficiency condition fails here because energy use creates the disutility pollution. We could impose a similar efficiency condition but its form would depend on how pollution entered utility. Alternatively, or in addition, the reader may add a condition requiring the marginal rate of substitution between consumption and pollution equal its marginal product. We leave a discussion of optimality until section 5 .

${ }^{49}$ It is helpful to recall $\theta$ is constant and (38) is CRS.
} 
resources and effective labor would grow at the rate $\mathrm{g}+\mathrm{n}$ and there would be no resource drag. In fact, however, the resource base $S(0)>0$ is finite and exhaustible, and this implies that $g_{R}<0 .{ }^{50}$ Any non-positive $g_{R}$ is feasible because we can always choose the level of resource use such that the finite stock is eliminated asymptotically. Therefore, the ratio of resources to effective labor in production falls over time and this reduces growth below the Solow level. Indeed as (41) shows, growth in final output could be negative if resource constraints loom too large. ${ }^{51}$

$>$ From our earlier equations it is straightforward to show that $a_{3}=b_{2} b_{4}$ and hence the existence of finite resources lowers growth by an extent determined by the resource share in final output. To see this note that if the share of final output going to resources approached zero, then $a_{3}$ approaches zero, and $G_{Y}$ in (41) approaches $g+n$ the Solow growth rate.

It is now straightforward to write growth in per capita output as just:

$$
g_{y}=g-\left[\frac{a_{3}}{1-a_{1}}\right]\left[g+n-g_{R}\right]
$$

which shows technological progress has to offset both population growth and the reduction in resources over time in order for per capita income to rise. To make this clear and relate our model here to the Stokey Alternative, suppose the resource in question offered an indestructible flow of services per unit time; i.e. suppose it was Ricardian land. Then $g_{R}=0$ and growth in per capita income is positive if and only if:

$$
a_{2} g>a_{3} n
$$

The left hand side of (43) represents the Solow forces of technological progress the strength of which depends on the share of labor in overall production and the rate of labor augmenting technological progress. Aligned against these are the Malthusian forces lowering output per person by applying more and more labor to the fixed stock of land. The rate of population growth and the share of land in production determine the strength of the Malthusian forces. Note the similarity between (43) and our earlier (30). The condition in (43) arises when $g_{R}=0$ and $g_{y}>0$; the condition in (30) has $g_{E}=0$, and $g_{y}>0$. Note the parallel between emissions and resources.

To generate falling pollution we will need a strong compositional shift and hence $g_{R}<0$ is our standard case. Our first condition for sustainability is that (42) is positive. Our second condition is that pollution must fall over time. Log differentiating our emissions function in (40) yields:

$$
g_{E}=-g_{A}+g_{\chi}+g_{Y}+g_{e(\theta)}
$$

${ }^{50}>$ From our stock equation we have $S(t)=S(0)-\int_{o}^{t} R(\tau) d \tau$ where $S(t)$ must be non-negative. This implies that $R(\tau)$ cannot rise over time along a balanced growth path.

${ }^{51}$ Recall however the Solow result [See Solow (1974)] that with zero technological progress and zero population growth, a program of constant consumption can be maintained as long as the share of resources in final output is less than the share of capital. We cannot derive this condition from (41) directly because we have already imposed a constant $Y / K$, which is inconsistent with this program. 
to eliminate the possibility of emissions falling because of technological progress in abatement as in the Green Solow model, we set $g_{A}$ to zero. To eliminate the possibility of greater abatement efforts holding pollution in check as in the Stokey Alternative, we set $g_{e(\theta)}=0$. This leaves only changes in the composition of inputs to offset the rising scale effect of ongoing growth.

Straightforward calculations then show that the growth rate of energy per unit of final output is simply given by:

$$
g_{\chi}=-\left[1-b_{3}\right]\left[\left[\frac{b_{4}}{1-b_{3}}\right]-\left[\frac{a_{3}}{1-a_{1}}\right]\right]\left[g+n-g_{R}\right]<0
$$

The sign of (45) is negative (see footnote 47). Not surprisingly, the energy intensity of final output must fall over time.

Putting the growth rate of output and energy intensity together we find emissions will fall if and only if:

$$
g_{E}=(g+n)-\left[b_{3}\left[\frac{a_{3}}{1-a_{3}}\right]+b_{4}\right]\left[(g+n)-g_{R}\right]<0
$$

Note the first element in (46), $(g+n)$, is exactly the scale effect of output growth in the Green Solow model. And instead of technological progress in abatement appearing to offset the scale effect of growth, we now have emissions per unit of final output falling from the composition effect given by the second negative term. The growth rate of output is lowered by the drag of natural resources and hence as the economy "abates" by altering its input mix this creates drag much as in Stokey (1998).

There is a tension therefore between the desirability of moving away from natural resource use in order to lower pollution emissions and the cost of doing so in terms of growth. This of course is a primary concern of many developing countries and has limited their participation in the Kyoto Protocol to limit global warming. Because of our addition of a fixed natural resource, in some cases, composition effects alone cannot generate positive balanced growth with a non-deteriorating environment.

To investigate we graph $G y$ from (42) and $G_{E}$ from (46) in Figure 11 below. We have graphed these growth rates against the rate of change in effective labor per unit resource; that is against, $\left[(g+n)-g_{R}\right]$ since this term plays a key role in both emissions growth and per capita growth. There are several things to note about it. First, suppose resources were in unlimited supply; then their services could "grow" over time at the same rate as effective labor: $g+n$ and we would have $g_{R}=g+n$. Such a wonderful existence corresponds to points along the vertical axis in the figure. In particular we see that with no resource drag, per capita output growth equals $g$. With a finite resource base the growth rate of resource use must be negative and this means that per capita income growth must be lower as shown by the negatively sloped line labeled $G_{y}$ starting at $g$ and intersecting the horizontal axis at point B. Movements along this line correspond to changes in the growth rate of resource use $g_{R}$. 
Similarly, if there were unlimited resources the energy intensity of GDP would remain constant and emissions would rise lock step with output. This unlimited resources scenario corresponds to a point along the vertical axis with the rate of aggregate output growth and emissions of $(n+g)$. Again, since resource use must decline over time the true growth rate of emissions must be lower as shown by the line labeled $G_{E}$ that intersects the horizontal axis at $\mathrm{A}$. The growth rate of emissions falls as we move to the right along this line because final output grows more slowly, and final output uses less energy per unit output.

$>$ From these observations it is clear that at all points to the left of A, growth in emissions is positive; points to the right of $\mathrm{A}$, growth in emissions is negative. Similarly, all points to the left of $\mathrm{B}$ have positive per capita output growth; points to the right have negative growth. Putting these results together we see that ongoing growth in per capita incomes and an improving environment may not be feasible in some cases. In particular, the bold line segment $\mathrm{AB}$ represents the feasible region. Taking $g$ and $n$ as exogenous, this region gives us a range of resource exploitation rates, $g_{R}$, that are consistent with our twin goals. ${ }^{52}$

To understand the determinants of the feasible region it proves useful to consider the zero population growth case. If population growth is zero, then the two lines have the same vertical intercept as shown by the dotted $n=0$ line that is parallel to $G_{E}$. Whether positive growth and falling emissions is possible only depends on the relative slopes of $G_{E}$ versus $G_{y}$. Algebra tells us a region such as AB will always exist with zero population growth. The logic is simply that emissions growth falls with both reduced output growth and a changing energy intensity of production. Both occur as we increase drag by moving right in the figure. Therefore, once resource drag has lowered per capita output growth to zero at a point like B the scale effect is zero, but emissions growth must be strictly negative because the composition effect is still driving energy intensity downwards. Consequently, a feasible region like $\mathrm{AB}$ exists.

When population growth is positive, this logic fails. As we raise the population growth rate the $G_{E}$ curve shifts to the right and eventually intersects the horizontal axis at B. This in effect raises the scale effect. At this point, positive growth with declining emissions is not possible. The reason is simply that emissions growth is rising in $n$ (a scale effect), whereas growth in output per capita falls with $n$ because of resource drag. Once we choose $n$ large enough - as shown by the dashed line labeled $n_{1}>n$ - the feasible region disappears. ${ }^{53}$

These results have a decidedly negative flavor to them. An environmental policy that lowers the growth rate of emissions and lowers the energy intensity of final output, also lowers per capita growth to such an extent that an improving environment and real income gains may be unattainable. There are several reasons why we should be cautious in interpreting these negative results. The first is simply that we have ruled out a role for active abatement as in the Stokey Alternative. And we have ruled out technological progress as in the Green Solow model. While adding more avenues of adjustment is always good, active abatement lowers

\footnotetext{
${ }^{52}$ You can derive the exact extraction level associated with any rate of exploitation by employing the materials balance constraint for resources.

${ }^{53}$ The issue of feasibility also arises in the Stokey Alternative although we didn't focus on it there. Recall Stokey (1998) assumed $n=0$. Our analysis here suggests that this is not an innocuous assumption.
} 
pollution emissions but creates drag just as reducing energy use does. Routine calculations show that if we let all three avenues of adjustment operate, we can write our two balanced growth path requirements as:

$$
\begin{gathered}
G_{y}=\underbrace{g}_{\text {Green Solow }}-\underbrace{R D\left[(g+n)-g_{R}\right]}_{\text {natural resource drag }}+\underbrace{P P D\left[g_{e(\theta)}\right]}_{\text {pollution policy drag }}>0 \\
G_{E}=\underbrace{g+n-g_{A}}_{\text {Green Solow }}-\underbrace{E I\left[(g+n)-g_{R}\right]}_{\text {composition effect }}+\underbrace{T E\left[g_{e(\theta)}\right]}_{\text {technique effect }}<0
\end{gathered}
$$

where $\mathrm{RD}$ is a positive constant representing resource drag, and PPD a positive constant representing pollution policy drag. Note that in general with both resource exhaustion and abatement rising, there are two sources of drag on per capita income growth. Corresponding to each source of drag is of course a component of emission reduction. In the second equation EI is a positive coefficient representing energy intensity changes. This corresponds to a composition effect. In addition TE is a positive coefficient representing changes coming from increased abatement; this represents a technique effect.

Putting all this together in terms of our figure, we find that allowing for technological progress in abatement $\left(g_{A}>0\right)$ shifts the growth of emissions line $G_{E}$ inward expanding the feasible region. This should come as no surprise. Adding active abatement shifts both lines down (the economy grows slower as do emissions), having an ambiguous effect on the feasible region. Raising population growth from zero however shrinks the region making it more likely that both requirements cannot be met.

What then are we to make of our stylized facts from the introduction? Emission levels have been falling in many countries while growth in per capita income remained positive. Pollution abatement costs have trended upwards but only slowly, and energy prices - while rising - have not been rising at fast rates. ${ }^{54}$ We have already seen that these features are roughly consistent with the Green Solow model and less so with the Stokey Alternative. Here we find that relying on changes in energy intensity alone can work in lowering emissions but it does so only with strong compositional shifts towards less energy intensive goods. In our formulation these shifts are only consistent with a rising real price of energy over time. To see this note that energy's share in final output is fixed; take final output as the numeraire, and conclude that the real price of energy must rise along the balanced growth path at the rate $-\chi>0$.

In Figure 10 we plot the real price of three energy sources: oil, natural gas, and coal. For ease of reading all prices are set to 100 in 1957. It is very risky to draw any strong conclusions from this data. The real price of oil has almost doubled since 1957; the price of natural gas is rising quite quickly, while the price of coal has increased the least over the period. Naturally these price increases have created some composition effects as predicted by our source and sink model, but only over certain periods of time. For example, Wing

\footnotetext{
${ }^{54}$ Note from (37) that the relative price of energy to final good output must rise along the model's balanced growth path because we have already shown that the energy intensity of production, $\chi$, falls over time (see $(45))$.
} 
and Ekhaus (2003) examine the history of energy intensity in US production and divide its changes into those accruing from a changing mix of US industries and those accruing from within industry improvements in energy efficiency (which would correspond to a fall in $\Omega$ ). Their findings suggest that from the late 1950s until the mid 1970s changes in the composition of US industries played a major role in reducing overall energy intensity. But during the 1980s and 1990s the reduction in US aggregate energy intensity has come from improvements in energy efficiency at the industry level. Therefore changes in the composition of output cannot carry the burden of explanation of our data.

Instead these compositional changes must have been helped along by significant technological progress in abatement or energy efficiency $(\Omega)$. The evidence for these changes is very strong. For example in a detailed study of the energy efficiency of consumer durables Newell et al. (1999) find strong support for a significant role for autonomous technological progress (over $60 \%$ of the change in energy efficiency), and supporting roles for induced innovation created by higher energy prices. Similar evidence is presented by Popp (2002) who examines the impact of higher energy prices on the rate of innovation in key energy technologies. Using a database of US patenting activity over the 1970-1993 period, Popp explains variation in the intensity of energy patenting across technology groups as a function of energy prices, the existing "knowledge stock" in a technology area and other covariates such as federal funding for R\&D. There are two main results from the study. The first is that a rise in energy prices shown in Figure 10 created induced innovation and a burst in patenting activity after the oil price shocks.

The second major result is that while prices are a significant determinant of patenting activity, other factors are also very important. For example, the existing stock of knowledge (as measured by an index of previous patenting weighted for impact) in a technology area has a large impact on subsequent patenting. For example, Popp reports that the average change in knowledge stocks over the period raise patenting activity on average by $24 \%$; while the average change in energy prices over the period raise patenting on average by only $2 \%$. Knowledge accumulation and spillovers are very important in determining the pace of future innovation. ${ }^{55}$

Taking these considerations into account would likely expand our feasible region AB. For example, if the emission intensity $\Omega$ fell when either energy prices rose (as in the sourceand-sink model) or abatement intensified (as in the Stokey Alternative), then composition changes and active abatement could play a smaller role in checking the growth of pollution. This would of course make feasibility more likely.

Adding complications to our existing models would however take us too far afield, and as yet we know of no research that explicitly links energy prices, induced innovation and

\footnotetext{
${ }^{55}$ Related empirical work by Kaufmann (2004) however is less sanguine about the ability of technical change to lower energy intensity in the long run. Kaufman examines the 1929-1999 period and argues that estimates of autonomous energy efficiency increases have been drastically overstated because changes in the composition of inputs and outputs have had led to a significant lowering of energy intensity. Instead he argues that inter fuel substitutions and reductions in household energy purchases are largely responsible for the declining trend in the energy intensity of GDP.
} 
pollution emissions within a growth framework. Instead we take a small step towards a theory of induced innovation in the next section when we introduce a model with learning by doing in abatement and reconsider our stylized facts. But before doing so, we should note that we have, to a certain extent, stacked the decks against sustainable growth by assuming environmental quality has no effect on production possibilities. We have assumed that reducing the flow of emissions has only a cost in terms of drag and no benefit in terms of heightened productivity in goods production due to higher environmental quality. Several authors have however postulated a direct and positive link between the productivity of final goods output and environmental quality. This link casts doubt on the validity of growth drag exercises like ours. A typical formulation would add to our models a shift term on the final goods production function that is increasing in environmental quality. For example, Bovenberg et al. (1995) and Tahovnen (1991) both postulate this type of additional interaction. Once we allow for a direct productivity response to an improved environment it is not clear that emission reductions lower growth. Bovenberg et al. and Tahovenen et al. both give sufficient conditions under which this additional channel dominates.

In general the less important are emissions in the direct production function, the more responsive is natural growth to a reduction in emissions, and the greater is the marginal productivity boost from a cleaner environment, the more likely it is that emission reduction could, in theory, boost growth. While it is certainly plausible that a deteriorating environment will lower productivity, it is however unclear how important these impacts are empirically. We suspect that for most of industrial production these environmental impacts are small. Certain industries such as farming or fishing are certain to have larger productivity effects from an improved environment, but these industries are small contributors to GDP in developed countries. It is likely that these induced productivity effects are greatest in poor developing economies and as yet have escaped the notice of serious empirical researchers.

While it is certainly possible for these direct productivity effects to exist, we feel the biggest restriction imposed by our analysis thus far is its failure to link the rising costs of pollution control to innovation targeted at raising the productivity of abatement. Induced changes in technology of this sort are likely to lower energy intensity over time given the price paths shown in Figure 10 and innovation in abatement technologies is likely to be forthcoming as abatement costs rise. Both of these induced effects would lower emissions per unit final output by altering $\Omega$. There is of course a large body of empirical research finding just such effects. But clearly these links are important although difficult to model in a growth framework, for as Popp notes

"The most significant result [sic of the study] is the strong, positive impact energy prices have on new innovations. This finding suggests that environmental taxes and regulations not only reduce pollution by shifting behavior away from polluting activities but also encourage the development of new technologies that make pollution control less costly in the long run.....simply relying on technological change is not enough. There must be some mechanism in place that encourages new innovation", p178. 
With this quote in mind we now turn to consider the role of innovation induced by regulation.

\section{Induced Innovation and Learning by Doing}

The series of models we have examined thus far explain the growth and environment data by focusing on technological progress in goods production, increased abatement efforts or changes in the composition of output over time. ${ }^{56}$ Missing from this list is a consideration of induced innovation lowering abatement costs. Induced innovation or learning by doing is prominent in both growth theory (since the writings of Arrow (1962)), and in environmental economics more generally. For example, Jaffe, et al (1995) stresses the role of induced technological advance in solving pollution problems and holding down abatement costs. New growth theory often adopts formulations that are in essence learning by doing models. In models where knowledge accumulates over time, innovators learn from this stock of knowledge. In models of human capital acquisition the evolution of human capital reflects the learning of past generations. And the simplest AK specification can be thought of a model where learning by doing in capital accumulation generates constant returns to capital accumulation at the economy wide level.

The introduction of learning by doing offers several new features to the growth and environment relationship. First, if abatement efforts are subject to learning by doing then this feature alone may generate the prediction of a first worsening and then improving environment. In a static setting, learning by doing is identical to increasing returns, and Andreoni and Levinson (2001) show how increasing returns to abatement can generate an EKC in a partial equilibrium endowment economy. ${ }^{57}$

Secondly, learning by doing alters the costs of pollution control. If learning by doing effects are unbounded, then growth with falling pollution levels could conceivably come at decreasing cost to society. In a world with bounded learning by doing the implications are less clear, but it seems likely that the drag of pollution policy would be smaller if learning by doing effects are present. An important feature of the static analysis mentioned above is that the authors generate falling pollution levels under quite weak assumptions on preferences. Specifically they do not need to adopt formulations where the demand for environmental protection is very income elastic. This suggests that a parallel dynamic analysis may escape these restrictions as well, because the cost of environmental control is now lower.

Third, if learning by doing arises from economy wide growth in the knowledge stock then learning by doing models offer the possibility of linking technological progress in abatement with that in goods production. Learning by doing models give us one way to make our assumptions about knowledge spillovers and technological progress consistent across sectors. And as our previous analysis makes clear, the relative rates of technological progress in goods

\footnotetext{
${ }^{56}$ To this we could add the set of papers invoking political economy arguments. See for example Jones and Manuelli (2001) and the related empirical work by Barrett (1998).

${ }^{57}$ Copeland and Taylor (2003) extend their analysis to a two-sector general equilibrium model with industry wide external economies in abatement and replicate their finding for a production economy.
} 
production and abatement are key to determining the sustainability of a balanced growth path.

Finally, although learning by doing is often modeled as a passive activity and not purposeful investment, learning by doing can be a form of induced innovation. If a worsening environment necessitates the imposition of pollution controls, and abatement is subject to learning by doing, we have effectively followed the advice of Popp in identifying a causal factor behind subsequent improvements in abatement technology.

\subsection{Induced Innovation and the Kindergarten Rule Model}

To discuss these issues, we now introduce the Kindergarten Rule model of Brock and Taylor (2003). This model, like those in the static literature, relies on learning by doing in the abatement process to hold pollution in check. Importantly, though since learning by doing is really an assumption about knowledge spillovers, the Kindergarten model adopts a consistent set of assumptions regarding the beneficial impact of knowledge spillovers. It assumes, similar to contributions in the AK growth literature, that knowledge spillovers in capital accumulation lead to constant returns at the aggregate level. Similarly, knowledge spillovers in abatement eliminate diminishing returns to abatement. As a consequence, we obtain a relatively simple model of growth with pollution controls where learning by doing reduces abatement costs but does not eliminate the drag of environmental policy entirely.

In order to focus on the implications of ongoing technological progress for the environment and growth, Brock and Taylor (2003) adopt the very direct link between factor accumulation and technological progress employed by Romer (1986), Lucas (1988) and others. By doing so they generate a simple one-sector model of endogenous growth and environmental quality. ${ }^{58}$

For simplicity they adopt a conventional infinitely lived representative agent, and assume all pollution is local. There is one aggregate good, labeled Y, which is either consumed or used for investment or abatement. There are two factors of production: labor and capital. There is zero population growth and hence $L(t)=L$; recall it is the rate of population growth relative to the rate of technological progress that is key, so here one of these rates is set to zero. In contrast to labor, the capital stock accumulates via investment and depreciates at the constant rate $\delta$.

\subsubsection{Tastes}

A representative consumer maximizes lifetime utility given by:

$$
W=\int_{0}^{\infty} U(C, X) e^{-\rho t} d t
$$

\footnotetext{
${ }^{58}$ Extensions of their framework to allow for purposeful innovation and a distinction between these two forms of capital, along the lines of Grossman and Helpman (1991) or Aghion and Howitt (1998), seem both feasible and worthwhile.
} 
where $C$ indicates consumption, and $X$ is the pollution stock. Utility is increasing and quasi-concave in $C$ and $-X$ and hence $X=0$ corresponds to a pristine environment. When we treat $X$ as flow, $X=0$ occurs with zero flow of pollution. When we allow pollution to accumulate in the biosphere we assume the (damaging) service flow is proportional to the level of the stock. Taking this factor of proportionality to be one, then $X$ is the damaging service flow from the stock of pollution given by $X$.

A useful special case of $U(C, X)$ is the constant elasticity formulation:

$$
\begin{aligned}
& U(C, X)=\frac{C^{1-\varepsilon}}{1-\varepsilon}-\frac{B X^{\gamma}}{\gamma} \text { for } \varepsilon \neq 1 \\
& U(C, X)=\ln C-\frac{B X^{\gamma}}{\gamma} \text { for } \varepsilon=1
\end{aligned}
$$

where $\gamma \geq 0, \varepsilon \geq 0$ and $\mathrm{B}$ measures the impact of local pollution on a representative individual.

\subsubsection{Technologies}

The assumptions on production are standard. Each firm has access to a strictly concave and CRS production function linking labor and capital to output $Y$. The productivity of labor is augmented by a technology parameter $T$ taken as given by individual agents. Following Romer (1986) and Lucas (1998) we assume the state of technology is proportional to an economy wide measure of activity. In Romer (1986) this aggregate measure is aggregate R\&D, in Lucas (1988) it is average human capital levels; in $A K$ specifications it is linked to either the aggregate capital stock or (to eliminate scale effects) average capital per worker. We assume $T$ is proportional to the aggregate capital to labor ratio in the economy, $K / L$, and by choice of units take the proportionality constant to be one. ${ }^{59}$

\subsubsection{From Individual to Aggregate Production}

Although we adopt a social planning perspective, it is instructive to review how firm level magnitudes aggregate to economy wide measures since this makes clear the assumptions made regarding the role of knowledge spillovers. We aggregate across firms to obtain the

\footnotetext{
${ }^{59} \mathrm{As}$ is well known, one-sector models of endogenous growth blur the important distinction between physical capital and knowledge capital and force us to think of "capital" in very broad terms. Extensions of our framework along the lines of Grossman and Helpman (1991) or Aghion and Howitt (1998) seem both possible and worthwhile. These extensions would however add additional state variables making our examination of transition paths difficult.
} 
$A K$ aggregate production function as follows: ${ }^{60}$

$$
\begin{aligned}
Y_{i} & =F\left(K_{i}, T L_{i}\right) \\
Y & =\sum_{i} F\left(K_{i}, T L_{i}\right) \\
Y & =T L F(K / T L, 1) \\
Y & =K F(1,1)=A K
\end{aligned}
$$

where the first line gives firm level production; the second line sums across firms; the third uses linear homogeneity and exploits the fact that efficiency requires all firms adopt the same capital intensity. The last line follows from the definition of $T$.

Summarizing: diminishing returns at the firm level are undone by technological progress linked to aggregate capital intensity leaving the social marginal product of capital constant.

We now employ similar methods to generate the aggregate abatement technology. To start we note pollution is a joint product of output and we take this relationship to be proportional. ${ }^{61}$ By choice of units we take the factor of proportionality to be one. Pollution emitted is equal to pollution created minus pollution abated. Abatement of pollution takes as inputs the flow of pollution, which is proportional to the gross flow of output $Y^{G}$, and abatement inputs denoted by $Y^{A}$. The abatement production function is standard: it is strictly concave and CRS. Therefore denoting pollution emitted by $P$, we can write pollution emitted by the ith firm as:

$$
P_{i}=Y_{i}^{G}-a\left(Y_{i}^{G}, Y_{i}^{A}\right)
$$

Now consider a Romeresque approach where individual abatement efforts provide knowledge spillovers useful to others abating in the economy. To do so we again introduce a technology shift parameter $\Gamma$, and assume it raises the marginal product of abatement. To be consistent with our earlier treatment of technological progress in production we assume $\Gamma$ is proportional to the average abatement intensity in the economy, $Y^{A} / Y^{G}$. Then much as before we have the individual to aggregate abatement technology transformation as:

$$
\begin{aligned}
P_{i} & =Y_{i}^{G}-a\left(Y_{i}^{G} \Gamma, Y_{i}^{A}\right) \\
P_{i} & =Y_{i}^{G}\left[1-\Gamma a\left(1, Y_{i}^{A} / Y_{i}^{G} \Gamma\right)\right] \\
\sum_{i} P_{i} & =\sum_{I} Y_{i}^{G}\left[1-\Gamma a\left(1, Y_{i}^{A} / Y_{i}^{G} \Gamma\right)\right] \\
P & =Y^{G}[1-\Gamma a(1,1)], a(1,1)>1 \\
P & =Y^{G}[1-\theta a(1,1)], \theta \equiv Y^{A} / Y^{G}
\end{aligned}
$$

where the first line introduces the technology parameter $\Gamma$; the second exploits linear homogeneity of the abatement production function; the third aggregates across firms; the fourth

\footnotetext{
${ }^{60}$ Implementing our planning solution by way of pollution taxes and subsidies to investment and abatement should be straightforward.

${ }^{61}$ Nothing is lost if we assume pollution is produced in proportion to the services of capital inputs. The service flow of capital is proportional to the stock of capital, and the stock of capital is proportional to output.
} 
recognizes that efficiency requires all firms choose identical abatement intensities, uses the definition of $\Gamma$ and notes that for abatement to be productive it must be able to clean up after itself. The fifth line defines the intensity of abatement, $\theta \equiv Y^{A} / Y^{G}$. Since abatement can only reduce the pollution flow we must have $\theta \leq 1 / a(1,1) .{ }^{62}$

It is important to note that the aggregate relationship between pollution and abatement given by the last line in (52) is consistent with empirical estimates finding rising marginal abatement costs at the firm level. Each individual firm has abatement costs given by foregone output used in abatement, and hence partially differentiating the first line of (52) and rearranging we find:

$$
\frac{\partial Y_{i}^{A}}{\partial P_{i}}=-1 /\left[\frac{\partial a}{\partial Y_{i}^{A}}\right]<0, \frac{\partial Y_{i}^{A 2}}{\partial P_{i}^{2}}>0
$$

Marginal abatement costs are rising at the firm level.

Marginal abatement costs at the society level, are however, constant. To see why totally differentiate (52) allowing $\Gamma$ and individual abatement to both vary. We find:

$$
\frac{d Y_{i}^{A}}{d P_{i}}=-1 /\left[\partial a / \partial Y_{i}^{A}\right]-\frac{\left[\partial a / \partial Y_{i}^{G}\right]}{\left[\partial a / \partial Y_{i}^{A}\right]} \frac{d \Gamma}{d P_{i}}
$$

$\Gamma$ is the average abatement intensity in the economy, which given identical firms, is just the abatement intensity for the typical ith firm. Using $\frac{d \Gamma}{d P_{i}}=\left[\frac{1}{Y_{i}^{G}}\right]\left[\frac{d Y_{i}^{A}}{d P_{i}}\right]$ and rearranging we obtain:

$$
\begin{aligned}
& \frac{d Y_{i}^{A}}{d P_{i}}=-\frac{Y_{i}^{A}}{\left[\left[\frac{\partial a}{\partial Y_{i}^{A}}\right] Y_{i}^{A}+\left[\frac{\partial a}{\partial Y_{i}^{G}}\right] \Gamma Y_{i}^{G}\right]} \\
& =-\frac{Y_{i}^{A}}{a\left(Y_{i}^{A}, \Gamma Y_{i}^{G}\right)}=-\frac{1}{a(1,1)}<0
\end{aligned}
$$

where the first line follows from rearrangement and the second by CRS in abatement. The result given in (55) is identical to what we find by differentiating the aggregate relationship between pollution and abatement given in the last line of (52).

Summarizing: diminishing returns at the firm level, that lead to rising marginal abatement costs, are undone by technological progress linked to aggregate abatement intensity leaving the social marginal cost of abatement constant.

The formulations of learning by doing that we have adopted are extreme. In general we would expect the productivity in abatement (or production) to adjust gradually in response to a slow moving measure of knowledge capital. In the cases developed here however the productivity boost from an increased knowledge capital occurs instantaneously. So instead

\footnotetext{
${ }^{62}$ Adding the possibility of investments in restoration would probably strengthen the case for sustainable growth. Abatement of pollution and restoration are however distinct activities. We imagine that a restoration production function would take as an input the current damage to the environment - our stock variable $X$ - and then apply inputs to restore it. This is quite different from abatement which operates to lower the current flow of pollution by use of variable inputs.
} 
of $\Gamma$ being a complicated function of the abatement intensities adopted in the infinite past history of the economy weighed by their relevance to productivity today, it is simply proportional to the current intensity. This is of course an abstraction, but a useful one since it frees us from keeping track of the evolution of two additional state variables (knowledge capital in abatement and knowledge capital in production), and allow us to capture the main feature of learning by doing models by linking the productivity of abatement to the intensity of this activity at the economy wide level. It also yields simple linear forms for production and abatement that add greatly to the model's tractability. This last feature is especially important in a model where the stock of environmental quality has already raised the number of state variables to two.

Putting these pieces together our planner faces the aggregate production relations for output and abatement given by the last lines of (50) and (52) together with the atemporal resource constraint linking gross output, abatement and net production:

$$
Y=Y^{G}-Y^{A}
$$

The Kindergarten model is only one approach to modeling endogenous growth and environment interactions. Closely related approaches in an AK framework are those of Stokey (1998), Smulders (1993) and Smulders and Gradus (1996). These papers all adopt AK models, but end up with different conclusions. Early work in a one-sector framework by Smulders (1993) and Smulders and Gradus (1996) demonstrated how continuing economic growth and constant environmental quality are compatible in an AK model. In constrast, Stokey (1998) demonstrated how continuing growth and constant environmental quality are not compatible within a AK set up. The difference in their results comes from their different assumptions on abatement. To see why this is true, start with (51), ignore knowledge spillovers, and work forward using now familiar steps to find:

$$
P_{i}=Y_{i}^{G} \phi(1-\theta), \phi(\theta) \equiv[1-a(1,1-\theta)]
$$

Stokey employs the specific functional form for $\phi$ given by $(1-\theta)^{\beta}$ for $\beta>1$, and this implies the CRS abatement production function given by:

$$
a\left(Y_{i}^{G}, Y_{i}^{A}\right)=Y_{i}^{G}\left[1-\left(1-\frac{Y_{i}^{A}}{Y_{i}^{G}}\right)^{\beta}\right]
$$

Using (57) it is now easy to show abatement is subject to diminishing returns:

$$
\frac{\partial P_{i}}{\partial Y_{i}^{A}}=-\beta(1-\theta)^{\beta-1}<0, \frac{\partial P_{i}^{2}}{\partial Y_{i}^{A 2}}>0
$$

which implies marginal abatement costs are rising at the aggregate level. Setting $Y^{A}=0$ we find the first unit of abatement lowers pollution by the amount $\beta>1$, somewhat similar to our formulation where $a(1,1)>1 .^{63}$ If we now combine (57) with (50), recall net output

\footnotetext{
${ }^{63}$ Since the marginal product of abatement is bounded when abatement is zero, Stokey (1998) is able to show that no regulation is undertaken initially and pollution rises lock-step with output.
} 
is $(1-\theta)$ times gross output, and introduce the variable $z=1-\theta$, we find the exact specification employed in Stokey (1998).

$$
Y=A K z, P=A K z^{\beta}
$$

Stokey's (1998) result that growth is not possible follows from matching an AK aggregate production function with strictly neoclassical assumptions on abatement adopted from Copeland and Taylor (1994). That is, if we think of the AK model as one of knowledge spillovers then Stokey has assumed these spillovers occur in production but not abatement. By doing so, she eliminates "technological progress" in abatement and this eliminates the possibility of sustainable growth.

Comparing our approach to the work of Smulders is more difficult because abatement is not specifically modeled and he considers a variety of formulations. By specializing his framework to the AK paradigm we find:

$$
Y=\alpha K, P=\left[\frac{K}{A}\right]^{\gamma}
$$

The first element is just a standard AK production function. The second relates what Smulders refers to as net or emitted pollution to the capital stock, K, and abatement, A. If we employ (60) and solve for emissions per unit of gross output we find:

$$
\frac{P}{Y}=\left[\frac{K}{A}\right]^{\gamma} / \alpha K
$$

If the economy allocates a fixed fraction of its output to abatement, $K / A$ is constant, and emissions per unit of gross output fall with the size of the economy. This reflects a strong degree of increasing returns. Moreover, the reader may note from (60) that pollution emitted goes to infinity as abatement goes to zero, which is inconsistent with pollution being a joint product of output. Therefore, Smulders and Gradus $(1993,1996)$ match AK aggregate production with assumptions on abatement ensuring increasing returns; and, in contrast with the Kindergarten specification, assume pollution is not a joint product of output.

\subsubsection{Endowments}

We treat pollution as a flow that either dissipates instantaneously - such as noise pollution or a stock that is only eliminated over time by natural regeneration - such as lead emissions or radioactive waste. When $X$ is a stock we have:

$$
\dot{X}=A K[1-\theta a]-\eta X
$$

where $\eta$ represents the speed of natural regeneration, and where for economy of notation we have denoted $a(1,1)$ by $a$. When $X$ is a flow we have:

$$
X=A K[1-\theta a]
$$




\subsubsection{The Kindergarten Rule}

We focus first on the possibility of balanced and continual growth, leaving to the next section a discussion of transition paths. Before we proceed with the formal analysis it proves instructive to step back slightly to consider the feasibility and optimality of sustainable growth. From our assumptions on abatement it is clear that if $\theta$ is set high enough all pollution emissions will be eliminated and we will enter a zero emission world. Therefore as long as $a>1$ there will exist a $\theta<1$ that generates zero emission technologies. And if $\theta<1$ then some output will be left over for consumption and investment which can in turn drive growth in output. It appears then that feasibility is guaranteed by knowledge spillovers in abatement generating a constant marginal product.

The assumption of $a>1$ is innocuous. Recall that abatement, like all other economic activities, pollutes. One unit of abatement creates one unit of pollution, but cleans up $a>1$ units of pollution. It is only this surplus between costs and benefits, $1-1 / a>0$ that makes abatement useful at all. But even if growth is feasible, abatement is costly and this will cause drag as in our earlier formulations. The remaining questions for sustainability are how large is this drag, how much will it lower the return to capital, and what restrictions on preferences will be needed to generate sustainable growth.

To answer these questions consider the following problem:

$$
\begin{aligned}
\text { Maximize } \int_{0}^{\infty} U(C, X) e^{-\rho t} d t \\
\text { s.t. } K(0)=K_{0}, X(0)=X_{0}, \text { and } \theta \leq 1 / a \\
\dot{K}=A K[1-\theta]-\delta K-C \\
\dot{X}=A K[1-\theta a]-\eta X
\end{aligned}
$$

where we adopt $U(C, X)$ from (49). Recall the fraction of gross output allocated to abatement is $\theta$ and since the flow of pollution into the environment cannot be negative this will never exceed 1/a. We can write the Hamilton-Jacobi-Bellman equation as:

$$
\rho W(K, X)=\operatorname{Max}\left\{\begin{array}{c}
H=\frac{C^{1-\varepsilon}}{1-\varepsilon}-\frac{B X^{\gamma}}{\gamma}+ \\
\lambda_{1}[A K[1-\theta]-\delta K-C]+\lambda_{2}[A K[1-\theta a]-\eta X]
\end{array}\right\}
$$

where $\rho W(K, X)$ is the maximized value of the program for the given initial conditions $\left\{K_{0}, X_{0}\right\}$, and $H$ is the current value Hamiltonian for our problem. The controls for this problem are consumption, $C$, and abatement intensity, $\theta$.

Observe the term involving our control variable, $\theta$,

$$
\operatorname{Max}\left\{A K \theta\left[-\lambda_{1}-a \lambda_{2}\right]\right\} \text { s.t. } 0 \leq \theta \leq 1 / a
$$

where $\lambda_{1}$ is the positive shadow value of capital and $\lambda_{2}$ is the negative shadow cost of pollution. Since the Hamiltonian is linear in $\theta$, the value of the term $S=\left[-\lambda_{1}-a \lambda_{2}\right]$ 
will largely determine the optimal level of abatement. When $S>0$, the shadow cost of pollution is high relative to that of capital. In this case abatement is relatively cheap and maximal abatement will be undertaken. Conversely when $S<0$ the shadow value of capital is high relative to that of pollution. In this case abatement is relatively expensive and zero abatement will occur. Finally, when $S=0$, the shadow values are equated and active, but not necessarily maximal, abatement will occur. Therefore, the value of $S$ determines when and if the economy switches from a zero-to-active-to-maximal abatement regime. We deal with these possibilities in turn.

Regardless of the value of $S$, the optimal level of consumption will always satisfy

$$
\frac{\partial H}{\partial C}=C^{-\varepsilon}-\lambda_{1}=0
$$

although the shadow value of capital and its dynamic path may differ across regimes.

When $S>0$, maximal abatement occurs and the dynamics are given by:

$$
\begin{aligned}
S & >0 \\
\theta & =\theta^{K}, \theta^{K} \equiv 1 / a \\
\dot{\lambda}_{1} & =-g \lambda_{1}, g \equiv A\left[1-\theta^{K}\right]-\delta-\rho \\
\dot{K} & =[g+\rho] K-C\left(\lambda_{1}\right), K(0)=K_{0}, C\left(\lambda_{1}\right) \equiv \lambda_{1}^{-1 / \varepsilon} \\
\dot{\lambda}_{2} & =\lambda_{2}[\rho+\eta]+B X^{\gamma-1} \\
\dot{X} & =-\eta X, X(0)=X_{0}
\end{aligned}
$$

By choosing the intensity of abatement $\theta=\theta_{K}$ there are no net emissions of pollution and the environment improves at a rate given by natural regeneration. We dub $\theta_{K}$ "the Kindergarten rule" because when economies adopt the Kindergarten rule pollution is cleaned up when it is created. ${ }^{64}$

Alternatively, $S$ may be exactly zero. In this case we have an interior solution for abatement, with the following dynamics:

$$
\begin{aligned}
S & =0 \\
\theta & \in\left[0, \theta^{K}\right] \\
\dot{\lambda}_{1} & =-g \lambda_{1} \\
\dot{K} & =[A[1-\theta]-\delta] K-C\left(\lambda_{1}\right), K(0)=K_{0}, C\left(\lambda_{1}\right) \equiv \lambda_{1}^{-1 / \varepsilon} \\
\dot{\lambda}_{2} & =\lambda_{2}[\rho+\eta]+B X^{\gamma-1} \\
\dot{X} & =A K[1-a \theta]-\eta X, X(0)=X_{0}
\end{aligned}
$$

In this situation pollution is not completely abated, and hence the evolution of environmental quality reflects both the level of active abatement and natural regeneration. And

\footnotetext{
${ }^{64}$ This is one of the most common rules taught in Kindergarten. For a list of common Kindergarten rules see All I Really Need to Know I Learned in Kindergarten: Uncommon Thoughts on Common Things by Robert Fulgham. Fulgham argues that the basic values we learned in grade school such as "clean up your own mess" (in effect our Kindergarten rule) and "play fair" are the bedrock of a meaningful life.
} 
finally, with no abatement at all we must have $S<0$. Both pollution and output rise over time yielding:

$$
\begin{aligned}
S & <0 \\
\theta & \in 0 \\
\dot{\lambda}_{1} & =-\lambda_{1}[A-\delta-\rho]-\lambda_{2} A \\
\dot{K} & =[A-\delta] K-C\left(\lambda_{1}\right), K(0)=K_{0}, C\left(\lambda_{1}\right) \equiv \lambda_{1}^{-1 / \varepsilon} \\
\dot{\lambda}_{2} & =\lambda_{2}[\rho+\eta]+B X^{\gamma-1} \\
\dot{X} & =A K-\eta X, X(0)=X_{0}
\end{aligned}
$$

Consider growth paths with active abatement. Then from (67) and (66) we find the shadow value of capital falls over time at a constant exponential rate:

$$
-g \equiv \frac{\dot{\lambda}_{1}}{\lambda_{1}}=-\left[A\left[1-\theta^{K}\right]-\rho-\delta\right]<0
$$

provided the net marginal product of capital, at the Kindergarten rule level of abatement, $\mathrm{A}\left[1-\theta^{K}\right]$, can cover both depreciation and impatience. We leave for now a detailed discussion of what this requires and assume it is true: $g>0$. Then it is immediate that consumption rises at the constant rate $g_{C}=g / \varepsilon>0$.

$>$ From the capital accumulation equations in both (66) and (67) we can now deduce that capital and output must grow at the same rate as consumption if $\theta$ is constant over time. To determine whether the intensity of abatement is constant over time, consider the accumulation equation for pollution:

$$
\dot{X}=A K[1-\theta a]-\eta X
$$

There are two ways (70) can be consistent with balanced growth. The first possibility is that we have a maximal abatement regime where $S>0$ holds everywhere along the balanced growth path. In this situation, $K$ grows exponentially over time and $\theta$ is set to the Kindergarten rule level. Using (66), this balanced growth path must have:

$$
\dot{X}=-\eta X \text { and } \theta=\theta^{K}
$$

In this scenario, the environment improves at the rate $\eta$ over time and abatement is a constant fraction of output $1>\theta^{K}>0$. As time goes to infinity the economy approaches a pristine level of environmental quality. Therefore the balanced growth path exhibits constant growth in consumption, output, capital and environmental quality. Consumption is a constant fraction of output and we have:

$$
g_{c}=g_{k}=g_{y}=g / \varepsilon>0, g_{x}=-\eta<0
$$

A second possibility is that abatement is active but not maximal. Define the deviation of abatement from the Kindergarten rule as $D(\theta)=\left(\theta^{K}-\theta\right) / \theta^{K}$. Using this definition rewrite (70) to find:

$$
\frac{\dot{X}}{X}=\frac{A K[D(\theta)]}{X}-\eta
$$


It is apparent that if the deviation of abatement from the Kindergarten rule fell exponentially, then it may be possible for $X$ to fall exponentially while $K$ rises. That is, in obvious notation, a possible balanced growth path would have:

$$
g_{k}+g_{D}=g_{x}<0
$$

In this situation abatement is at an interior solution at all times and becomes progressively tighter over time approaching the Kindergarten rule asymptotically. The inflow of pollution from production into the environment is always positive but environmental quality improves nevertheless. This intuitive description suggests that the possibility of this outcome must rely on both the pace of economic growth and the ability of the environment to regenerate. This is indeed the case as Brock and Taylor (2003) show that a necessary condition for us to remain in a $S=0$ regime with active abatement is simply:

$$
\eta(\gamma-1)>g
$$

This condition reflects two different requirements. The first is simply that $\gamma$ cannot equal one. If it did then the (instantaneous) marginal disutility of pollution is a constant and $\lambda_{2}$ is a constant as well. This would also imply that consumption be fixed as well. This is inconsistent with growth of any sort.

Assuming $\gamma$ not equal to one is necessary for balanced growth with an interior solution for abatement. But a second condition must also hold. Natural regeneration, $\eta$, must be sufficiently large relative to the growth rate $g$. If the rate of regeneration is high and growth rates quite low, then the optimal plan is to use nature's regenerative abilities to partially offset the costs of abating because the shadow value of foregone output is high in slow growth situations. Conversely, if regeneration is low and the growth rate $g$ relatively high, then no amount of abatement short of the Kindergarten rule will hold pollution to acceptable levels.

This intuition suggests a natural corollary for the case of flow pollutants. If pollution has only a flow cost it is "as if" the environment is regenerating itself infinitely fast. This intuition suggests that as we let $\eta$ get large, the results in the stock pollutant case should replicate those for a flow. This intuition is, in fact, correct. Brock and Taylor prove that when $g>0$ and $X$ is a flow pollutant, then sustainable economic growth with an ever improving environment is possible and optimal. With a flow pollutant, if $\gamma>1$, then the intensity of abatement approaches the Kindergarten rule level of abatement, $\theta^{K}$, asymptotically. Alternatively, if $\gamma=1$, then $\theta=\theta^{K}$ everywhere along the balanced growth path.

These results are important in showing how the Kindergarten rule generates sustainable growth. Sustainable growth requires two conditions. The first is that $g$ given in (69) is positive. The assumption $g>0$ requires the marginal product of capital, adjusted for the ongoing costs of abatement, be sufficiently high. A necessary condition is that $A\left[1-\theta^{K}\right]$ be positive, but this is guaranteed as long as abatement is a productive activity. Given abatement is productive, we still require the adjusted marginal product of capital, $A\left[1-\theta^{K}\right]$, to offset both impatience and depreciation. If abatement is not very productive, then $\theta^{K}=$ $1 / a$ will be close to one and growth cannot occur. If capital is not very productive or if the 
level of impatience and depreciation are high then ongoing economic growth cannot occur. These are however very standard requirements for growth under any circumstances. ${ }^{65}$

The second is that $h=g(1-1 / \varepsilon)+\rho>0$. This condition is the standard sufficiency condition for the existence of an optimum path in an AK model with power utility. ${ }^{66}$ This condition is of course weaker than that needed in earlier models generating declining pollution levels. For example, $\varepsilon$ is just $\sigma$ in the CRRA specification we used earlier and we have already seen that Stokey (1998), Lopez (1998) and others require $\sigma>1$ to generate declining emissions. Here the requirement is far weaker and this follows from the fact that consumer's are not required to make larger and larger sacrifices in consumption to fund an every growing abatement program.

\subsection{Empirical Implications}

The Kindergarten model relies heavily on the assumed role of technological progress in staving off diminishing returns to both capital formation and abatement. It is impossible to know apriori whether technological progress can indeed be so successful and hence it is important to distinguish between two types of predictions before proceeding. The first class of predictions are those regarding behavior at or near the balanced growth path. This set has received little attention in the empirical literature on the environment and growth, although balanced growth path predictions and their testing are at the core of empirical research in growth theory proper (see the review by Durlauf and Quah (1999)). The second set of predictions concern the transition from inactive to active abatement and these are related to the empirical work on the Environmental Kuznets Curve (See Grossman and Krueger (1993,1995) and the review by Barbier (2000)).

\subsection{Balanced Growth Path Predictions}

Using our previous results it is straightforward to show that near the balanced growth path we must have: convergence in the quality of the environment across all countries sharing parameter values but differing in initial conditions; the share of pollution abatement costs in output approaching a positive constant less than one; overall emissions rates falling and environmental quality rising; and emissions per unit output falling as production processes adopt methods that approach zero emission technologies. The model also presents predictions for the intensity of abatement that we discuss subsequently.

\footnotetext{
${ }^{65}$ In Keeler, Spence and Zeckhauser (1972) a similar condition describes their Golden Age capital stock. In their model with no endogenous growth the Golden Age capital stock is defined by (in our notation) the equality $f^{\prime}(K)[1-1 / a]-\delta=\rho$ simulations of the model assume $a$ to be 12 (see p.22). Chimeli and Braden (2002) assume a similar condition. Both studies assume abatement or clean up is a linear function of effort thereby ignoring the reality of diminishing returns and the necessity of ongoing technological progress.

${ }^{66}$ Denote the growth rate in an AK model with power utility by $g^{*}$, then in terms of our parameters we have $g^{*}=g / \varepsilon$ and the standard condition is $\rho+(\varepsilon-1) g^{*}$. This is equivalent to $h>0$. See Aghion and Howitt (1998, Equation (5.3)).
} 
Whether the cross-country predictions will be borne out by empirical work is as yet unknown but an examination of US data shows the model's strongest predictions - those regarding falling emissions and improving environmental quality - are not grossly at odds with available U.S. data. The most favorable evidence for the model is the slow movement in pollution abatement costs in the face of dramatically declining pollution levels. The model explains this feature of the data by recourse to specifics of the abatement function that hold abatement costs down much as exogenous technological progress does in the Green Solow model.

The prediction of declining emission intensities along the balanced growth path is also consistent with the data shown in Figure 1, but as in Stokey (1998) the model only predicts declining emissions to output ratios after regulation begins.

\subsection{The Environmental Catch-up Hypothesis}

We have so far focused on balanced growth paths but the large EKC literature concerns itself with what must be transition paths towards some BGP. To examine these predictions we present several transition paths in Figure 5. One of these paths is that of a Poor country having small initial capital $K^{P}$ but a pristine environment. The other is the path of a Rich country starting again with a pristine environment but with a much larger initial capital $K^{R}$. These differences in initial conditions could reflect variance across countries in geography, resource endowments or institutions that impact on initial productivity levels. Each economy starts with a pristine environment in stage I and grows. During this stage there is no pollution regulation: the environment deteriorates, $X$ rises, and the capital stock grows until the trajectory hits the Switching Locus labeled SL. Once the economy hits the Switching Locus active regulation begins and the economy enters stage II. ${ }^{67}$

It is apparent from the figure that the Poor country experiences the greatest environmental degradation at its peak, and at any given capital stock, (i.e. income level) the initially Poor country has worse environmental quality than the Rich. Moreover, since both Rich and Poor economies start with pristine environments, the qualities of their environments at first diverge and then converge. This is the Environmental Catch-up Hypothesis.

Divergence occurs because the opportunity cost of abatement (and consumption) is much higher in capital poor countries. A high shadow price of capital leads to less consumption, more investment and rapid industrialization in the Poor country. Nature's ability to regenerate is overwhelmed. The quality of the environment falls precipitously. In capital rich countries the opportunity cost of capital is lower: consumption is greater and investment less. Industrialization is less rapid and natural regeneration has time to work. The peak level of environmental degradation in the Rich country is therefore much smaller. But once we

\footnotetext{
${ }^{67}$ Brock and Taylor (2003) show the exact position and shape of the locus depend on whether parameters satisfy the fast growth or slow growth scenario. For the most part we will proceed under the assumption that economic growth is fast relative to environmental regeneration; that is (75) fails strongly and we have $\eta(\gamma-1)<g$. This implies $\theta(t)=\theta^{K}$ everywhere along the balanced growth path (Figure 12 implicitly assumes this result). For illustrative purposes we will sometimes discuss the parallel flow case (where we can think of $\eta$ approaching infinity but (75) failing because $\gamma=1$ ).
} 
enter Stage II abatement is undertaken and since abatement is an investment in improving the environment, it is only undertaken when the rate of return on this investment equals (or exceeds) the rate of return on capital. Since economies are identical, except for initial conditions, rates of return are the same across all countries in Stage II. Equalized rates of return require equal percentage reductions in the pollution stock. Therefore absolute differences in environmental quality present at the beginning of Stage II disappear over time.

Note how similar this intuition for the ECH is to that given for the EKC prediction in the Green Solow model. In the Green Solow model initial rapid growth overwhelms nature's ability to dissipate pollution starting from its initial position at a biological equilibrium. Eventually growth slows and the environment's regenerative powers restore its quality slowly over time. Growth is initially rapid in the Solow model because of diminishing returns. In the Kindergarten model, growth is initially rapid because there is no regulation and no drag from pollution policy to lower the marginal product of capital. And once regulation is active, growth slows because regulation lowers the net marginal product of capital. The environment's regenerative powers then restore its quality slowly over time. Both explanations have nature overwhelmed early on and both give prominent roles to a declining marginal product of capital.

The discussions above, and Figure 5, assume the fast-growth-slow-regeneration assumptions hold. We chose this case to discuss and illustrate because it illustrates the forces at work very clearly. Since many of the same conclusions hold when growth is relatively slow we only provide a sketch here of some differences. There is again a Switching Locus which divides Stage I from Stage II. The Switching Locus again defines a unique $X^{*}$ that is declining in $K^{*}$. The most important difference is that once a trajectory of the system hits this new Switching Locus it remains within it forever. If the economy is below the locus then abatement is inactive and $K$ rises at a rapid rate: $X$ increases rapidly until the Switching Locus is reached in finite time. If the initial $(K, X)$ is above the locus, maximal abatement is undertaken but this drives down the shadow cost of pollution very quickly and we again hit the locus, this time, from above.

Once on the locus, countries remain trapped within it thereafter and this implies the economy's choice of abatement remains interior; i.e. the trajectory follows along the Switching Locus maintaining $M A C=M D(K, X)$ throughout. Over time abatement rises and the intensity of abatement approaches the Kindergarten rule in the limit. Therefore, the slow growth case is very similar except that the model now predicts an even stronger form of convergence. All transition paths remain on the Switching Locus once active abatement begins; therefore policy active countries share the same path for environmental quality and income levels in Stage II.

\subsection{The ECH and the EKC}

Brock and Taylor prove that all economies capable of sustained growth must follow the stage I - stage II life cycle producing an EKC like relationship between income and environmental 
quality. ${ }^{68}$ Their income and growth prediction is however somewhat different from a standard EKC result. They predict that countries differentiated only by initial conditions exhibit initial divergence in environmental quality followed by eventual convergence. ${ }^{69}$ Moreover, as Figure 5 makes clear countries make the transition to active abatement at different income and peak pollution levels. This of course throws into question empirical methods seeking to estimate a unique income-pollution path. More constructively it suggests that an important feature of the data may well be a large variance in environmental quality at relatively lowincome levels with little variance at high incomes. Empirical work by Carson et al. (1997) relating air toxics to U.S. state income levels is supportive of this conjecture:

"Without exception, the high-income states have low per-capita emissions while emissions in the lower-income states are highly variable. We believe that this may be the most interesting feature of the data to explore in future work. It suggests that it may be difficult to predict emission levels for countries just starting to enter the phase, where per capita emissions are decreasing with income", p. 4478 .

In some cases however, (initially) Rich and Poor will make the transition at the same income level but still exhibit our Catch-up Hypothesis. To investigate, we report the switching locus in the fast growth case. It takes on an especially simple form given by:

$$
M A C=\frac{1}{a}=\frac{B}{[\rho+\gamma \eta]} X^{* \gamma-1}\left[h K^{*}\right]^{\varepsilon}=M D\left(K^{*}, X^{*}\right)
$$

which is the downward sloping and convex relationship between pollution and capital depicted in Figure 5. The left hand side of (76) represents marginal abatement costs. The right hand side is marginal damage evaluated at $\left\{K^{*}, X^{*}\right\}$. Marginal damage is increasing in the pollution stock provided $\gamma$ exceeds one, and since the flow of national (and per-capita) income $Y$ is always proportional to $K$, it is apparent that the income elasticity of marginal damage with respect to flow income is given by $\varepsilon$. Large values of $\varepsilon$ correspond to the strong income effects referred to earlier

Let $\gamma$ approach one. Then the slope of the Switching Locus approaches infinity and all countries attain their peak pollution levels at the same $K^{*}$. But even with a common turning point differences in environmental quality remain. Moreover, these are not simple level differences because countries initially diverge and then converge after crossing $K^{*}$. To eliminate our catch-up hypothesis we must assume regeneration is infinitely fast: $X$ is a

\footnotetext{
${ }^{68}$ The addition of perfect capital markets can affect the pollution and income path greatly. To a certain extent a country is running down its environment initially to accumulate capital. With perfect capital markets it is possible to eliminate stage I entirely in some cases. Given many less developed countries have very limited and imperfect access to capital markets it is difficult to know the empirical importance of this result. It suggests however that access to capital markets may be an excluded country characteristic in EKC style regressions.

${ }^{69}$ It is possible to show $X$ is rising throughout Stage I and this ensures points along the Switching Locus do indeed represent peaks in pollution levels.
} 
flow. In this case Brock and Taylor show the Switching Locus is again vertical at a given $K^{*}$. More importantly, since pollution is proportional to production before $K^{*}$, and policies are identical after $K^{*}$ : initial conditions no longer matter.

These results tell us that when pollution is strictly a flow, all countries share the same income pollution path. But when pollution does not dissipate instantaneously, initial conditions matter. We have the Environmental Catch-up Hypothesis, and empirical methods must now account for the persistent role of initial conditions. ${ }^{70}$

\subsection{Pollution Characteristics}

The ECH focuses on cross-country comparisons in pollution levels, but says little about how predictions vary with pollutant characteristics. And while most authors have focused on generating an EKC relationship there has been very little work examining how these predictions vary with pollutant characteristics. This is unfortunate since there is good data in the U.S. and elsewhere that could be fruitfully employed to test within country but across pollutant predictions. This is especially important since many models can generate the EKC result.

To demonstrate the Kindergarten model's across pollutant predictions consider regeneration first and start from a position where $\eta=0$ (radioactive waste). Brock and Taylor (2003) show that the Switching Locus in Figure 5 shifts outwards as we raise $\eta$. The response is to delay action and allow the environment to deteriorate further. Once we raise $\eta$ sufficiently the economy eventually enters the fast regeneration regime and here we find abatement delayed in another manner - it is introduced slowly by the now gradual implementation of the Kindergarten rule. Faster regeneration then implies that countries either begin abatement at higher income levels or allow their environments to deteriorate more before taking action. Surprisingly, fast regeneration will be associated with lower and not higher environmental quality - at least over some periods of time or ranges of income. ${ }^{71}$

A change in regeneration rates also affects the pace of abatement. If a pollutant has a long life in the environment, then once abatement begins it is clear that natural regeneration can play only a small role. Consequently the optimal plan calls for an initial period of inaction before starting a very aggressive abatement regime: the immediate adoption of the Kindergarten rule. When $\eta$ is relatively large we are in the fast regeneration regime and

\footnotetext{
${ }^{70}$ This result may explain why empirical research investigating the EKC has been far more successful with air pollutants like SO2, than with water pollutants or other long lasting stocks (see the review by Barbier (2000)).

${ }^{71} \mathrm{An}$ especially colorful example of delay in abatement caused by rapid natural regeneration is that of the City of Victoria in British Columbia. Every day, the Victoria Capital Regional District (CRD) dumps approximately 100,000 cubic meters of sewage into the Juan de Fuca Strait. Scientific studies have long argued that since the sewage is pumped through long outfalls into cold, deep, fast moving water there is no need for treatment. The CRD has always used these studies to delay building a treatment facility. Current plans are for secondary treatment to begin in 2020, but until then over 40 square kilometers of shoreline remains closed to shell fishing. Background information can be found at the Sierra Legal Defense fund site http://www.sierralegal.org/m_archive/1998-9/bk99_02_04.htm
} 
abatement is intensified gradually and only approaches the Kindergarten rule level in the limit.

Putting the predictions for the timing and intensity of abatement together, Brock and Taylor find that very long-lived pollutants should be addressed early with their complete elimination compressed in time. It is optimal to delay action on short-lived pollutants and adopt only a gradual program of abatement. This description of optimal behavior is of course consonant with the historical record in several instances where long-lived chemical discharges and gas emissions were eliminated very quickly by legislation, whereas short-lived criteria pollutants have seen active regulation but not elimination over the last 30 years.

Pollutants also differ in their toxicity. The marginal disutility of toxics could exceed those classified as irritants, and damages from toxics may rise more steeply with exposure. The first feature of toxics implies their abatement should come early. This is clear from (76) where increases in B shift the Switching locus inwards and hasten abatement. Surprisingly very convex marginal damages (a high $\gamma$ ) call for the gradual and not aggressive elimination of pollution. The logic is that any reduction in the concentration of toxics has a large impact on marginal damage. Therefore, only by lowering emissions slowly can we match a steeply declining value of marginal reductions with a falling opportunity cost of abatement. Therefore, although toxics may have large absolute negative impacts on welfare, this argues for their early, but not necessarily aggressive, abatement.

And finally how does the income elasticity of the demand for environmental quality $(\varepsilon)$ affects the onset and pace of regulation? We have already shown that the restriction of $\varepsilon>1$ is not needed to generate sustainable growth. This parameter does however have a role to play in determining the timing of regulation. To illustrate its role consider the fast growth regime and let the gross marginal product of capital, A, rise. This necessarily raises $g$ and if $\varepsilon>1$, the Switching Locus shifts in. Abatement is hastened. When $\varepsilon<1$, abatement is delayed and peak pollution levels shift right. ${ }^{72}$ A similar set of results holds for increases in the productivity of abatement although there is an additional conflicting force. Therefore, in contrast to earlier work Brock and Taylor (2003) finds that the income elasticity of marginal damage has an important role to play in determining the income level at which abatement occurs and the resulting pollution level, but virtually no role in determining if the environment will improve nor its rate of improvement.

\section{Conclusion and Suggestions for Future Research}

The relationship between economic growth and the environment is not well understood: we have only limited understanding of the basic science involved - be it physical or economic - and we have very limited data. In this review we have tried to evaluate ongoing efforts, both theoretical and empirical, to understand this relationship. We started by introducing definitions for the scale, composition and technique effects of growth on pollution, and then

\footnotetext{
${ }^{72}$ Our use of the terms delayed or hastened does not refer to calendar time, but rather to whether actions occur at a higher or lower income level.
} 
constructed three simple theoretical models to highlight the role each can play in generating sustainable growth. Throughout we have tried to link these models to the existing literature and in a very rudimentary way evaluated their predictions using data on pollution emissions, abatement costs and resource prices.

This is a research topic on the periphery of growth theory proper. It placement reflects the lack of a core model to work with and the paucity of data for empirical analyses. This is unfortunate because an understanding of the relationship between economic growth and the environment may be key to long run prosperity; it is certainly of interest to developing country governments searching for a balance between material growth and environmental protection, and it is also of great interest in the developed world given current debates over global warming, its costs, and the costs of its amelioration.

Our review has revealed much heterogeneity in terms of approach and methods used in theoretical work. Some heterogeneity is to be expected, but too much dissipates effort. By examining the pollution creation and abatement process in some detail we hoped to direct future efforts more productively. We showed that standard assumptions such as CRS and concavity of the abatement production function lead to tractable formulations where pollution emissions appear in much the same way as other factors. By doing so we were able to show how we can evaluate the costs of environmental policy in a manner similar to that used to evaluate the drag of natural resources on growth. By making this connection precise we provided a bridge between the early resources and growth literature of the 1970s with the recent literature on pollution and income. We also hope to instill in others the need to provide micro foundations for assumptions over the amount of pollution emitted or abated in production, since we have repeatedly shown the importance of these assumptions for a model's ability to generate sustainable growth.

Our theoretical review contains three main messages. The first comes directly from our Green Solow model where we showed how the typical convergence properties of the neoclassical model together with a standard natural regeneration function yield an Environmental Kuznets Curve. This suggests that efforts to explain the EKC via complicated processes of political economy, IRS, freer trade, and differential factor growth, etc. may be unnecessary. At the very least it points out that the interplay of natural and Solow growth dynamics certainly work towards this finding.

Our second message concerns drag. We have shown throughout that efforts to limit pollution and raise environmental quality create a drag on growth rates. This finding was stronger in some cases since rapid population growth could eliminate the possibility of sustainable growth entirely. The drag calculations we provided are for illustration and not meant to substitute for more serious enquiry that must include empirical estimation of key parameters. Nevertheless these calculations are helpful in focusing our efforts on key parameters (the share of emissions in final good production or the rate of change in pollution abatement costs), and demonstrate how difficult it is to generate sustainable growth in a country with significant population growth. The calculations also offer a quick litmus test; if a specification suggests environmental policy reduces growth by $40 \%$, something is surely amiss. It is hoped that drag calculations of the type we have conducted become a more standard feature 
in the literature.

Finally, we have shown how different assumptions on abatement can produce very different results for sustainability (recall the contradictory results of Smulders and Stokey in the AK model). To a certain extent progress in this literature has been slowed because researchers have too many degrees of freedom in choosing their specification. Some restrictions are imposed by the requirement of a balanced growth path, but this still leaves much leeway to the researcher. We have adopted a consistent specification of pollution creation and abatement based on the common, if not innocuous, assumptions of constant returns, concavity and pollution being a joint product of output. Within these confines we have then argued that technological progress in abatement, distinct from that in final goods, is key to generating sustainable growth at reasonable costs. By identifying this as a key requirement we hope to direct future research efforts towards a theory of induced innovation where both relative prices and pollution regulations determine the pace and direction of improvements in abatement technology.

Our review of empirical work shows that the existing literature has made relatively few contributions to our understanding. The Environmental Kuznet's curve stands out as a key empirical regularity, but continued progress in this area can only come with a more serious consideration of other related data. One contribution of this review has been to show that many of the theoretical models capable of generating an EKC also contain predictions in other directions that are worthy of examination. The simple Green Solow model had strong predictions for the emission intensity of GDP; the Stokey Alternative contained sharp predictions about the time profile of abatement costs; the Source-and-Sink model contained links between energy prices, energy use, and pollution levels; and finally, the Kindergarten model produced a cross-country catch-up hypothesis as well as yielding several within-country but across-pollutant predictions. Further progress in our understanding can only come from a tighter connection between theory and data.

This review has been limited by its focus. It has been a review of work linking industrial pollution and growth with only small asides to consider natural resource use. In many cases the formal structure of the models resembled those in the renewable resource literature, but we did not provide a review of findings there. As such we have sidestepped the rather thorny issues of property rights protection and the efficiency of environmental policies. We have done so not because we believe that these issues do not merit attention, but rather because adding a useful discussion of these topics would make this review unwieldy. It should be emphasized however that a common feature of the resources we examined was their welldefined property rights. This is true for air quality when the quality is determined by local pollution; and it is true of oil and other energy resources.

There are however an important class of resources where property rights enforcement is lax or where no property rights exist at all. Property rights problems arise in three main areas. These are: local and transnational fisheries; the global atmospheric commons; and lastly, the forest stocks in many developing countries. It is somewhat ironic that these renewable resources are under far more threat than the so-called exhaustible resources such as oil, gas or minerals. The reason for this is inescapable: the diffuse nature of many of 
these resources has led to a lack of property rights and very little management. Therefore, while our focus on industrial pollution is perhaps defensible in that it determines the air quality and health prospects for hundreds of millions of people across the globe, we should not forget other vexing problems arising from the lack of property rights. And while our data and the existing empirical results suggest that many local pollution problems are well in hand or respond well to increases in incomes brought about by growth, global pollution problems, such as global warming, appear to be far more difficult to solve. ${ }^{73}$ Therefore, it may be that the real threat to continued growth arises not from the relatively small drag introduced by existing environmental policies, but from the absence of new policies to stem more serious global problems.

\footnotetext{
${ }^{73}$ See Schmalensee, Stoker, and Judson (1998) and Holtz-Eakin and Selden (1995).
} 


\section{References}

[1] Aghion, P. and P. Howitt (1998), Endogenous Growth Theory, MIT Press, Cambridge MA.

[2] Andreoni, J. and A.Levinson (2001), "The Simple Analytics of the Environmental Kuznets Curve," Journal of Public Economics, May , 80(2): 269-286.

[3] Antweiler, A., B. Copeland and M. S. Taylor (2001), "Is Free Trade Good for the Environment," American Economic Review 94, 1, September: 877-908.

[4] Arrow, K. (1962), "The Economic Implications of Learning by Doing" The Review of Economic Studies, Vol. 29, No. 3. June: 155-173.

[5] Arrow, K., P. Dasgupta, L. Goulder, G. Daily, P. Ehrlich, G. Heal, S. Levin, K. Maler, S. Schneider, D. Starrett, B. Walker (2003), "Are we consuming too much?", at P. Dasgupta's website, Cambridge.

[6] Barbier, E.(1997), "Environmental Kuznets Curve Special Issue: Introduction", Environment and Development Economics 2: 369-381.

[7] Barnett, H.J. and C. Morse (1963), Scarcity and Growth: The Economics of Natural Resource Availability, John Hopkins Press, Baltimore.

[8] Barret, S. and K. Graddy (2000), "Freedom, Growth, and the Environment", Environment and Development Economics. Vol. 5: 433-456

[9] Berndt, E.R.(1990), "Energy Use, Technical Progress and Productivity Growth: A Survey of Economic Issues", The Journal of Productivity Analysis, 2: 67-83 .

[10] Bovenberg, A.L., and S. Smulders (1995), "Environmental quality and pollution augmenting technological change in a two sector endogenous growth model", Journal of Public Economics, 57: 369-391.

[11] Brander, J.A., and M. S. Taylor (1997), "The Simple Economics of Easter Island: A Ricardo-Malthus model of renewable resource use", American Economic Review 88, No. 1: $119-138$.

[12] Brock, W.A. (1977), "A Polluted Golden Age", in V.L. Smith, ed. Economics of natural and environmental resources (Gordon and Breach Science Publishers, London).

[13] Brock, W.A. and D. Starrett (2003), "Managing systems with nonconvex positive feedback,", Environmental and Resource Economics, 26, Iss. 4, Dec.: 575-624

[14] Clark, C. (1990). Mathematical Bioeconomics, Wiley. 
[15] Brock, W.A. and M.S. Taylor (2004),. "The Green Solow model". NBER Working Paper No. w10557. June.

[16] Brock, W.A. and M.S. Taylor (2003), "The Kindergarten Rule for Sustainable Growth". NBER Working Paper No. w9597. April .

[17] Cole, M.A., A.J. Rayner and J.M. Bates (1997), "The environmental Kuznets curve: an empirical analysis", Environmental and Development Economics, 2, 401-416.

[18] Copeland, B.R., and Taylor M.S. (1994), "North-South Trade and the Environment", Quarterly Journal of Economics, 109: 755-787.

[19] Copeland, B.R., and Taylor M.S. (2003), Trade and the Environment: Theory and Evidence, Princeton University Press, Princeton, NJ.

[20] Copeland, B.R., and Taylor M.S. (2004), "Trade, Growth and the Environment", Journal of Economic Literature, forthcoming.

[21] Dasgupta, P, and G. Heal (1974), "The Optimal Depletion of Exhaustible Resources", The Review of Economics Studies, Vol. 41, Symposium Issue on the Economics of Exhaustible Resources: 3-28.

[22] Dasgupta, P, and G. Heal (1979), "Economic Theory and Exhaustible Resources, Cambridge Economic Handbooks, Cambridge University Press.

[23] Dasgupta, P. and K. Maler (2003), "The economics of non-convex ecosystems: Introduction," Environmental and Resource Economics, 26, Iss. 4, Dec.: 499-602 .

[24] Dechert, W.D. e.d. (2001), Growth Theory, nonlinear dynamics and Economic modeling, Edward Elgar: Cheltenham.

[25] Durlauf, S.N. and D.T. Quah (1999), "The New Empirics of Economic Growth", in the Handbook of Macroeconomics 1, chapter 4, J.B. Taylor and M. Woodford, Eds. Elsevier Science B.V.:235-308.

[26] EPA (2004), Strategic Plan, Benefits the Costs of EPA's Activities available at http://www.epa.gov/ocfo/plan/plan.htm

[27] EPA (1990), Environmental Investments: The Cost of a Clean Environment.

[28] Forster, B.A. (1973), "Optimal Capital Accumulation in a Polluted Environment" Southern Economic Journal, 39: 544-547

[29] Gale L. and Mendez J.A. (1998), "A note on the relationship between, trade, growth, and the environment". International Review of Economics and Finance 7(1): 53-61 
[30] Goulder, L.H. and Schneider, S.H. (1999), "Induced Technological change and the Attractiveness of $\mathrm{CO} 2$ abatement policy", Resource and Energy Economics, August, 21 (3-4): 211-253.

[31] Grossman G.M, and A. B. Krueger (1993), "Environmental Impacts of a North American Free Trade Agreement," in The US-Mexico Free Trade Agreement, P. Garber, ed. Cambridge, MA: MIT Press.

[32] Grossman G.M, and A. B. Krueger (1995), "Economic Growth and the Environment," Quarterly Journal of Economics: 353-377.

[33] Grossman G.M. and Helpman E. (1991), Innovation and Growth in the Global Economy. MIT press.

[34] Harbaugh, W. Arik Levinson, and David Molloy Wilson (2002), "Reexamining the Empirical Evidence for an Environmental Kuznets Curve". The Review of Economics and Statistics.84(3) August: 541-551.

[35] Hartwick, J.M. (1977), "Intergenerational Equity and the Investing of Rents from Exhaustible Resources, American Economic Review, 66, December.

[36] Hilton, H., and A. Levinson (1998), "Factoring the Environmental Kuznets Curve: Evidence from Automotive Lead Emissions," Journal of Environmental Economics and Management, 35: 126-141.

[37] Holtz-Eakin, D. and T. Selden (1995), "Stoking the fires? CO2 emissions and economic growth," Journal of Public Economics, 57: 85-101.

[38] Hotelling, H. (1931) "The Economics of Exhaustible Resources", Journal of Political Economy, 39 April: 137-175.

[39] Jaffe, A.B., K. Palmer (1997), "Environmental Regulation and Innovation: A panel data study", Review of Economics and Statistics, Nov.79(4): 610-619.

[40] Jaffe, A.B., S.R. Peterson, and P.R. Portney (1995), "Environmental Regulation and the Competitiveness of U.S. Manufacturing: What does the Evidence tell us?, Journal of Economic Literature, Vol. XXXIII, March: 132-163.

[41] Jaffe, A. B. and R.G. Newell, and R.N. Stavins (forthcoming), "Technological change and the Environment" in the Handbook of Environmental Economics, Karl-Goran Maler and Jeffrey Vincent eds.. North-Holland/Elsevier Science, eds.

[42] John, A. and R. Pecchenino (1994), "An overlapping generations model of growth and the environment," The Economic Journal, 104: 1393-1410.

[43] Jones C.I. (2001), Introduction to Economic Growth. Second Edition. W.W. Norton \& Company. 
[44] Jones, L.E. and R.E. Manuelli (2001), "Endogenous Policy Choice: The Case of Pollution and Growth,", Review of Economic Dynamics, 4, Issue 2, April: 245-517.

[45] Jorgenson, D.W. and P.W. Wilcoxen (1990), "Environmental Regulation and U.S. economic growth", Rand Journal of Economics, 21, summer: 314-340.

[46] Kaufman, Robert F.(2004), "The Mechanisms for Autonomous Energy Efficiency Increases: A Cointegration Analysis of US Energy/GDP Ratio", The Energy Journal, 25, No. 1.

[47] Keeler, E., M. Spence, and R. Zeckhauser (1972), "The Optimal Control of Pollution", Journal of Economic Theory, 4: 19-34.

[48] Levinson, A., Taylor M. S. (2003), "Unmasking the Pollution Haven Effect", paper presented at the NBER Environmental Economics Meetings, Boston, Summer. Available at http://www.ssc.wisc.edu/ ${ }^{\sim}$ staylor/

[49] Lopez, R. (1994), "The environment as a factor of production: the effects of economic growth and trade liberalization", Journal of Enviornmental Economics and Management 27: $163-184$.

[50] Lucas, R.E. Jr. (1998), "On the Mechanics of Economic Development," Journal of Monetary Economics, 22: 3-42.

[51] Meadows, D.H., Meadows, D.L., Randers, J., Behrens, W.W. (1972), The limits to Growth, Universe Books, New York.

[52] Meadows, d.H., Meadows, D.L., Randers, J. (1991), Beyond the Limits, Earthscan Publications, London.

[53] McConnell, K.E. (1997), "Income and the demand for environmental quality", Environment and Development Economics 2: 383-399.

[54] Newell, R.G., A.B. Jaffe, and R.N. Stavins (1999), "The Induced Innovation hypothesis and energy saving technological change", Quarterly Journal of Economics, August: 941975.

[55] Nordhaus, W. (1992), "Lethal Model 2: The Limits to Growth Revisited" Brookings Papers on Economic Activity, Volume, No. 2: 1-59.

[56] Pezzey, J.C.V., and Withagen, C. (1998), "The Rise, Fall and Sustainability of CapitalResource Economies", Scandinavian Journal of Economics, 100, (2): 513-527.

[57] Popp, D. (2002), "Induced Innovation and Energy Prices", American Economic Review, Vol. 92, No. 1, March: 160-180. 
[58] Rodriguez, F., and J.D. Sachs (1999), "Why Do Resource Abundant Economies Grow more slowly", Journal of Economic Growth, 4, September: 277-303.

[59] Robinson, J.A. and T.N. Srinivasan (1997), "Long-term consequences of population growth: technological change, natural resources, and the environment", Handbook of Population and Family Economics, eds. M.R. Rosenzweig and O. Stark, Elsevier Science.

[60] Romer, P. (1986), "Increasing Returns and Long Run Growth", Journal of Political Economy, 94, October: 1002-37.

[61] Rose, A. and C.Y. Chen (1991), "Sources of change in energy use in the U.S. economy, 1972-1982: a structural decomposition analysis", Resources and Energy 13: 1-21.

[62] Schmalensee, R., Stoker T.M. and Judson R.A. (1998), "World Carbon Dioxide Emissions: 1950 - 2050", The Review of Economics and Statistics, 80, Issue 1, February: $15-27$

[63] Scheffer, M., S.R.Carpenter (2003), "Catastrophic regime shifts in ecosystems: linking theory to observation", Trends in Ecology and Evolution, Vol. 18, No. 12, December: 648-656.

[64] Scholz, C.M. and G. Ziemes (1999), "Exhaustible Resources, Monopolistic Competition, and Endogenous Growth", Environmental and Resource Economics, 13: 169-185.

[65] Selden T. and D. Song (1994), "Environmental quality and development: Is there a Kuznets curve for air pollution emissions?" Journal of Environmental Economics and Management 27: 147-162.

[66] Shafik N. and S. Bandyopadhyay (1994), "Economic Growth and Environmental Quality: time series and cross country evidence," Washington D.C: The World Bank.

[67] Slade, M.E. (1987), "Trends in Natural Resource commodity prices: an analysis in the time domain", Journal of Environmental Economics and Management, 9: 122-137.

[68] Smulders, J. (1994), Growth, Market Structure, and the Environment: Essays on the Theory of Endogenous Economic Growth. Tilburg University.

[69] Smulders, S. (1999), "Endogenous Growth Theory and the Environment", in J.C.J.M. van den Berg (eds.) Handbook of Enviornmental and Resource Economics, Cheltenham: Edward Elgar: 610-621.

[70] Smulders, S. and R. Gradus.(1996), "Pollution abatement and long-term growth", European Journal of Political Economy, 12: 505-532.

[71] Solow, R.M. (1974), "Intergenerational Equity and Exhaustible Resources", Review of Economic Studies (Symposium): 29-46. 
[72] Solow, R. (1973), "Is the end of the world at hand", Challenge, March-April: 39-50.

[73] Solow, R.M., (1993), "An almost practical step toward sustainability", Resources Policy 19(3); 162-172.

[74] Stiglitz, J. (1974), "Growth with Exhaustible Natural Resources: Efficient and Optimal Growth Paths" The Review of Economic Studies, Vol. 41, Symposium on the Economics of Exhaustible Resources: 123-137.

[75] Stern, David, I. (2003), "The rise and fall of the environmental kuznets curve," Department of Economics, Rensselaer Polytechnic Institute, http:www.rpi.edu/dept/economics/.

[76] Stokey, N.(1998), "Are there limits to Growth," International Economic Review, 39(1): 1-31

[77] Sue Wing, Ian, and R.S. Eckhaus (2003), "The Energy Intensity of US Production: Sources of Long-Run Change, paper presented at the 5th USAEE/IAEE session of the Allied Social Science Association meeting, Washington, D.C. Jan. 4.

[78] Tahvonen, O., and J. Kuuluvainen (1991), "Optimal Growth with renewable resources and pollution", European Economic Review, 35: 650-661.

[79] Valente, S. (2002), "Renewable Resources and Sustainable Development", mimeo, Universita di roma.

[80] Vincent, J.R. (1997), "Testing for environmental Kuznets curves within a developing country", Special Issue on Environmental Kuznets Curves, Environment and Development Economics 2 (4): 417-431.

[81] Weitzman, M. L.(1999), "Pricing the Limits to Growth from Mineral Depletion", Quarterly Journal of Economics, May: 691-706. 


\section{FIGURES}

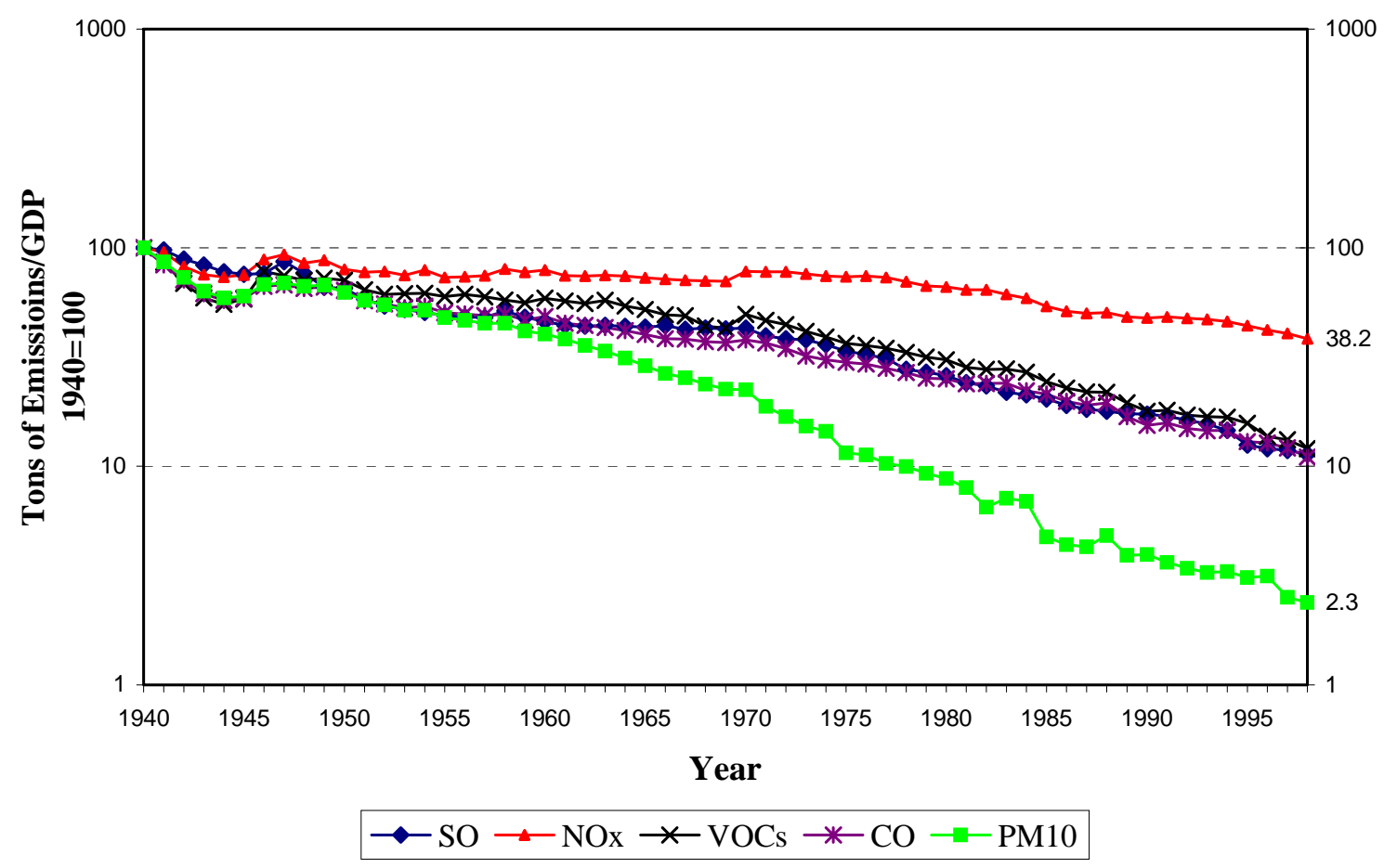

Figure 1: Emission intensities, 1940-1998. Tons of emissions/real GDP. 


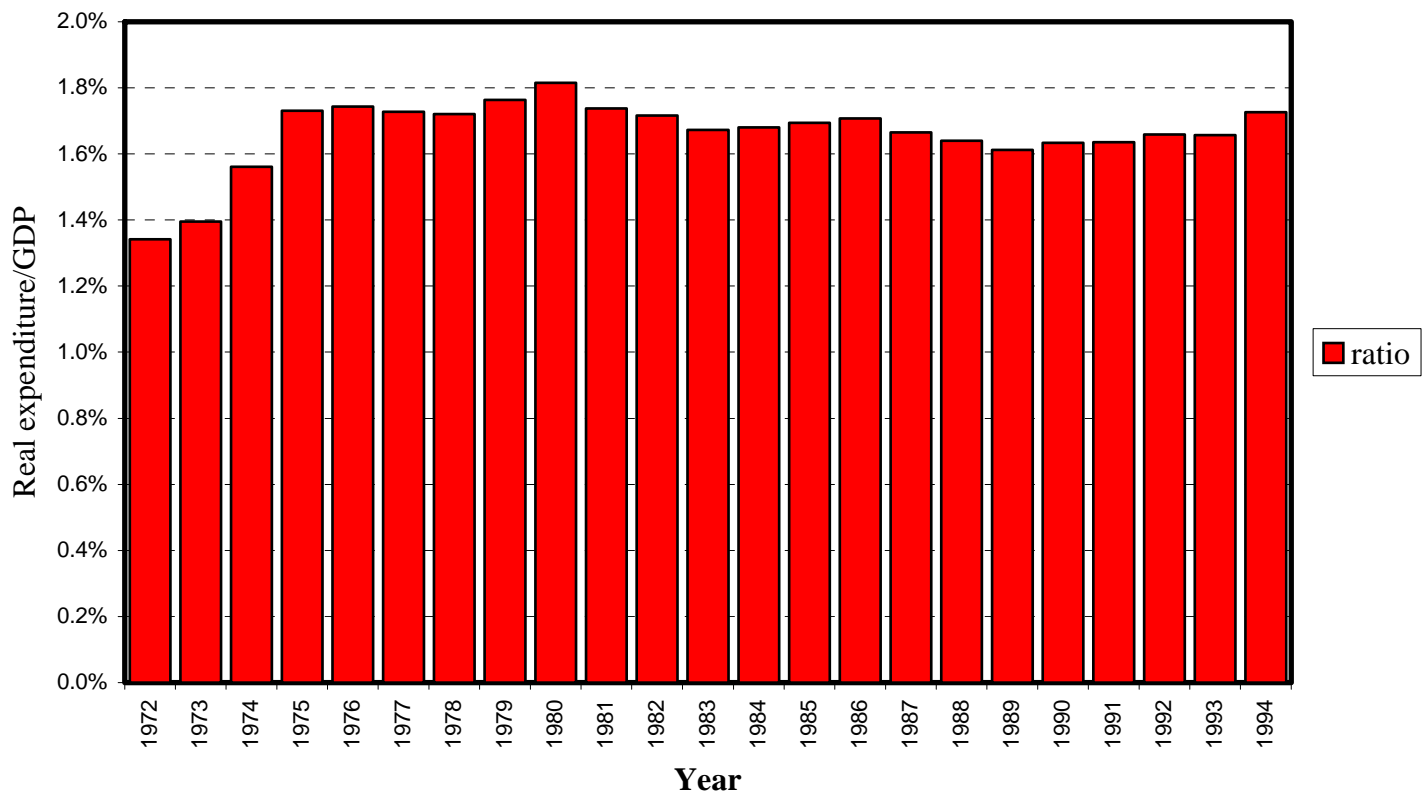

Figure 2: Pollution abatement costs, 1972-1994. PACE/GDP.

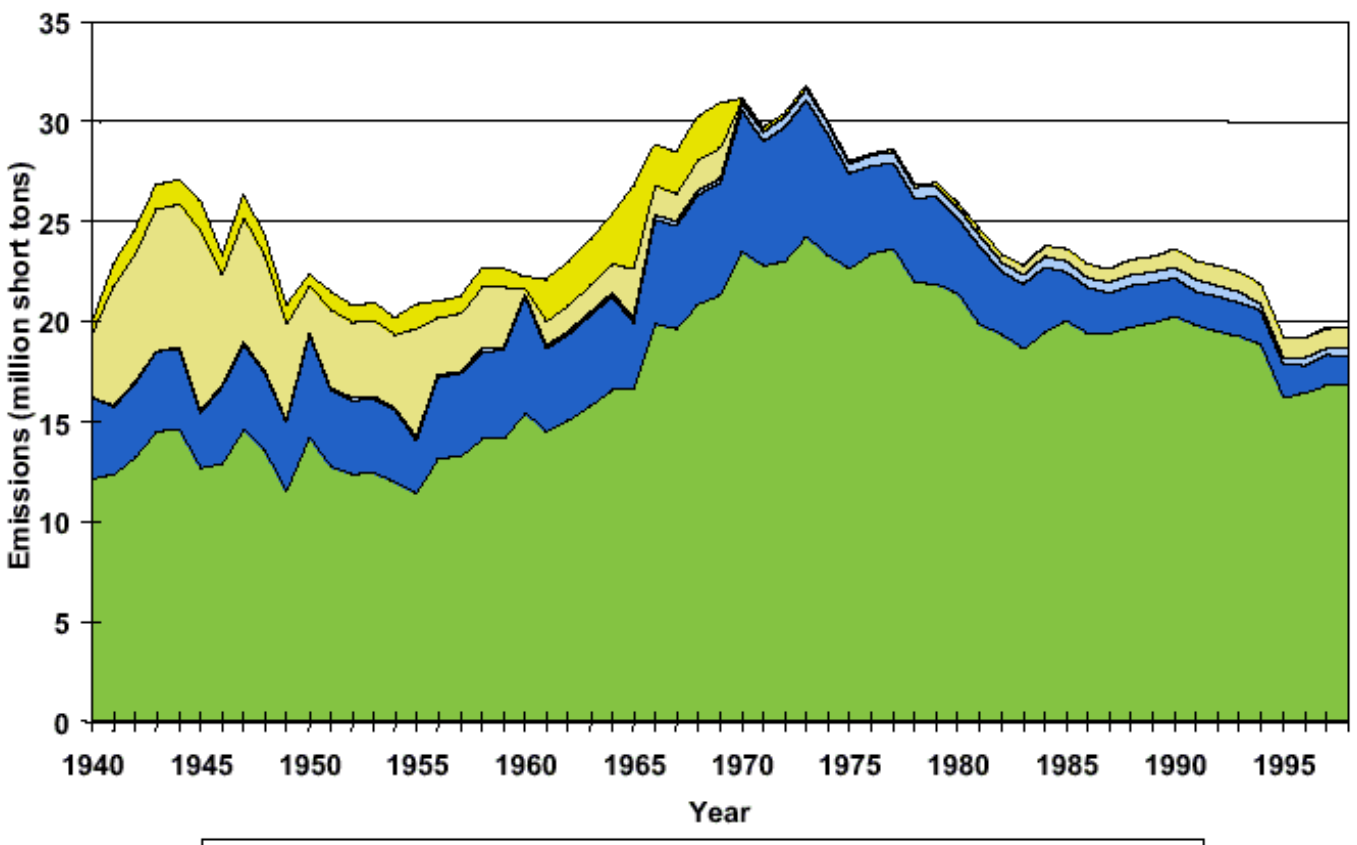

$\square$ Fuel Combustion $\square$ Industrial Processing $\square$ On-road $\square$ Non-road $\square$ Miscellaneous

Figure 3: Sulfur dioxide emissions, 1940-1998. 


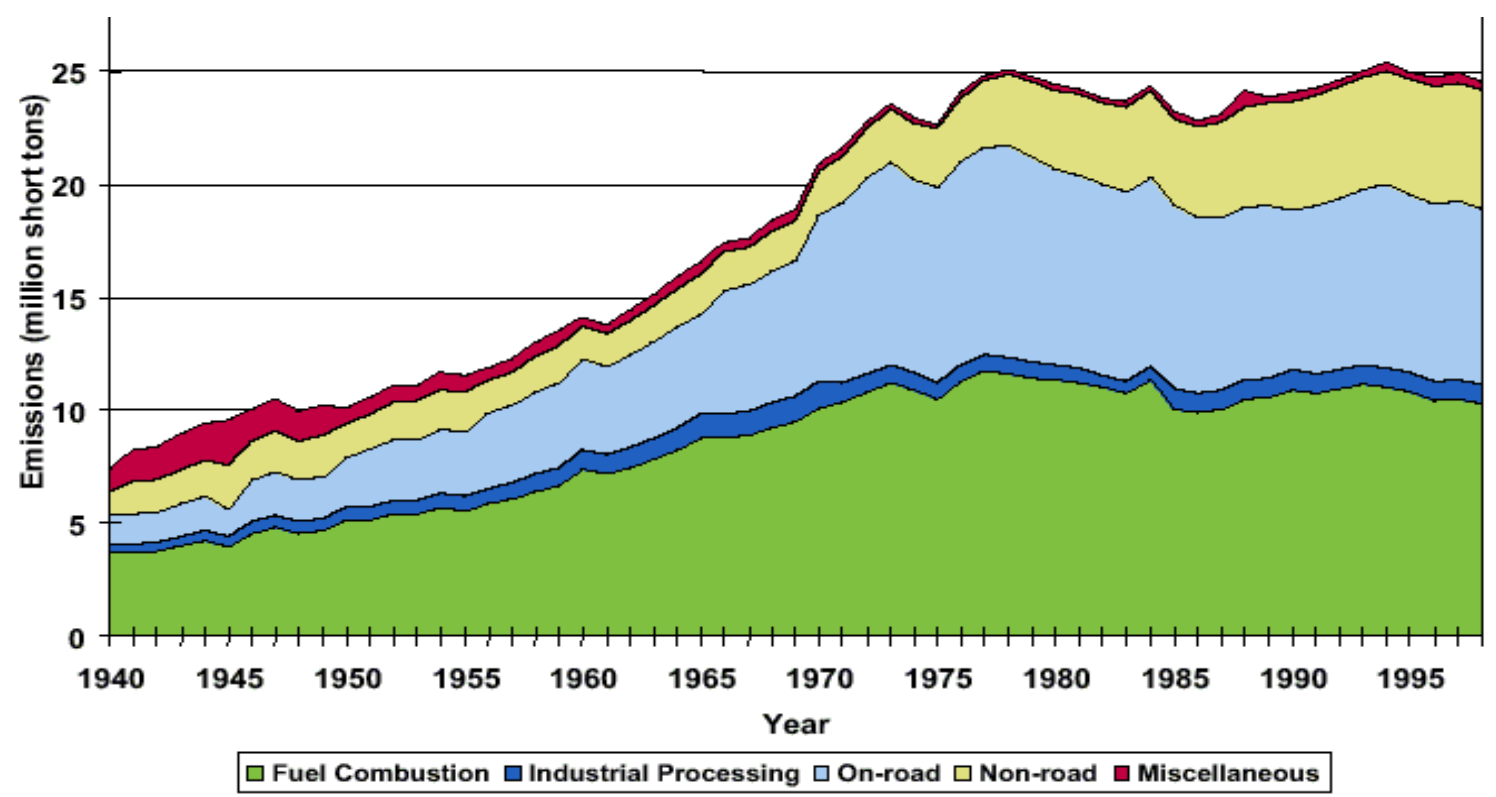

Figure 4: Nitrogen oxide emissions, 1940-1998.

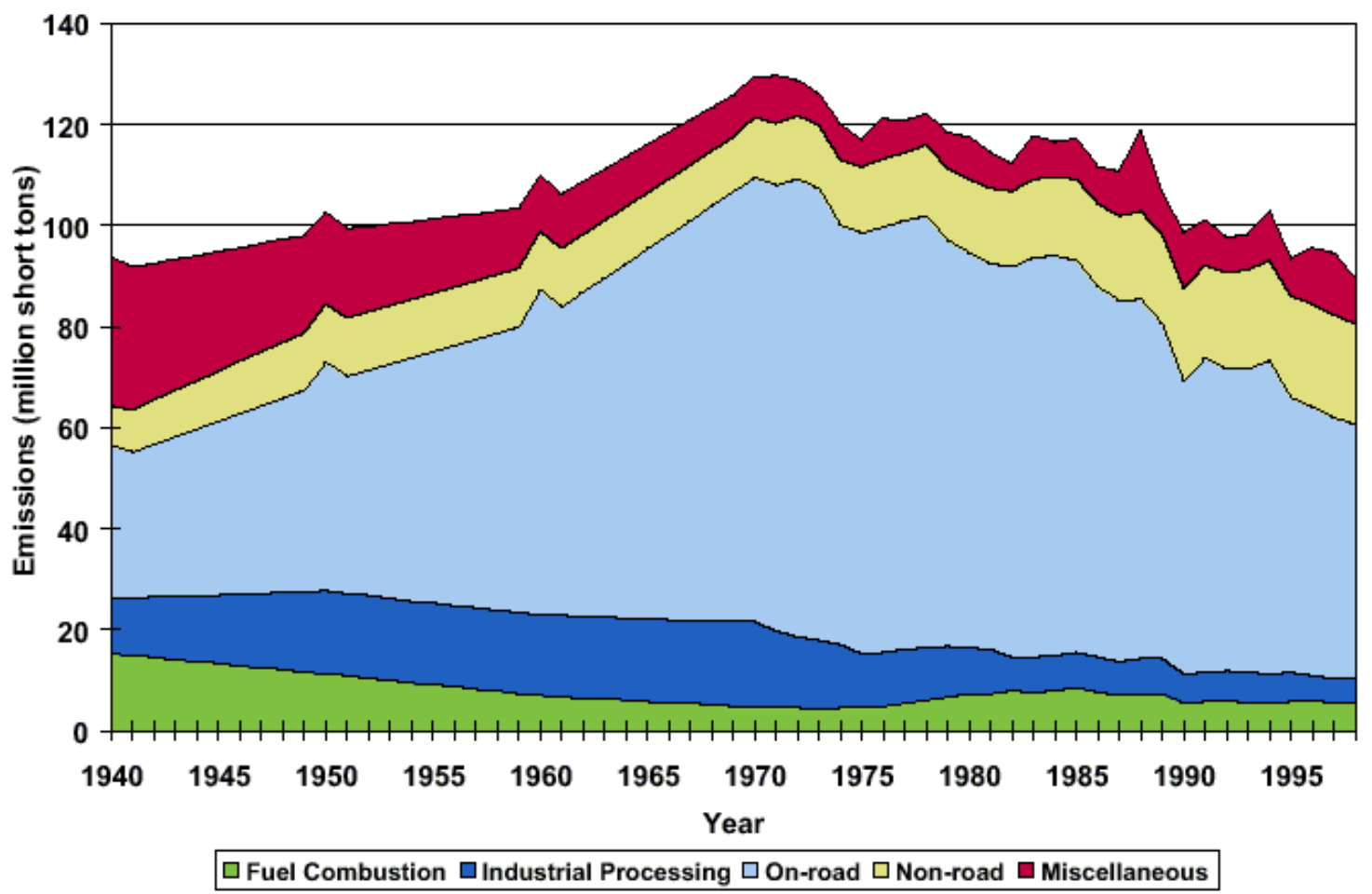

Figure 5: Carbon monoxide emissions, 1940-1998. 


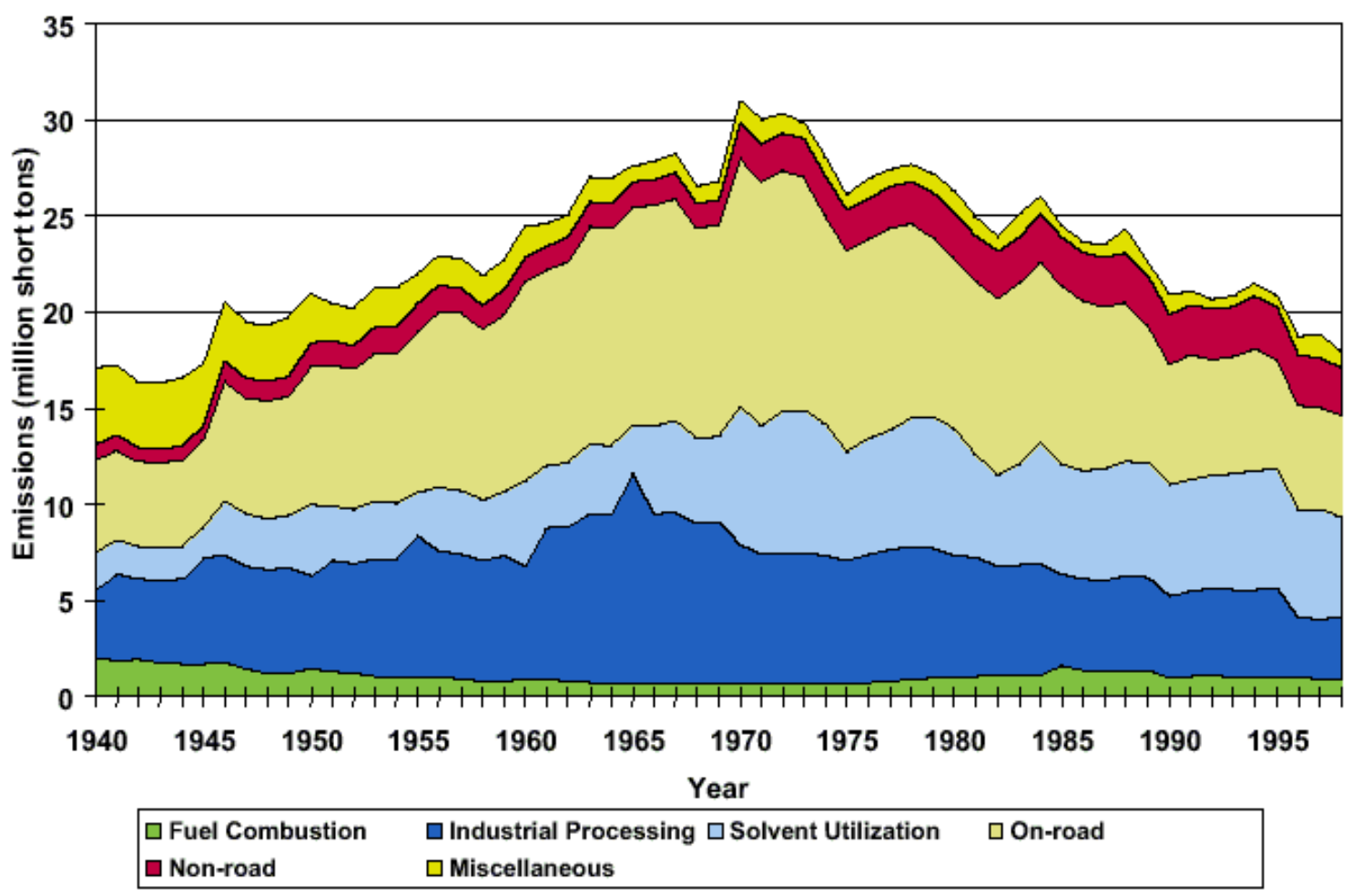

Figure 6: Volatile organic compounds, 1940-1998 


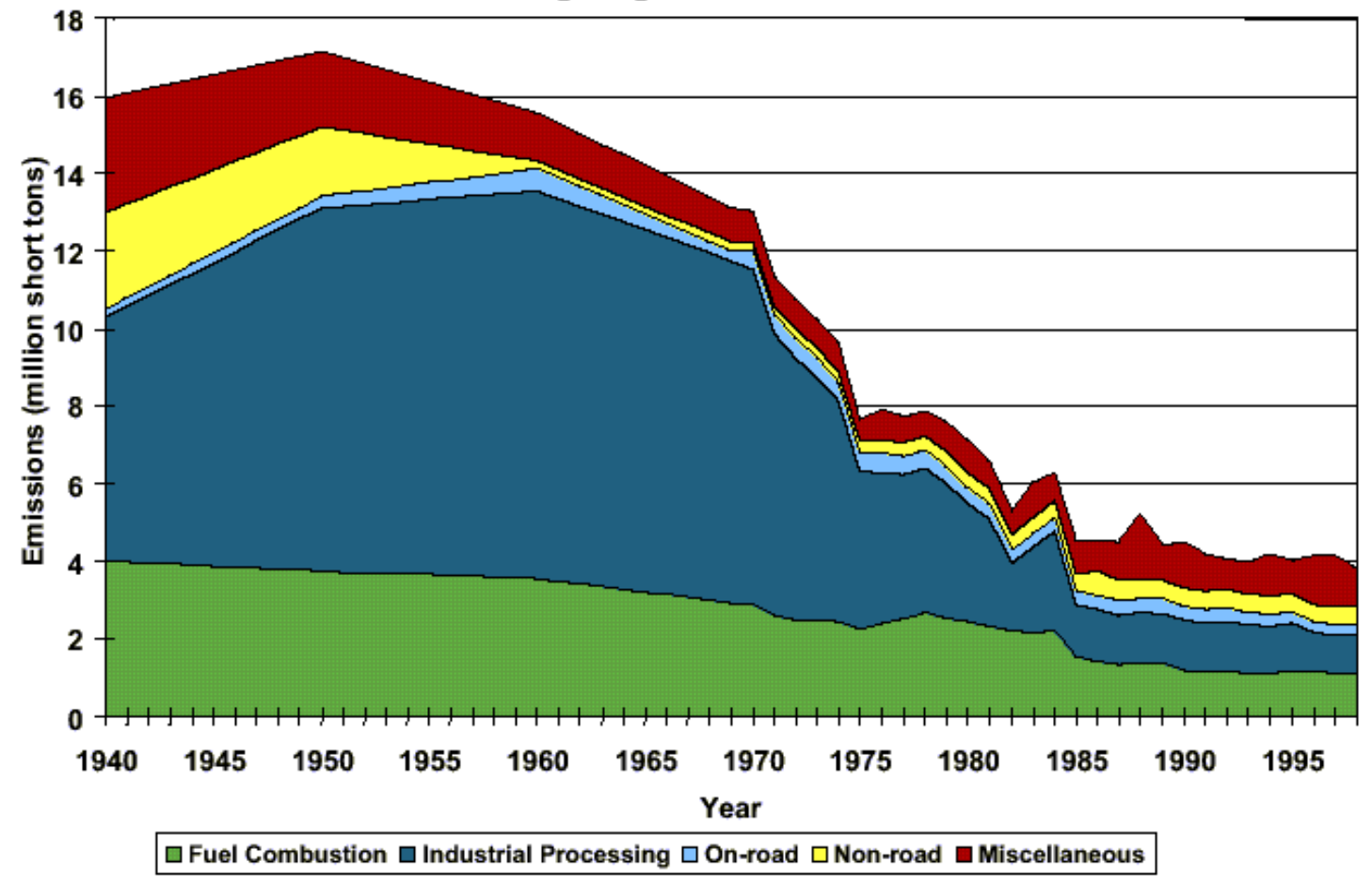

Figure 7: Particular matter PM10, 1940-1998. 


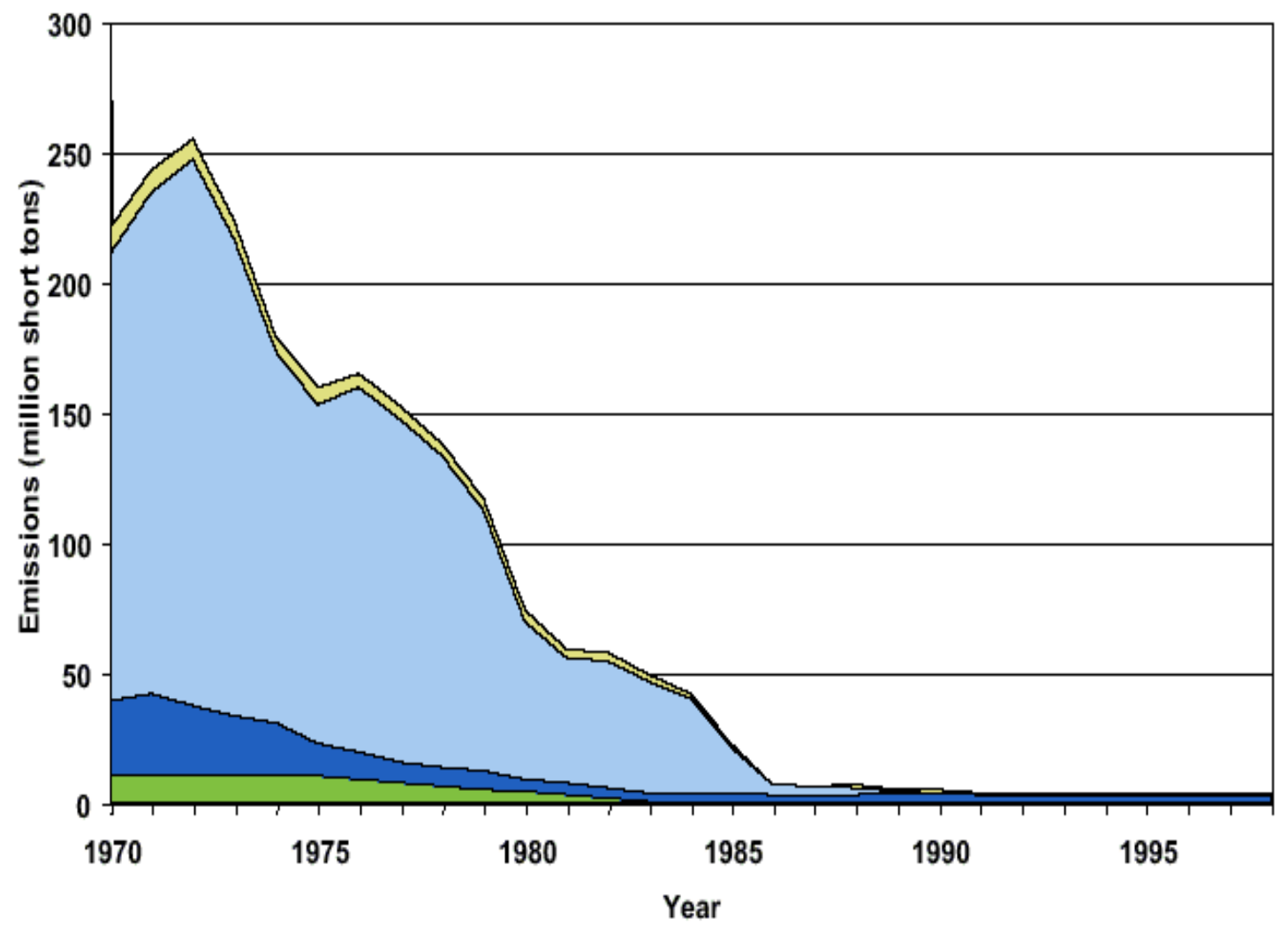

$\square$ Fuel Combustion $\square$ Industrial Processing $\square$ On-road $\square$ Non-road $\square$ Miscellaneous

Figure 8: Lead emissions 1970-1998. 


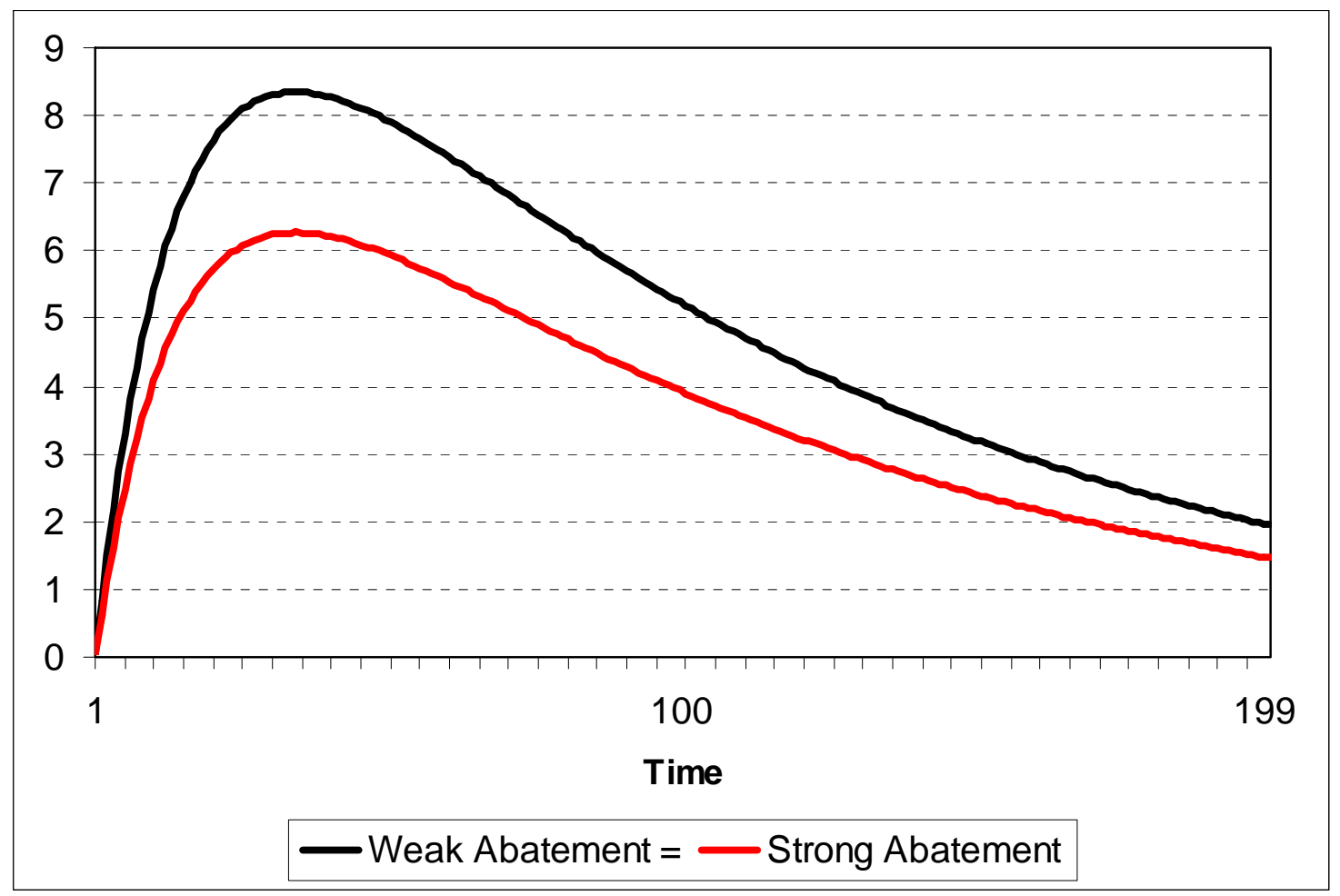

Figure 9: The green solow benchmark. 


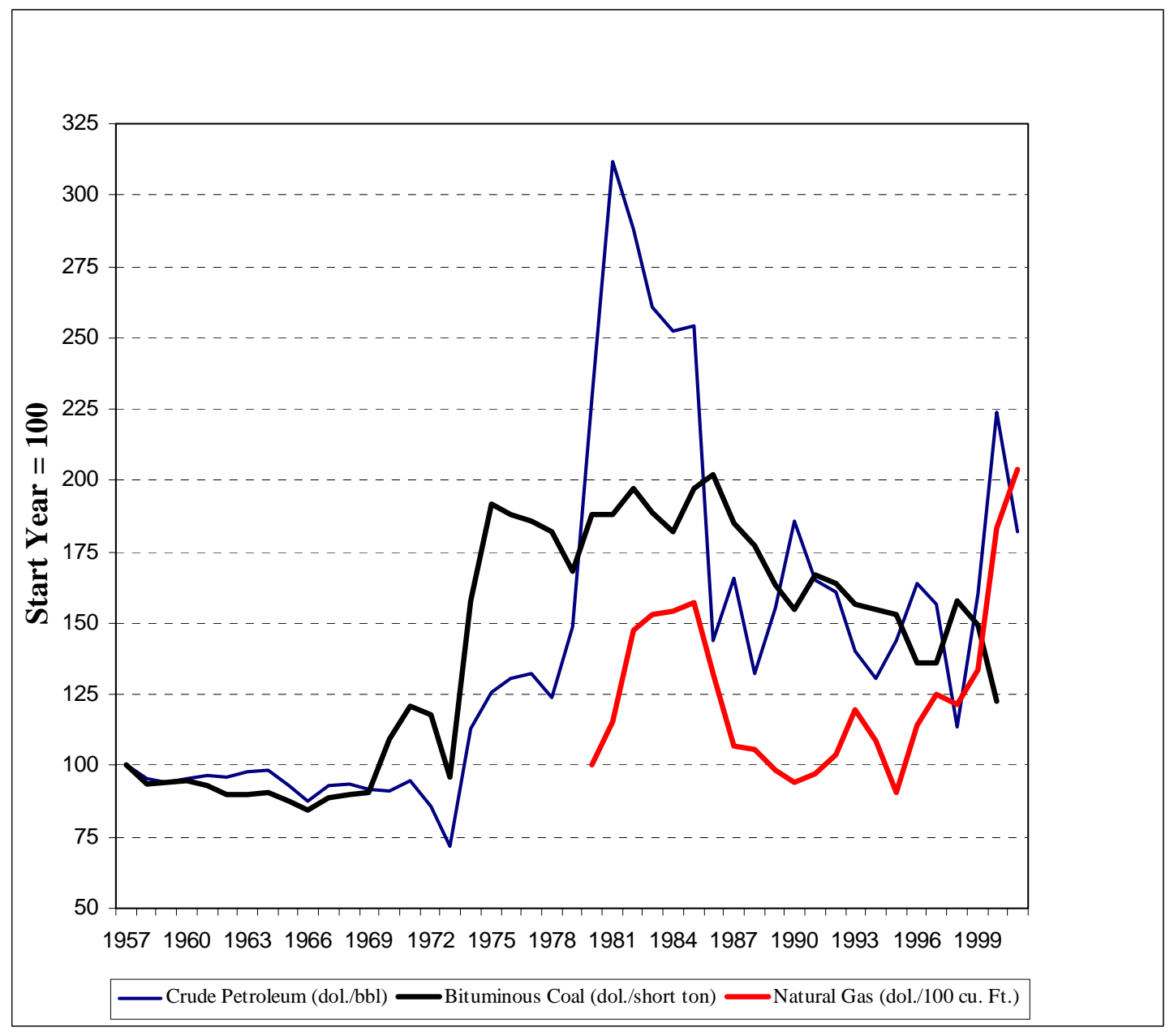

Figure 10: Real energy prices. 


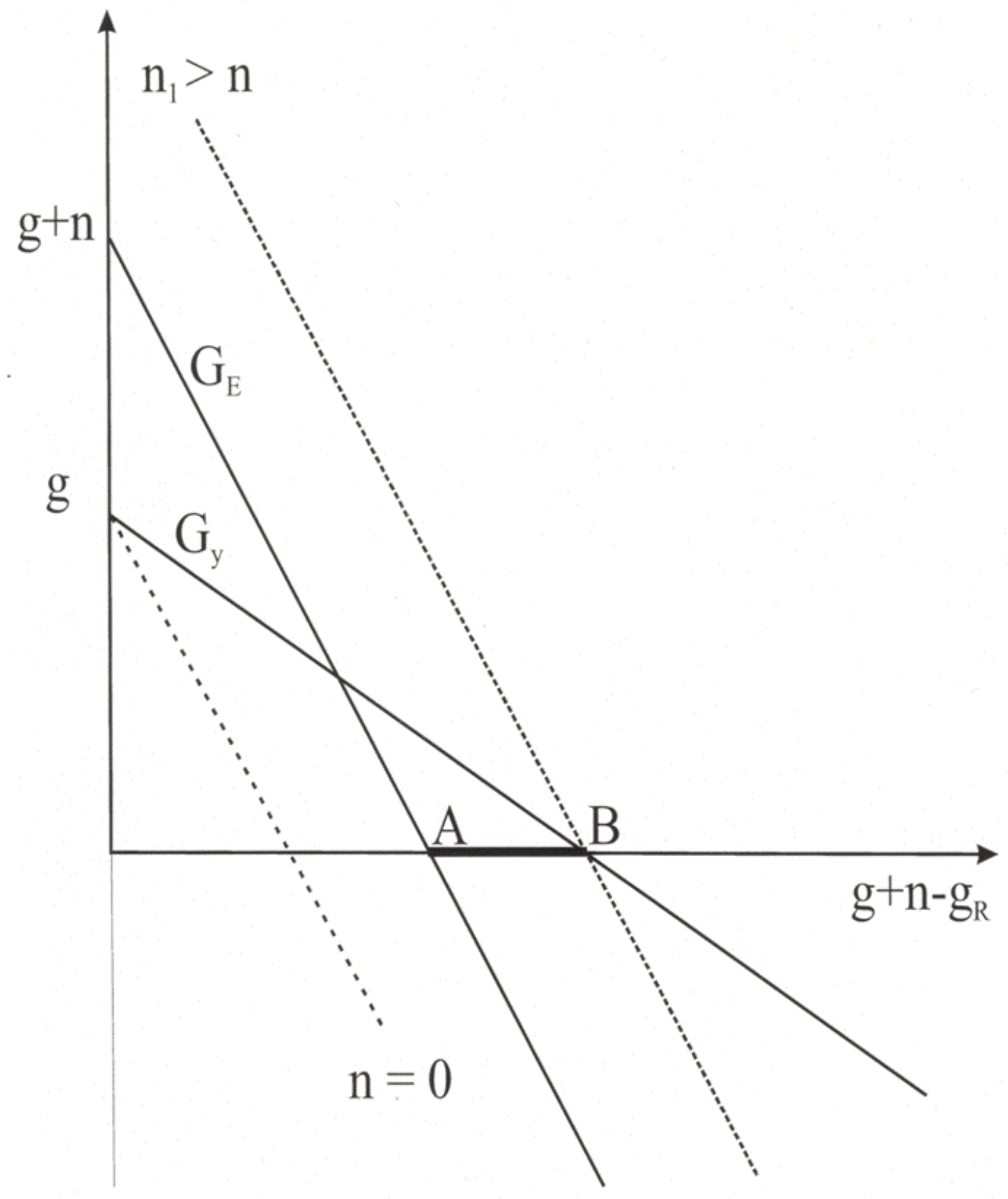

Figure 11: Feasibility: resource drag per capita growth. 


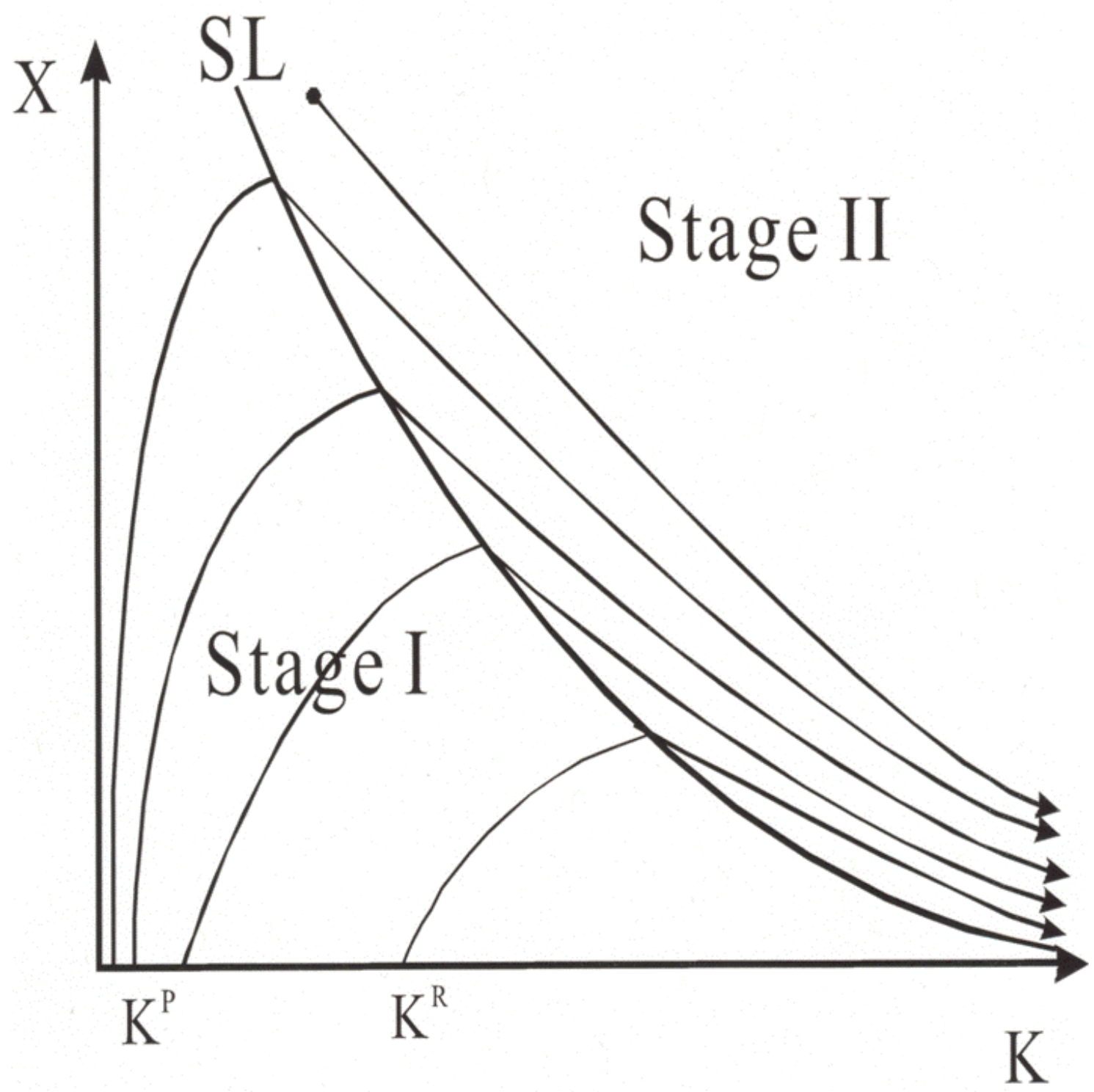

Figure 12: Transition paths. 